\title{
Inhibitory neuronal changes following a mixed diffuse-focal model of traumatic brain injury
}

\author{
Simone F. Carron ${ }^{1 *}$, Mujun Sun ${ }^{3}$, Sandy R. Shultz ${ }^{2,3}$, , Ramesh Rajan ${ }^{1}$ \\ ${ }^{1}$ Neuroscience Research Program, Biomedicine Discovery Institute, Dept of Physiology, \\ Monash University, Melbourne VIC, Australia \\ ${ }^{2}$ Department of Medicine and Neuroscience, Monash University, Melbourne VIC, Australia \\ ${ }^{3}$ Department of Medicine, The University of Melbourne, Melbourne VIC, Australia
}

Corresponding author: Simone Carron

Short Title: Interneuronal changes following a fluid percussion injury

\section{Author Contributions}

SC designed the study, collected the data, performed the analyses, wrote the manuscript and generated all figures. SS performed animal surgery and trauma induction. RR obtained funding and designed the study. MS helped with behaviour data collection and analysis. All authors have approved final manuscript.

\section{Data Availability Statement}

The data that support the findings of this study are available from the corresponding author upon reasonable request.

\begin{abstract}
Traumatic brain injury (TBI) can result in excitation:inhibition imbalance, as well as a range of chronic neurological deficits. However, how TBI affects different interneurons, and how this relates to behavioral abnormalities, remains poorly understood. This study examined the effects of a mixed diffuse-focal model of TBI, the lateral fluid percussion injury (LFPI), on interneurons, 8 weeks post-TBI in rats. Brains were labeled with antibodies against calbindin (CB), parvalbumin (PV), calretinin (CR), neuropeptide Y (NPY) and somatostatin (SOM), and the number of interneurons were assessed in the cortex and hippocampus following LFPI. LFPI caused a reduction in the numbers of interneurons mediating both perisomatic and dendritic inhibition in the somatosensory cortex. In hippocampus, there were heterogenous changes in the number of interneurons while motor cortex, showed no obvious loss in any of the subsets of interneurons after TBI. In parallel to the investigations of changes in the number of interneurons, we also investigated the long-term behavioral consequences of LFPI. Behaviorally, rats given an LFPI displayed transient reduction in performance in motor tasks and were significantly impaired in reversal learning in the water maze task post-TBI. We also report here progressive neurodegeneration in cortex and hippocampus indicated by fluorojade $C$ in the different brain areas examined after injury. Our findings suggest differential vulnerability of inhibitory neurons to LFPI in the different brain areas examined after injury. These data will aid in evaluation of new treatments for TBI and help target specific neuronal subtypes as a function of injury time and type.
\end{abstract}

This is the author manuscript accepted for publication and has undergone full peer review but has not been through the copyediting, typesetting, pagination and proofreading process, which may lead to differences between this version and the Version of Record. Please cite this article as doi: $10.1002 / \mathrm{cne} .24746$

This article is protected by copyright. All rights reserved. 
Keywords: Traumatic brain injury, Fluid percussion injury, Head Trauma, Neural injury, Interneurons, Immunohistochemistry, Inhibition, Cortex, Hippocampus

(RRID:AB_10000343); calbindin (RRID:AB_10000347); calretinin (RRID:AB_10000320); neuropeptide Y (RRID:AB_1566510); somatostatin (RRID:AB_2255365)

\author{
Abbreviations \\ CB- calbindin \\ CBP- Calcium Binding Protein \\ CR- calretinin \\ CCI- closed cortical impact \\ dTBI - diffuse traumatic brain injury \\ LFPI- Lateral fluid percussion injury \\ NPY- neuropeptide Y \\ PV- parvalbumin \\ SOM- somatostatin \\ SE- status epilepticus \\ TAI - traumatic axonal injury \\ TBI- traumatic brain injury \\ WDIA- weight drop impact acceleration
}

\title{
Introduction
}

Traumatic brain injury (TBI) is a neurodegenerative disorder caused by the application of mechanical trauma to the brain leading to short and long term neuronal functionality changes that underlie excitation:inhibition (E:I) imbalance. TBI patients often present with a complex combination of diffuse and focal injury resulting in chronic neurological deficits including sensory(Galvin et al., 2009; Lew et al., 2004; Raymond et al., 1996), motor(Levin et al., 1979) (Haaland et al.,, 1994; Kuhtz-Buschbeck et al., 2003), emotional and cognitive impairments(Arciniegas, et al., 2002; Finnanger et al., 2013; S. Hall \& Bornstein, 1991; Levin et al., 1979). Diffuse damage includes only microscopically-visible diffuse axonal injury, neuroinflammation and diffuse vascular injury (Andriessen et al., 2010). In contrast, focal injury is characterized by lesion formation, lacerations, haemorrhages and contusions that can be detected by imaging techniques.

The well-established lateral fluid percussion brain injury (LFPI) model creates a mixed diffuse-focal brain injury by rapid ejection of a small volume of fluid onto the exposed dura, producing both a focal cortical contusion ipsilaterally and a diffuse injury contralaterally apart from histological damage to subcortical brain areas such as the hippocampus (Hicks et al., 1996; Smith et al., 1997) and thalamus(Conti et al., 1998). Previously, in other studies in our laboratory, we have examined the changes in neuronal functionality in rat somatosensory cortex, specifically the whisker-recipient barrel cortex, induced by diffuse and mixed TBI in the short and long term using the two different models 
of brain injury: the weight drop impact acceleration model(Alwis et al., 2012; Johnstone et al., 2013 ; Yan et al., 2013) for severe diffuse injury and the LFPI model(Johnstone et al., 2014; Johnstone et al., 2015) for severe mixed diffuse and focal injury. In both models the 24h post-trauma period was characterised by suppression of neuronal responses in the upper somatosensory cortical layers with this effect decreasing with cortical depth (Johnstone et al., 2014; Johnstone et al., 2013).

In the longer term there were marked differences between the two models. In diffuse injury there was neuronal hyperexcitation at 8 weeks in the upper somatosensory cortical layers (Alwis et al., 2012), consistent with previous demonstrations that brain injury selectively impairs inhibitory neurons (Cantu et al., 2015) and our previous study showing calretinin-expressing interneurons were reduced in supragranular barrel cortex (Carron et al., 2016); these changes would compromise the E:I balance to favour excitation, resulting in the hyper-excitation observed in neuronal responses. While excitation can also be affected after trauma,(D'Ambrosio et al., 1998; Faden et al., 1989; Norris \& Scheff, 2009; Sick et al., 1998; Witgen et al., 2005) changes in inhibition more likely account for the E:I imbalance we found to occur in sensory cortex after diffuse TBI(Carron et al., 2016).

However, in the mixed brain LFPI model, normal neuronal responses occurred in all cortical layers at 12 weeks post trauma (Johnstone et al., 2015). It has been suggested that after LFPI, excitatory activity and connectivity is enhanced and inhibition compromised in the cortex,(Bonislawski et al., 2007; Hall \& Lifshitz, 2010) but this could not account for the normal neuronal functionality reported by Johnstone and colleagues (Johnstone et al., 2015). Instead the latter data suggests that there is cortical circuit reorganisation after LFPI trauma to maintain the normal neuronal responses and the difference from diffuse TBI suggests that this may specifically involve inhibitory circuits. Thus, further investigation is required to clarify the fate of different types of inhibitory neurons, especially in cortex, which has not been studied, following a LFPI.

Given the well-established sensorimotor deficits caused by TBI (Alwis et al., 2013; Alwis et al., 2012; Johnstone et al., 2013), we selected for examination the sensory and motor cortex. Further, given the consistent reports of loss of inhibition in hippocampus following [focal] TBI(Huusko et al., 2015; Pavlov et al., 2011), we also examined this sub-cortical region for the effects of mixed diffuse-focal TBI. Now, using the LFPI, we investigate whether a mixed diffuse-focal TBI affects different subsets of inhibitory neurons 8 weeks post injury, 8 weeks being a time point where we see stable TBI-induced neuronal changes without any confounds or overlays of age-related deterioration. Differential effects of LFPI on different inhibitory interneuronal types has been shown (Huusko et al., 2015) in hippocampus, with interneurons mediating perisomatic inhibition being more vulnerable to injury than interneurons mediating dendritic inhibition in long-term injury (1 and 6 months post-LFPI). We now report very different effects, of loss of both perisomatic (PV) and dendritic (CB,CR and SOM) inhibition mediating interneurons in hippocampus and in the somatosensory cortex, but also upregulation of NPY and SOM interneurons and interhemispheric differences in hippocampal sub regions. Previous studies have shown acute and transient cognitive and motor deficits 
following LFPI in the absence of neuronal loss or cell death (Gurkoff et al., 2013). Consistent with these studies we also report no changes in motor cortex inhibitory interneurons consistent with behavioural normality observed in motor tasks at 8 weeks post LFPI.

These results indicate injury time, type and brain area specific changes in inhibitory circuits and have important implications in understanding how inhibitory neurons are affected and inhibition in general compromised with respect to injury type. Development of effective therapies in TBI will therefore need to recognize specific changes in particular subsets of inhibitory neurons as a function of injury type and time.

\section{Materials and Methods}

Animals and study design

Male Sprague-Dawley rats (aged 12 weeks) were obtained from the Animal Resources Center (Western Australia). All rats were housed individually under a $12 \mathrm{~h}$ light/dark cycle with food and water ad libitum. Following acclimatization in the animal housing which included behaviour tests, rats were allocated to receive either a moderate LFPI $(n=10)$ (mortality rate of $23 \%$ (3/13 rats died immediately after LFPI)) or sham injury $(\mathrm{n}=10)$. Animals were then allowed to recover for 8 weeks post-injury during which they were behaviourally tested. At 8 weeks post-injury animals were euthanized and the brains obtained for histological analysis. Experiments were conducted in accordance with the National Health and Medical Research Council, Australia, Code of Practice for the Care and Use of Animals for Scientific Purposes and was approved by the Monash University Standing Committee on Ethics in Animal Experimentation and the Melbourne Health Animal Ethics Committees.

\section{Lateral Fluid Percussion Injury}

Brain injury was induced using a standardized LFPI method as previously described (Bao et al., 2012; Johnstone et al., 2014; Johnstone et al., 2015; Shultz et al., 2012a; Shultz, et al., 2012b). Briefly, anaesthesia was induced by inhalation with $4 \%$ isofluorane in oxygen (2L/min). Throughout surgery anaesthesia was maintained with $2 \%$ isofluorane and 500 $\mathrm{mL} / \mathrm{min}$ of oxygen flow delivered through a nose cone. Rats were held by ear bars in a stereotaxic frame and subcutaneously injected with an analgesic (carprofen; $5 \mathrm{mg} / \mathrm{kg}$ ) prior to surgery. A craniotomy creating a circular window $(5 \mathrm{~mm}$ in diameter), centred at anteroposterior (A/P; 3.0mm,mediolateral [M/L] $4.0 \mathrm{~mm}$ with reference to bregma) was then performed under aseptic conditions to expose the dura mater. Dental acrylic and cyanoacrylate was used to secure a modified female Luer-Lock cap over the craniotomy window. The cap was then filled with sterile fluid. Following this, the rats were removed from anaesthesia and attached by the female Luer-Lock cap to the fluid percussion device. A single moderate fluid percussion pulse of 2.5 -3.0 atm was delivered by the injury device to the intact dura at the first response of hind limb withdrawal to a toe pinch. The scalp was sutured and the female Luer-Lock cap removed immediately post-injury. Sham injured rats had the same craniotomy and injury cap except that no fluid percussion force was delivered. Post-injury measures of apnoea, unconsciousness and self-righting reflex were monitored as 
indicators of severity of injury (see Table 1)(Bao et al., 2012; Gurkoff et al., 2006; Shultz et al., 2012a; Shultz et al., 2011; Shultz, et al., 2012b)

\begin{abstract}
Behaviour Testing
Whisker Nuisance Task: The whisker nuisance task (McNamara et al., 2010) was used to examine persistent sensory deficits post LFPI. Behavioural responses to whisker stimulation are observed during this task. Animals are placed in an empty cage for 5 minutes acclimatization. The mystacial whiskers on both sides of the face are then stimulated with a wooden stick for 3 consecutive 5 min periods (approximately 30 secs apart). Stimulation is absent during behavioural observations. Rats were assessed based on a scoring criteria comprising of 8 categories (freezing, stance and body position, breathing, whisker position, whisking response, evasiveness, response to stick presentation, and grooming) on a 0-2 point non parametric scale $(0=$ behavioural response absent, $1=$ behavioural response present and $2=$ behavioural response was profound). Normal responses to stimulation were scored a zero value while abnormal behavioural responses were scored a value of 2 . The maximum cumulative score of all categories in the whisker nuisance task is 16 . Low scores (0-4) is indicative of normal behaviour while high cumulative scores (8-16) indicated abnormal behaviour. Animals were tested every day for the first week post injury and then 1 day/ week over the next 7 weeks.
\end{abstract}

Rotarod: As in our previous TBI studies (Alwis et al., 2016; Alwis et al., 2012; Carron et al., 2016; Johnstone et al., 2013; Johnstone et al., 2014; Johnstone et al., 2015) a standard rotarod test was used to assess sensorimotor function following injury. Grip strength and sensorimotor function are assessed by recording the maximum rotational speed at which the rats can maintain their position on the rotarod, a rotating cylinder comprising of 18 stainless steel rods ( $1 \mathrm{~mm}$ diameter). Rotational speed is incremented by $1.5 \mathrm{rpm}$ every 3 seconds. All animals received training on the rotarod twice ( 2 days apart) in the week prior to surgery. Animals were tested every day from day 1 for the first week post surgery and then 1 day/ week for the next 7 weeks. Each day's score was divided by the highest score that same animal received in its pre-trauma/surgery tests. Scores were expressed as a \% rotarod score for that animal. The \% scores were then averaged for all LFPI and sham animals.

Beam Walk: Sensorimotor function was also assessed using the beam task (Wright et al., 2017). During the acclimatization period rats were trained to traverse a $100 \mathrm{~cm}$ long beam with a width of $4 \mathrm{~cm}$ on one edge and $2 \mathrm{~cm}$ on the other. The training session consisted of five trials each on the $4 \mathrm{~cm}$ and $2 \mathrm{~cm}$ edge. A trial began when the rat was placed on one end of the beam and ended when it had successfully traversed the entire $100 \mathrm{~cm}$ beam or a maximum trial time of 60 secs had elapsed. Traverse time, number of slips and falls were used as measures of sensorimotor function post injury. If the rat fell off the beam during a trial it was given a time of 60 secs. Animals were also assessed based on their ability to cross the beam and scored as follows: $0=$ normal walking for at least $50 \mathrm{cms}$; $1=$ crawling with abdomen touching the beam; $2=$ inability to move on the beam; $3=$ inability to balance on the beam. Similar to the rotarod testing regime, post-injury, animals were tested every day from day 1 for the first week and then 1 day/ week for the next 7 weeks on the beam. 
Elevated-Plus Maze: The elevated-plus maze (EPM) was used to assess anxiety-associated behaviour. The EPM consists of two open arms (arms not enclosed by walls) and two closed arms (arms enclosed by 18-inch high walls). Rats were placed in the centre of the maze and allowed to explore the maze for 5mins. Exploratory behaviour was recorded with an overhead camera and the amount of time spent in open and closed arms as well as number of entries into them were quantified using EthoVision tracking software (Noldus Information Technology bv, Wageningen, The Netherlands). A percentage score was calculated for time spent in the open arms (time in open arm/ [time in open arm + time in closed arm] (Bao et al., 2012; Johnstone et al., 2015; Shultz et al., 2011) as a measure of anxiety as time spent in open arms was decreased in rats with anxiety related behaviour. As a measure of locomotion the number of entries into the closed arm of the maze was also calculated. EPM testing was done on day1 of week 8 post injury.

Water Maze: Spatial cognition was assessed with a water maze test using a circular pool (160 $\mathrm{cm}$ in diameter) filled with tap water $\left(29^{\circ} \mathrm{C}\right)$. Testing was done on day 2 (acquisition session) and 3 (reversal session) of week 8 post injury. A clear acrylic glass escape platform was hidden $2 \mathrm{~cm}$ below the water in the one of the quadrants (south-east for acquisition and northwest for reversal) of the pool. The acquisition phase comprised of ten training trials with a maximum given time of 60 secs for each trial (Tan et al., 2016). A trial began when the rat was placed in the circular pool adjacent to and facing the pool wall and ended when the rat found and stood on the hidden platform or the maximum trial time of 60 secs elapsed. Each trial began from any one of the pool wall start locations (north, south, east or west quadrant) in a pseudo-random schedule to avoid repeated sequential starts from the same quadrant. Reversal testing was done $24 \mathrm{~h}$ after acquisition. All reversal procedures were similar to acquisition with the exception of the hidden platform being placed in the opposite quadrant. Etho Vision software was used to calculate search time and the number of direct and circle swims to the hidden platform as a measure of spatial place memory. Swim speed was also calculated in cms/sec and assessed as a measure of motor ability.

Tissue preparation for Immunohistochemistry/immunofluorescence

Following behavioural testing at 8 weeks post injury animals were sacrificed and studied for histology. Animals were deeply anaesthetized with Lethobarb (Sodium pentobarbitone; 300 $\mathrm{mg} / \mathrm{ml}$ ) and transcardiaclly perfused with physiological saline followed by $4 \%$ paraformaldehyde in $0.2 \mathrm{M}$ phosphate buffer. The entire brain was carefully removed from the skull and post-fixed in PFA for another 48 hours. Brains were then sliced into 2-4 mm blocks (rostral to caudal) using a rat brain matrix (Zevic Instruments, USA) and processed for paraffin embedding. The blocks were processed in formalin for 20 mins and then dehydrated in increasing concentrations of alcohols (70\% and 90\% 20 mins each, three 20 mins changes of $100 \%$ and then again for 40 mins in 100\%) followed by xylene ( 2 x 30 mins, 1 x 1 hour) and final infiltration of paraffin wax (2 x 40 mins, 1 x 1 h). Tissue blocks were embedded in paraffin wax and stored at room temperature until further use. Ten $\mu \mathrm{m}$ coronal sections were then cut from the processed paraffin tissue blocks with a microtome (microTec, model 4060, Germany). 
We studied the effects of LFPI in the primary motor cortex, somatosensory cortex and hippocampus. Brain regions were identified based on stereotaxic coordinates, anatomical and histological boundaries according to the Paxinos and Watson rat brain atlas (Paxinos and Watson, 1997). Motor cortex sections were obtained from the brain region extending from $3.7 \mathrm{~mm}$ to $1.7 \mathrm{~mm}$ rostral to bregma. Somatosensory cortex sections were obtained from region extending from $-2.30 \mathrm{~mm}$ to -4.16 caudal to bregma. Dorsal Hippocampal sections were obtained from region extending form $-2.30 \mathrm{~mm}$ to $-4.52 \mathrm{~mm}$ caudal from bregma.

From each animal, six brain sections were chosen for each brain region and were stained and analysed for each of the inhibitory neuronal subtypes (see below). Sections were chosen in a systematic manner ensuring an interval of at least $30 \mu \mathrm{m}$ to avoid any bias in cell counting.

Immunohistochemistry for inhibitory neurons

To identify any loss of inhibitory neurons at 8 weeks post LFPI, we stained for standard markers of inhibitory neurons, namely three calcium binding proteins parvalbumin (PV), calbindin (CB), calretinin (CR), and the neuropeptides, neuropeptide Y (NPY) and somatostatin (SOM) (Freund \& Buzsaki, 1996; Hendry et al., 1984; Kawaguchi \& Kubota, 1997). These interneuron subsets comprise the majority of inhibitory neurons and are populations with minimal overlap (Demeulemeester et al., 1989; Hendry et al., 1984; Kubota \& Kawaguchi, 1994; Rogers, 1992).

Parvalbumin immunohistochemistry: We have previously described in detail the protocol for PV immunohistochemistry and the other interneuronal markers namely CB, CR, NPY and SOM used in this study (Carron et al. 2016, Carron et al 2018). Briefly, paraffin-embedded sections were dewaxed in xylene ( $3 \times 5$ mins) and rehydrated in 100\% ethanol ( $3 \times 2$ mins), followed by a rinse in distilled $\mathrm{H}_{2} \mathrm{O}(2 \times 2$ mins). Sections were subjected to $0.1 \%$ citrate buffer Antigen retrieval ( $\mathrm{pH}$ 6.0) and microwaved on high setting (1-2 mins) and then allowed to stand in the citrate buffer for 30 mins after microwaving. Then, sections were washed in distilled $\mathrm{H}_{2} \mathrm{O}$ for 10 mins. Endogenous peroxidase activity was quenched with $0.3 \%$ peroxidase in 50\% 0.1 M PBS/ 50\% Methanol (MeOH) (20 mins). Sections were rinsed twice in 0.1 M PBS, blocked with 7\% NGS in PBS-Tx for an hour, and incubated overnight (for $16-18 \mathrm{~h}$ ) at $4^{\circ} \mathrm{C}$ in a primary antibody solution containing PV antibody (mouse monoclonal,1:2500, PV 235, Swant) diluted in PBS with Triton-x (PBS-Tx) and 7\% normal goat serum (NGS).

Following overnight incubation, sections were rinsed in $0.1 \%$ tween and incubated with the secondary antibody, polyclonal goat anti -mouse (1:500, Dako, Denmark) in 0.1M PBS and 5\% NGS for an hour at room temperature. Sections were rinsed twice in $0.1 \mathrm{M}$ PBS, treated with avidin-biotin complex (ABC) solution (Vectatstain, PK-6100, Vector laboratories, USA) in 0.1 M PBS for 30 mins. Sections were again washed in PBS ( 2 x 10 mins) and stained neurons were visualized with a chromagen solution (3, 3'diaminobenzidine (DAB) Peroxidase (HRP) Substrate Kit, SK-4100, Vector Laboratories, 
USA) dissolved in distilled $\mathrm{H}_{2} \mathrm{O}$ applied on the sections and incubated for 7-10 mins. Sections were then rinsed in distilled $\mathrm{H}_{2} \mathrm{O}$ twice, dehydrated in $100 \%$ ethanol ( $3 \times 2 \mathrm{mins}$ ) and xylene (3 x 2 mins) and cover slipped using DPX mounting media. No immunoreactivity was detected in negative control sections in which primary antibody was omitted from the staining protocol.

Similar protocols were used for CB, CR, NPY and SOM (Carron et al; 2016, Carron et al., 2018) with the only differences being the specific primary and secondary antibodies used.

Calbindin: For CB immunohistochemistry the primary antibody was a mouse monoclonal anti-calbindin D-28k (1:5000,Swant Cat\# 300 Lot\# RRID:AB_10000347) and the secondary antibody was a polyclonal goat anti -mouse (1:300, Dako).

Calretinin: Here the primary antibody was a mouse monoclonal anti-calretinin $((1: 2500,6 B 3$, Swant, Cat\# 6B3 Lot\# RRID:AB_10000320) and the secondary antibody was a polyclonal goat anti -mouse (1:300, Dako).

Neuropeptide Y: Here the primary antibody was a rabbit polyclonal anti-neuropeptide Y ((1:2,500 [ab30914], Abcam, Cambridge, UK, Cat\# ab30914 Lot\#RRID:AB_1566510) and the secondary antibody was a polyclonal goat anti -rabbit (1:300, Dako).

Somatostatin: Here the primary antibody was with a rabbit polyclonal anti-somatostatin primary antibody (1:2,500 [MAB354], Millipore, Bedford, MA, Cat\# MAB354 Lot\# RRID:AB_2255365) and the secondary antibody was a polyclonal goat anti -rabbit (1:300, Dako).

Fluoro Jade C staining: Fluoro-Jade C (FJC) staining is a simple histological technique used to detect degenerating neurons. The Biosensis Fluoro-Jade C 'Ready to Dilute' kit (Biosensis) was used as per manufacturer's specifications and staining protocol to detect neurodegeneration in the cortex and hippocampus. Briefly, slides were dewaxed in xylene (2 x $5 \mathrm{~min}$ ), 100\% ethanol ( $2 \times 3 \mathrm{~min})$ and then one change of $70 \%$ ethanol for $3 \mathrm{~min}$. Slides were then rinsed in $\mathrm{ddH}_{2} \mathrm{O}$ ( $2 \mathrm{~min}$ ) and incubated in potassium permanganate for 12 mins to quench any non-specific staining. Slides were then rinsed again in $\mathrm{ddH}_{2} \mathrm{O}$ for 2 min before incubation in Fluoro-Jade $\mathrm{C}$ and DAPI solution for $12 \mathrm{~min}$ in the dark. Slides were then rinsed in $\mathrm{ddH}_{2} \mathrm{O}$ and then dried at $50-60^{\circ}$ in the oven. Following this slides were placed in xylene (2-5 mins) and cover slipped with DPX mounting media. Slides were then scanned at a magnification of 40x using ScanScope AT Turbo slide scanner (Aperio, CA, USA), visualized and analysed by Aperio ImageScope (v11.2.0.780, Aperio) and ImageJ (NIH, USA). Slides were graded semi-quantitatively for the presence of FJC positive cells.

\section{Data Analysis}

Estimation of neuronal number and density in brain regions: We used similar neuronal number and density estimation methods as described in detail in our previous studies (Carron 
et al., 2018; Carron et al., 2016). Briefly, neuronal density rather than absolute neuronal numbers were estimated for cortical sections. Stained sections from the two investigated cortical areas were scanned at a magnification of 40x using ScanScope AT Turbo slide scanner (Aperio, CA, USA), visualized and analysed by Aperio ImageScope (v11.2.0.780, Aperio) and ImageJ (NIH, USA) to estimate the neuronal density of inhibitory neurons in these brain areas. The motor and somatosensory cortex regions of interest were then extracted from the entire scanned and magnified sections based on stereotaxic coordinates and anatomical boundaries in the Paxinos and Watson rat brain atlas. The extracted images were imported into ImageJ and using Image J plugins: grid and cell counter, cortical neuronal density was estimated. A counting grid was superimposed on the cortical region of interest and immunopositive neurons were counted bilaterally (left and right hemispheres) from 8 random squares (each with area point of $10,000 \mu \mathrm{m}^{2}$ ) within the grid for the supragranular (layers 1-3), granular (layer 4) and infragranular (layers 5 and 6) cortical layers. Inclusion and exclusion line counting criteria were applied while counting neurons from within the grid. Only neurons with strongly stained soma and those with entire cell body completely inside the counting frame and on or within the inclusion line of the grid were counted. CB staining is also weakly found in some excitatory cortical and hippocampal pyramidal cells apart from inhibitory neurons. However, faintly stained CB pyramidal cells with distinct morphology from interneurons were identified and excluded from the analysis.

We analysed 6 sections for each animal and each stain, from each of the two studied cortical areas. Neurons were quantified and averaged to derive a single mean number to represent the number of neurons for that stain for that cortical area per animal. As described in previous studies (Carron et al., 2018; Carron et al., 2016), neuronal density (neurons $/ \mathrm{mm}^{2}$ ) in cortical areas were estimated using the formula $\mathrm{N}=\left(\Sigma \mathrm{Q}^{-} /\left(8 \times 10^{4}\right)\right) \times 10^{6}$, where $\Sigma \mathrm{Q}^{-}$was the average of the neurons counted per animal/cortical layer, 8 represents the number of random squares analysed within the grid for each cortical layer. To avoid bias all neuronal counts were done by a blind observer. Neuronal density $/ \mathrm{mm}^{2}$ was estimated from the numbers of healthy neurons counted in layers 2/3, 4 and 5/6. Stereology was not employed for counting as the sections used for analysis were only flat mounted and only $10 \mu \mathrm{m}$ in thickness to allow for uniform staining and antibody penetration.

Absolute neuronal numbers were counted from the hippocampal sub regions owing to the lower numbers of inhibitory neurons in hippocampus in each stained section compared to cortex. Stained sections of the hippocampus were scanned at a magnification of 40X. Region of interests were extracted and imported into ImageJ to quantify and average neuronal numbers in each of the sub regions. Immunostained neurons were counted bilaterally in defined sub fields of the hippocampal formation, namely the CA1, CA2/3 region and dentate gyrus (DG). Six sections from hippocampus were analysed, quantified, averaged per animal/stain to derive a single mean number for each hippocampal sub region to represent the mean number of that subclass of inhibitory neuron per section/animal.

Sham interhemispheric data were pooled together for cortical laminar and hippocampal subfield analysis and any outliers above and below 2.55 standard deviation of 
the mean sham contralateral neuronal numbers were removed from the analyses for consistency and to avoid any compromise caused by the craniotomy on the sham ipsilateral neuronal numbers. Ipsilateral and contralateral neuronal density and numbers in LFPI animals are represented as percentages of corresponding sham control values.

Cortical thickness measurements: Cortical thickness was measured in somatosensory and motor cortices from parvalbumin stained sections used for neuronal number analysis. Cortical layers were clearly distinguishable in PV stained sections and were identified based on neuronal density, anatomical and histological boundaries according to the Paxinos and Watson chemoarchitectonic atlas of the rat forebrain. As previously described in detail (Carron et al., 2018; Carron et al., 2016), briefly stained sections were scanned at a 40x magnification using ScanScope AT Turbo slide scanner (Aperio, CA, USA) and visualized by Aperio ImageScope (v11.2.0.780, Aperio). Using the ruler tool of ImageScope thickness for each cortical layer was manually drawn and measured as the shortest vertical distance from the pial surface to distinct visible cortical layers (L1, L2/3, L4, L5 and L6). Three sections were measured per animal per treatment group (LFPI and sham ( $\mathrm{n}=6$ each)) to obtain an average for each cortical layer.

Statistical Analysis

Behaviour: Behaviour data for the rotarod, beam walk, whisker nuisance task and search time in Water maze were analysed using a two-way repeated measures ANOVA and Bonferroni post-hoc tests. While the EPM tasks and Water maze swim speed and direct and circle swims parameters were analysed using an independent samples t-test using Graph Pad Prism (Graph Pad Prism software, Inc., La Jolla, CA, USA).Statistically, tests were considered significant at $\mathrm{p}<0.05$.

Histology: Data for somatosensory and motor cortical layers and hippocampal sub regions were treated as separate datasets and analysed separately. The means of quantified neuronal numbers between LFPI and sham groups and interhemispheric differences in LFPI animals were analysed by a Mann-Whitney $U$ test and Monte Carlo two-tailed estimate of significance, with a 99\% confidence level (SPSS Inc., Chicago, IL, USA). Cortical thickness data between treatment groups were analysed using the Mann-Whitney U test as well, using Graph Pad Prism (Graph Pad Prism software, Inc., La Jolla, CA, USA). All data are expressed as mean \pm standard deviation. Statistically, tests were considered significant at $\mathrm{p}$ $<0.05$.

\section{Results \\ Behavioural Findings}

Whisker Nuisance Task: LFPI animals showed a trend towards more averse responses to whisker stimulation over the 8 week test period but this was only significant from day 1 - day 7 (Fig. 1a; Day 1; LFPI = 7.7 \pm 0.8 , Sham $=0.4 \pm 0.16, \mathrm{p}<0.05$; Day 7; LFPI $=2.3 \pm 0.97$, Sham $=$ $0 \pm 0.00$, Two way repeated measures ANOVA, Bonferroni post-hoc, $\mathrm{p}<0.05$ ) after trauma. 
Rotarod: There were no significant differences between the LFPI and sham groups presurgery. LFPI animals performed significantly worse than shams on the rotarod from day 1-3 post-trauma: (Fig. 1b; Day 1: LFPI = $37.37 \pm 11.07$, Sham $=84.29 \pm 11.79$; Day 2: LFPI= $39.16 \pm$ 14.87, Sham = 96.19 \pm 6.05; Day 3: LFPI= 55.09 \pm 14.20 , Sham $=106.76 \pm 10.50$, Two way repeated measures ANOVA, Bonferroni post-hoc, $\mathrm{p}<0.05)$. Performance in LFPI animals gradually improved from day 4 to week 8 , and was not significantly different from sham controls during this time.

Beam Walk: The beam walk task was used to assess sensorimotor function after trauma. No significant differences were observed between LFPI and sham groups prior to trauma. A twoway repeated measures ANOVA (Bonferroni post-hoc, $\mathrm{p}<0.05$ ) showed a significant decrease in beam walk scores in LFPI animals up to day 2 (Fig. 1c; Day 1: LFPI $=1.5 \pm 0.37$, Sham=0.7 \pm 0.34 ; Day 2: LFPI $=1.3 \pm 0.37$, Sham $=0.4 \pm 0.16$ ). The LFPI rats also displayed a trend of increased number of slips and falls compared to shams up to 8 weeks but only significant at day 3 post-TBI (Day 3; LFPI $=3 \pm 1.76$, Sham $=1 \pm 1.44$, (Fig. 1d; Two way repeated measures ANOVA, Bonferroni post-hoc, $\mathrm{p}<0.05$ ).

There were no significant differences in beam traverse time between shams and LFPI animals indicating that basic motor function was still intact.

Elevated Plus Maze: Anxiety-associated behaviour was assessed using the EPM at 8 weeks after LFPI. LFPI animals did not appear to be more anxious than shams following 8 weeks of recovery. No significant differences were found in the percent of time spent in the open arm (Fig. 1e; LFPI= 11.89 \pm 4.12 , Sham $=9.10 \pm 3.06$, Unpaired t test, $\mathrm{p}>0.05$ ) or number of closed arm entries (Fig. 1f; LFPI= 4.5 \pm 1.36 , Sham=7.1 \pm 2.1 , Unpaired t test, $\mathrm{p}>0.05$ ).

Water Maze: The Water maze was used to assess spatial cognition after trauma. No significant differences were observed between LFPI and shams during the acquisition phase (Fig. $1 \mathrm{~g}, \mathrm{h \& i}$ ). Search time was significantly different between LFPI and sham animals only for the first trial of the reversal phase of testing (Fig. $1 \mathrm{j}$; LFPI= 54.56 \pm 3.73 , Sham= 23.76 \pm 6.91 , Two way repeated measures ANOVA, Bonferroni post-hoc, $\mathrm{p}<0.05$ ). Percentage of direct and circle swims (Fig. $1 \mathrm{k}$; LFPI $=16 \pm 5.20$, Sham $=40 \pm 6.99$, Unpaired t test, $\mathrm{p}<0.05$ ) decreased in LFPI animals at 8 weeks during the reversal phase indicating cognitive deficits. Swimming speed (Fig.1 i\&l) did not differ between the two groups during both phases suggesting that motor ability was not a confounding factor.

\section{Changes in thickness of cortical layers in somatosensory and motor cortex}

To ensure that laminar changes caused by the fluid percussion injury itself had no influence on neuronal density we measured cortical thickness in the somatosensory and motor cortex. At 8 weeks after LFPI, total thickness (Fig. 2a) and laminar analysis (thickness of cortical layers L1-L6) of the somatosensory (Fig. 2b) and motor cortices (Fig. 2c) did not reveal any significant changes $(\mathrm{p}>0.05)$ either between LFPI and sham animals. Data are presented in Table 2. 


\section{Histological analysis of inhibitory interneurons in cortex and hippocampus}

For the analyses of changes in neurons in the brain, we examined sections from the primary motor cortex (3.7 $\mathrm{mm}$ to $1.7 \mathrm{~mm}$ rostral of bregma) and primary somatosensory cortex (-2.30mm to -4.16 caudal to bregma) and dorsal hippocampus (-2.30 mm to $-4.52 \mathrm{~mm}$ caudal from bregma) in Sham and LFPI animals ( $\mathrm{n}=10$ each, 6 sections/ animal). Neuronal density was estimated from the number of interneurons in both ipsilateral and contralateral hemispheres of the somatosensory and motor cortical layers 2/3, 4 and 5/6 in each section. Sections from the dorsal hippocampus were examined from the brain area ranging from -2.56 $\mathrm{mm}$ to $-4.52 \mathrm{~mm}$ caudal of bregma for sham and LFPI animals ( $\mathrm{n}=10$ each, 6 sections/ animal) The number of inhibitory neurons were quantified and averaged bilaterally in CA1, CA2/3 and dentate gyrus (DG) in LFPI and sham animals. For flow of reading, details of neuronal density and statistical significances are presented in Table 3, and only percentage summary statements are presented in the figures and text below.

\section{Somatosensory cortex}

Visual microscopic analysis of the immunostained sections of somatosensory cortex was backed up by unbiased quantitative estimation of neuronal density and the latter data are presented for the five stains (three CBPs, viz., PV, CB and CR, and two neuropeptides, viz., NPY and SOM) in figure 3.

Parvalbumin Immunoreactivity: At 8 weeks neuronal density of PV neurons was significantly reduced in the (Fig.3.a) ipsilateral supragranular and infragranular layers of the somatosensory cortex when compared with sham controls. The LFPI ipsilateral supragranular (L1-3) and infragranular (L5-6) layers were 72\% and 82\% $(\mathrm{p}<0.05)$ of sham values (Fig.4.a). Contralaterally, neuronal density of PV neurons was not significantly different from sham counterparts.

Interhemispheric differences revealed that PV neuronal density was lower ipsilaterally than contralaterally in supragranular (ipsilaterally $73 \%$ of contralateral cell numbers, $p<0.05$ ) and granular (ipsilaterally $85 \%$ of contralateral cell numbers, $\mathrm{p}<0.05$ ) layers of the LFPI somatosensory cortex. Neuronal morphology included multipolar cells (Fig 5.a) corresponding to basket and chandelier cells (Kawaguchi \& Kubota, 1997; Kubota \& Kawaguchi, 1994; Markram et al., 2004) in cortical layers.

Calbindin Immunoreactivity: CB-IR was abundant in supragranular layers $2 / 3$ of the somatosensory cortex corresponding to vertically oriented bipolar (Fig 5.b), bitufted or double bouquet cells (DeFelipe, 1997) and weakly stained pyramidal cells (Kubota \& Kawaguchi, 1994) that were excluded from the analysis as only inhibitory interneurons were counted in this study. Quantitative analysis of CB-IR neuronal density confirmed the absence of any statistically significant differences between LFPI and sham animals (Fig 3b). However, interhemispheric differences were observed in the LFPI infragranular cortex (Fig.4b; ipsilaterally $62 \%$ of contralateral cell numbers, $\mathrm{p}<0.05$ ). 
Calretinin Immunoreactivity: CR-IR was observed in all cortical layers (L1-L6) in Sham and LFPI animals. Unique to layer 1, large CR-IR neurons with horizontal processes (Condé et al., 1994; Hestrin \& Armstrong, 1996) were predominant in uninjured Sham controls than in LFPI animals (Fig 5.c). Neuronal morphology included ovoid and fusiform cells, that resembled vertically oriented bipolar cells. Dense long vertical processes of CR immunoreactivity and strongly stained varicosities devoid of cell soma were observed in layers 2-6 in both Sham and LFPI animals.

The density of CR neurons was significantly reduced in ipsilateral supragranular (L1L3) layers of somatosensory cortex compared to sham controls (Fig.3 c), being 74\% of that of shams ( $<<0.05$; Fig.4c). Contralaterally, neuronal density of CR neurons was not significantly different from sham counterparts.

Finally, interhemispheric differences revealed that CR neuronal density was lower ipsilaterally than contralaterally in supragranular layers (72\% of cells remaining ipsilaterally as compared contralateral side, $\mathrm{p}<0.05$ ) of the LFPI somatosensory cortex.

Neuropeptide Y Immunoreactivity: NPY-IR was present in cortical layers 2-6 of the in both groups (Fig 3d). In layers 2/3, neuronal morphology included neurons with oval and rounded soma with mostly horizontal and vertically oriented processes (Fig 5d). While some NPY immunoreactive cells with horizontal processes were observed in layers 5-6 and nearer to the white matter area. Dense immunoreactive processes were observed in all layers of both treatment groups. NPY-IR did not show any statistically significant differences in (Fig.4d) supragranular layers 2/3, input layer 4 and infragranular layers 5/6 between LFPI and Sham animals or interhemispheric differences in LFPI animals.

Somatostatin Immunoreactivity: SOM-IR neurons with round or fusiform cell soma and mostly vertically oriented ascending and descending processes were present in cortical layers 2-6 in Sham and TBI animals (Fig 5e). SOM neurons appeared to be morphologically bipolar in layers 2-6. At 8 weeks after trauma neuronal density of SOM neurons was significantly reduced in the ipsilateral supragranular, granular and infragranular layers of the somatosensory cortex when compared with sham controls (Fig.3e). The ipsilateral (Fig.4e) supragranular (L1-3), granular (L4) and infragranular (L5-6) layers were 61\%, 47\% and 64\% $(p<0.05)$ of that shams after LFPI. Contralaterally, neuronal density of SOM neurons was significantly different from sham counterparts in supragranular (75\% of that of shams) and infragranular ( $145 \%$ of that of shams) layers.

Interhemispheric differences revealed that SOM neuronal density was lower ipsilaterally than contralaterally in granular (43\% of cells remaining ipsilaterally as compared contralateral side, $\mathrm{p}<0.05)$ and infragranular $(44 \%$ of cells remaining ipsilaterally as compared to contralateral side, $\mathrm{p}<0.05$ ) layers of the LFPI somatosensory cortex.

\section{Motor cortex}

As with the somatosensory cortex sections, visual microscopic analysis of immunostained motor cortex sections was backed up by unbiased quantitative estimation of neuronal density and the latter data are presented for the five stains in Figure.6. 
Parvalbumin Immunoreactivity: PV-IR was present in layers 2-6 of motor cortex in both groups (Fig 6a). PV neurons appeared to be mostly multipolar with horizontal and vertically oriented processes in all layers from 2-6 (Fig 8a). Heavy neuropil labelling and PV-IR puncta outlining unstained target neurons were more prominent in layers 5-6 compared to other cortical layers. Long PV-IR vertical processes were present in layers 5-6.

PV-IR did not show any statistically significant differences in (Fig. 7a) supragranular layers 2/3, input layer 4 and infragranular layers 5/6 between LFPI and Sham animals or interhemispheric differences in LFPI animals in the motor cortex.

Calbindin Immunoreactivity: CB-IR neurons were observed in layers 2-6 of the motor cortex in both LFPI and Sham animals. In supragranular layers 2-3, CB cells appeared to be morphologically either multipolar or bipolar and were mostly multipolar in the infragranular layers 5-6 (Fig 8b). Weakly stained CB-IR excitatory pyramidal cells observed in layers 2-3 were excluded from the quantitative analysis.

CB-IR also did not show any statistically significant differences in (Fig. 6b \& Fig. 7b) supragranular layers 2/3, input layer 4 and infragranular layers 5/6 between LFPI and Sham animals or interhemispheric differences in LFPI animals in the motor cortex.

Calretinin Immunoreactivity: CR-IR neurons were observed in L1-L6 of the motor cortex in both LFPI and sham animals. CR neurons appeared to be bipolar, bitufted and fusiform with vertically oriented processes in layers 1-6 (Fig 8c). CR-IR was abundant in layers 1-4 and less frequent in layers 5-6. No significant differences were observed between (Fig. 6c \& Fig.7c) LFPI and sham animals for CR-IR in any of the motor cortical layers. No differences were noted interhemispherically in LFPI animals.

Neuropeptide Y Immunoreactivity: NPY-IR neurons were present in layers 2-6 in both groups. Morphologically, NPY neurons appeared to be bipolar in layers 2-with oval or spindle shape soma and vertically oriented processes (Fig 8d). Few multipolar cells were present in layers 2-6 of the motor cortex. NPY-IR also did not show any statistically significant differences in (Fig. 6d \& 7d) supragranular layers 2/3, input layer 4 and infragranular layers 5/6 between LFPI and Sham animals or interhemispheric differences in LFPI animals in the motor cortex.

Somatostatin Immunoreactivity: SOM-IR neurons were present in all layers of the motor cortex in both treatment groups. SOM cells appeared to be mostly bipolar with vertically oriented processes with rounded and spindle shaped soma (Fig 8e). While in layers 2/3 and $5 / 6$ some SOM neurons appeared to be multipolar with horizontally oriented processes. Neuronal density of SOM-IR did not show any significant differences (Fig. 6e \& 7e) interhemispherically in LFPI animals or between LFPI and sham animals in any of the motor cortical layers.

\section{Hippocampus}


Dorsal hippocampal sections was examined from the area extending from $-2.56 \mathrm{~mm}$ to $-4.52 \mathrm{~mm}$ caudal of bregma. The number of inhibitory neurons were quantified and averaged bilaterally in CA1, CA2/3 and dentate gyrus (DG) in both groups.

Parvalbumin Immunoreactivity: Laminar analysis revealed dense PV-IR neurons were present in stratum oriens and stratum pyramidale layers of CA1 and CA2/3 and hilar regions of the DG of both groups of animals. Fewer PV-IR neurons were observed in the stratum radiatum and lacunosum moleculare layers of the CA1 and CA3 and molecular layer of the DG. PV-IR puncta outlining their target neurons were observed in the stratum pyramidale layer of CA1 (Fig 11a) and CA2/3 as well as granular layer of the DG in both groups. Morphologically, PV neurons looked like basket cells and axo-axonic cell types (Kosaka et al., 1987) based on axonal arborisations and rounded or ovoid shaped soma. At 8 weeks after trauma PV neurons were significantly reduced in the ipsilateral supragranular DG of LFPI animals (Fig. 9a\&b) when compared with sham controls. PV-IR neurons in the ipsilateral DG was $89 \%(p<0.05)$ that of shams after LFPI (Fig.10.a). Contralaterally, PV neuronal numbers were not significantly different from sham counterparts. Interhemispherically, no significant differences were observed in LFPI animals.

Calbindin Immunoreactivity: Laminar analysis revealed frequent CB-IR neurons with vertically oriented dendritic processes in the stratum radiatum layer of CA1 and CA2/3 subregions (11b). CB neurons with horizontally oriented processes were also present in stratum oriens, stratum radiatum and lacunosum moleculare layers of the CA1 and CA2/3. Morphologically, cells appeared to be multipolar in the CA3 sub-region of both LFPI and Sham animals.

The number of CB neurons (Fig. 9c\&d) was significantly reduced in the LFPI contralateral CA1 when compared with sham controls, being (Fig. 10B) 69\% $(\mathrm{p}<0.05)$ that of shams. Ipsilaterally, neuronal number of CB neurons was not significantly different from sham counterparts. Interhemispheric comparisons in LFPI animals revealed that CB neuronal number was greater ipsilaterally than contralaterally in CA1 $(134 \%$ of cells remaining ipsilaterally as compared to contralateral side, $\mathrm{p}<0.05)$ and CA2/3 $(134 \%$ of cells remaining ipsilaterally as compared to contralateral side, $\mathrm{p}<0.05$ ).

Calretinin Immunoreactivity: CR-IR was most abundant in the DG and CA3 sub-regions of the dorsal hippocampus of LFPI and sham animals. Morphologically, the soma of CR neurons were either multipolar or bipolar in shape. Dense CR-IR fibres were observed surrounding the puncta of target cells in the DG of both groups (Fig 11c). CR-IR also did not show any statistically significant differences in CA1, CA2/3 AND DG sub regions of hippocampus between LFPI and Sham animals. Interhemispheric comparisons in LFPI animals revealed that CR neuronal number (Fig. 10c) was greater ipsilaterally than contralaterally in CA2/3 (120\% of cells remaining ipsilaterally as compared to contralateral side, $\mathrm{p}<0.05)$ and DG (119\% of cells remaining ipsilaterally as compared to contralateral side, $\mathrm{p}<0.05)$. 
Neuropeptide Y Immunoreactivity: NPY-IR neurons were found mostly in the hilar region of the DG in Shams and LFPI animals (Fig 11d). Morphologically, NPY cells were either multipolar or bipolar in shape with oval, rounded or fusiform soma.

The number of NPY expressing neurons (Fig. 9e\&f) was significantly increased in the LFPI ipsilateral CA1 when compared with sham controls, being (Fig. 10d) $131 \%(p<0.05)$ that of sham values. Contralaterally, the number of NPY neurons was not significantly different from sham counterparts. Interhemispheric comparisons in LFPI animals revealed that NPY neuronal number was greater ipsilaterally than contralaterally in CA1 $(140 \%$ of cells remaining ipsilaterally as compared to contralateral side, $\mathrm{p}<0.05)$ and CA2/3 (175\% of cells remaining ipsilaterally as compared to contralateral side, $\mathrm{p}<0.05$ ).

Somatostatin Immunoreactivity: SOM-IR neurons were found in all sub regions of the dorsal hippocampus in both groups, SOM neurons were denser in the hilar region (Fig 11e) and very scarce in granular and molecular layers of the DG. In the CA1 SOM-IR neurons were very rarely observed in the radiatum/lacunosum layers were almost all confined to the stratum oriens. SOM cells were mostly concentrated in stratum pyramidale and radiatum/lacunosum layers of the CA2/3 region. Morphologically, the neurons appeared to be multipolar with fusiform somata.

The numbers of SOM-expressing neurons (Fig. 9g\&h) were significantly increased in the LFPI ipsilateral CA1 and CA2/3 (Fig. 10d) when compared with sham controls, being $152 \%$ and $138 \%(\mathrm{p}<0.05)$ that of shams. Contralaterally, SOM neuronal numbers were not significantly different from sham counterparts. Interhemispheric comparisons in LFPI animals revealed that SOM-IR was increased ipsilaterally compared to contralaterally in CA1 ( $200 \%$ of cells ipsilaterally compared to contralateral side, $\mathrm{p}<0.05$ ) CA2/3 (195\% of cells ipsilaterally compared to contralateral side, $\mathrm{p}<0.05)$ and DG $(154 \%$ of cells ipsilaterally compared to contralateral side, $\mathrm{p}<0.05$ ).

\section{Neuronal degeneration: Fluoro Jade $\mathbf{C}$ analysis}

The fluoro jade $\mathrm{C}$ stain allowed for histological detection of degenerating neurons in different brain areas following LFPI. Detection of FJC positive cells confirmed the extent of neurodegeneration in the brain regions examined here, namely motor and somatosensory cortex and hippocampus. Stained sections were assessed for FJC positive cells, regions of positive staining were rated as low (yellow), moderate (orange) or high intensity (red) as depicted in Figure 12. Regions scored as moderate or high were evaluated on a semiquantitative arbitrary scale from none $(-)$ to mild $(+)$, moderate $(++)$ and strong $(+++)$.

As shown in Table 4. No FJC positive cells were observed in the brain regions of sham controls (Fig. 13a\&b). LFPI animals were observed to have a large number of FJC positive cells representing degenerating cells in the ipsilateral somatosensory cortex (Fig. $13 c \& d)$ and occasionally in the contralateral side as well. FJC positive cells were also observed in the CA1 (Fig. 13e), CA2/3 (Fig. 13f) and DG (Fig. 13g\&h) of the LFPI animals. 


\section{Discussion}

In this study we examined how the mixed diffuse-focal LFPI model (i.e., a substantially different phenotype from the diffuse-injury model used in our previous study (Carron et al., 2016)) affects different subsets of inhibitory neurons at 8 weeks post injury, and how this associates with consequences on behaviour. We investigated the changes in the numbers of five different subpopulations of inhibitory neurons at 8 weeks post LFPI in cortex (motor and somatosensory) and hippocampus and conducted a suite of behaviour tests to assess sensory, motor and cognitive ability post LFPI.

\section{Loss of interneurons mediating perisomatic and dendritic inhibition in somatosensory cortex, and acute sensory behavioural hypersensitivity}

In our 8 week study on diffuse TBI, dendritic inhibition mediating CR interneurons alone were reduced, in the supragranular layers of the somatosensory cortex, while immunoreactivity for PV, CB, NPY and SOM remain unchanged, in any layer. Here we report mixed diffuse-focal TBI induced by LFPI caused a reduction in both perisomatic inhibition mediating PV interneurons and dendritic inhibition mediating CR and SOM neurons in the somatosensory cortex at 8 weeks post trauma.

PV expressing inhibitory neurons were reduced bilaterally in LFPI animals and were significantly lower in numbers in the ipsilateral supragranular and infragranular cortex of LFPI animals when compared to shams, to $72 \%$ and $82 \%$ of sham surgery values in the supragranular and infragranular layers respectively. CR interneurons were also reduced in the ipsilateral supragranular layers, to $74 \%$ of shams. SOM-expressing neurons were reduced significantly in ipsilateral supragranular, granular and infragranular layers of the somatosensory cortex in LFPI animals, to $61 \%, 47 \%$ and $64 \%$ that of sham surgery animals, respectively. NPY neurons appeared to be preserved 8 weeks after LFPI while CB neurons showed a non-significant trend towards reduction in ipsilateral somatosensory cortex. Finally, interhemispheric assessment showed that SOM neurons were also reduced in supragranular layers in the contralateral somatosensory cortex to 75\% of sham levels; however, overall, there were significant reductions in PV, CB, CR and SOM neurons ipsilaterally when compared to the contralateral side in LFPI animals suggesting that the damage is more pronounced on the ipsilateral side, which faces the brunt of the traumatic insult.

To the best of our knowledge, there are no studies that have examined changes in inhibitory neurons in the somatosensory cortex at 8 weeks following a mixed diffuse-focal TBI. A study by Cantu and colleagues demonstrated a similar loss of PV and SOM interneurons in the somatosensory cortex superficial and deep layers at 2-4 weeks after CCI induced focal TBI (Cantu et al., 2015). Thus, in somatosensory cortex, loss of PV and SOM interneurons appears to occur relatively early after focal injury whereas loss of CR interneurons occurs later (at least after the 2-4 week time point examined by Cantu and colleagues) and is consistent across focal and diffuse TBI; in the latter model, loss of CR interneurons is seen late after diffuse TBI. As in the case of diffuse TBI, after LFPI injury we found here that the loss of CR interneurons only occurred in supragranular barrel cortex. 
What are the functional implications of the loss of these specific interneuronal pools in sensory cortex? PV interneurons target the soma and axon initial segment of excitatory cells and other interneurons, mediating perisomatic inhibition (Freund \& Katona, 2007) and their loss should alter neuronal connectivity and network balance. Consistent with this expectation, PV neuronal loss impairs the gamma oscillations required for modulating excitatory signals and enhancing cortical circuitry performance (Sohal et al., 2009). The other two classes of affected interneurons, CR-expressing and SOM-expressing interneurons, mediate dendrite-targeting inhibition. CR interneurons of supragranular layers 2/3 have descending axon collaterals that target excitatory cells and other interneurons in deeper layers $5 / 6$ of the cortex possibly providing inhibition within a mini column (Barinka \& Druga, 2010) and therefore a loss of these cells could also result in reduced columnar inhibition apart from dendritic inhibition also mediated by CR cells. The story is more complex with respect to the SOM interneurons. In granular layer 4 SOM neurons comprise almost $20-40 \%$ of inhibitory neurons (Rudy et al., 2011) and differ from SOM neurons in other cortical layers in that they have axons with extensive arborisations confined within layer 4 (Ma et al., 2006). SOM neurons in L4 have higher firing frequency than L2/3 SOM neurons (Xu et al., 2013) and usually target other interneurons, particularly PV neurons, and may therefore play a critical role in cortical plasticity by reducing feed forward inhibition of PV interneurons on principal cells and through disinhibition of transmission of thalamic afferent signals (Xu et al., 2013).

Despite loss of interneurons in the somatosensory cortex at 8 weeks post trauma, LFPI rats only displayed hypersensitivity to whisker stimulation for the first week post injury, with whisker nuisance scores being only significantly different from sham controls up to day 7 post injury. Consistent with this acute hypersensitivity, LFPI rats did not display heightened anxiety compared to shams in the EPM task at 8 weeks post injury as indicated by no differences in the time spent in the open arms of the maze. However, although there were no significant differences in the whisker nuisance tasks scores between the two groups, it is worth noting that the LFPI animals always did slightly and consistently worse than sham controls for the remaining weeks 2-8 duration of testing. This persisting small decrement in behaviour performance is more consistent with the interneuronal loss at 8 weeks than the recovery of functional responsiveness of surviving neurons seen at 12 weeks after LFPI (Johnstone et al., 2015).

Finally, in contrast to the loss of neurons noted ipsilaterally, at 8 weeks after LFPI, SOM neurons were found to be upregulated in the infragranular layers of the contralateral hemisphere in LFPI animals, to $145 \%$ of sham controls. Inhibition mediated by dendrite targeting interneurons such as SOM plays a significant role in modulating dendritic excitatory synaptic plasticity (Bar-Ilan et al., 2012).We therefore speculate that the upregulation of SOM expressing inhibitory neurons in contralateral cortex may be a compensatory effect involving the long term recovery of functional responsiveness to fine tune and shape excitatory synaptic plasticity following trauma and maintain the normal cortical activity observed at 12 weeks after LFPI (Johnstone et al., 2015). Whether this played any role in the recovery of sensory behaviours in the whisker nuisance task remains speculative. 


\section{No loss of motor cortex interneurons correlates with behavioural recovery in motor tasks}

Motor cortex showed no obvious loss in any of the subsets of interneurons we examined in this study and this paralleled the behavioural normality in motor tasks seen at 8 weeks after LFPI. LFPI animals were not significantly different from the sham counterparts in the number of closed arm entries in the EPM task and displayed no locomotor deficits at 8 weeks post injury. Rotarod and beam walk scores showed only a transient reduction in performance within the first week and had essentially recovered within this week. An exception was the beam walk task performance at 8 weeks post-injury where some LFPI animals seemed to traverse the beam with their abdomen touching the beam and ended up scoring worse than previously. Testing conditions and environment can exert a significant influence on beam walking performance (Goldstein \& Davis, 1990) and these factors may have influenced this outcome in our study. While beam walk testing was done in the same behaviour testing room from weeks 1-7, testing at week 8 had to be moved to a different room due to unforeseen reasons; this change in setting may have been a confounding factor that contributed to a decline in performance in LFPI animals in week 8 following recovery from weeks 2-7. Previously we reported increased number of slips and falls in the beam walk task 12 weeks after LFPI.(Johnstone et al., 2015) These differences may reflect that in the previous study beam walk performance was assessed only once at 12 weeks after LFPI while in the current study testing was conducted daily for the first week and then one day a week for the next 8 weeks. Performance on motor tasks like the beam walk and rotarod involve a learning component (Buitrago et al., 2004) and frequent testing might have contributed to the better performance observed in LFPI animals in this 8 week study. Alternatively the week 8 drop in beam walk performance we noted here may reflect a further decline that was captured at the 12 week time point by Johnstone and colleagues - perhaps brain injury speeds up some ageing-related decrement in motor task performance.

\section{Heterogenous changes in hippocampal interneurons and association with spatial memory and cognitive impairment}

In hippocampus we found heterogenous changes 8 weeks after trauma: a decrease in PV and CB interneurons in ipsilateral DG and contralateral CA1, upregulation of NPY interneurons in ipsilateral CA1 and upregulation of SOM interneurons in ipsilateral CA1 and CA2/3. Similar reductions in PV expressing interneurons were reported in the same strain of rats (Sprague Dawleys) at 1 and 6 months in the DG and CA1 after LFPI (Huusko et al., 2015). In a different strain of rats (Wistar), several other studies show reductions in PV neurons in the hilus of the ipsilateral DG at 1 week (Toth, Hollrigel, Gorcs, \& Soltesz, 1997) and in ipsilateral DG and CA3 but not CA1 at 7 days (Zhang B. et al., 2011) after LFPI. These studies demonstrate loss of PV neurons at various time points after LFPI and reflect the ongoing degeneration and damage to this subset of interneurons following mixed diffusefocal injury. In contrast, in diffuse TBI, there is upregulation of PV neurons in hippocampal CA1 and CA2/3 subfields (Carron et al., 2016) suggesting that the susceptibility of PV hippocampal neurons to trauma is injury type dependent. 
We also found reductions in the numbers of CB neurons in the contralateral CA1 of LFPI animals when compared with shams. No other studies have examined changes in $\mathrm{CB}$ expressing interneurons after LFPI. Only our previous study reports loss of CB neurons in the DG 8 weeks after induction of diffuse injury (Carron et al., 2016). Loss of CB expressing neurons have been reported in ischemic regions of cerebral cortex following focal cerebral ischemic injury (Ouh et al., 2013) and in both cerebral ischemia and TBI, similar secondary injury mechanisms such as inflammation excitotoxicity, oxidative stres and apoptosis contribute to loss of tissue integrity and cell death (Bramlett \& Dietrich, 2004). CB interneurons mediate dendritic inhibition to pyramidal cells and loss of this subtype following trauma could result in reduced dendritic inhibition in hippocampal subfields. The decreases in PV and CB neurons may also contribute to the post-TBI hippocampal-dependent behaviour deficits we report here in this study.

In contrast to the decreases in PV and CB, we found NPY and SOM inhibitory neurons were upregulated in ipsilateral CA1 and CA2/3 at 8 weeks after LFPI. NPY is widely expressed in neuronal tissue in humans as it is in the rodent brain. NPY is known to have a neuro-proliferative effect on hippocampal neuroblasts and precursor cells and modulates neurogenesis (Howell et al., 2003). Hippocampal NPY expression is also increased following limbic seizures (Marksteiner et al., 1989) suggesting its potential role in neuroprotection and counteracting hyperexcitability underlying epileptic seizures (Noe et al., 2008; Vezzani \& Sperk, 2004). Other studies have suggested the involvement of NPY in seizure induced hippocampal neurogenesis (El Bahh et al., 2001) particularly DG neurogenesis.(Bengzon et al., 1997; Parent et al., 1997) NPY neurons were upregulated 1 and 3 months after kainic acid induced epilepsy in parahippocampal regions such as the subiculum (Drexel et al., 2012).Given the potential role of NPY as a neuro-protectant, we speculate that the increase in NPY expressing neurons in CA1 after LFPI may in fact be a measure to modulate and promote neurogenesis after trauma. In contrast to our findings, Huusko and colleagues demonstrate a loss of NPY neurons in the ipsilateral DG and CA2/3 but not in CA1, 1 and 6 months after LFPI(Huusko et al., 2015). However, after diffuse TBI, we found no change in NPY neurons in any of the hippocampal sub regions. Thus, like the vulnerability of PV and CB, the vulnerability of NPY neurons appears to be injury type dependent. There are no other data currently available on the effects of TBI on NPY neurons. Further, hippocampal NPY overexpression is also associated with impaired spatial learning (Thorsell et al., 2000) and may account for the behavioural deficits we saw in LFPI animals in the water maze task that assesses spatial memory and cognition. LFPI animals were unable to self orient, scan and target the hidden platform within the circular pool as indicated by the lower percentage of direct and circle swims as opposed to their sham counterparts who adopted exploratory escape strategies to locate the shortest and quickest path to the hidden platform.

SOM neurons were increased in the ipsilateral CA1 and CA2/3 after LFPI. Similar increases of SOM neurons were observed 1 and 3 months after epilepsy in parahippocampal areas of the brain (Drexel et al., 2012). Interestingly, loss of SOM neurons was reported in ipsilateral DG at 1 month, extending to include CA1 and CA2/3 by 6 months after LFPI (Huusko et al., 2015). We did not observe this effect using the same model of injury, suggesting that changes in SOM neurons are not just injury type specific but also injury time 
dependent. Even in our previous study on diffuse TBI, we found no change in SOM neurons in any of the hippocampal subfields at 8 weeks (Carron et al., 2016). Although SOM neurons predominantly target the dendrites of target cells mediating dendritic inhibition, their axons also make axo-somatic and axo-axonic connections with pyramidal cells and other interneurons.(Gonchar, et al., 2002) Following epilepsy SOM neurons have been reported to appear larger with extended dendrites and axonal collaterals that make new synaptic connections with target cells (Zhang. W. et al., 2009) suggesting their role is shaping neuronal activity and plasticity. Like NPY, loss of SOM neurons in hippocampus has also been reported in association with decline in memory and hippocampal dependent learning tasks such as the water maze (Fitzgerald \& Dokla, 1989). Evidence suggests that somatostatin plays an important role in synaptogenesis and neural proliferation (Scheyltjens \& Arckens, 2016). Therefore we speculate that the increases we report in SOM neurons may simply be a compensatory effect in an effort to restore neuronal function and promote behavioural recovery after trauma.

\section{Ongoing neurodegeneration at 8 weeks after LFPI}

Fluoro-Jade $\mathrm{C}$ was used to identify degenerating neurons in the cortex and hippocampus following LFPI. FJC is sensitive to neuronal damage and stains degenerating neurons subjected to different types of neurotoxic insults (Schmued et al., 1997) including trauma. FJC positive cells were identified in ipsilateral somatosensory cortex, corpus callosum (CC) and CA1, CA2/3, DG hippocampal sub regions. Although neuronal degeneration was predominant ipsilaterally, fewer FJC positive cells were detected even in the contralateral somatosensory cortex, corpus callosum (CC) and DG at 8 weeks after LFPI. The pattern of FJC staining observed in our study is similar to FJC patterns of staining observed in other studies after LFPI however at earlier time points 3h, 24h, 48h and 7 days (Hallam et al., 2004; Sato et al., 2001). In the above two studies at earlier time points greater density of FJC positive cells were detected in hippocampal CA1 (Sato et al., 2001) and CA2/3 (Hallam et al., 2004). In contrast we observed strongest staining in ipsilateral somatosensory cortex and mild staining in the CA1, CA2/3 and DG hippocampal sub-regions at 8 weeks after LFPI. Taken together with our data neurodegeneration appears to be ongoing in cortex and hippocampus even at 8 weeks after LFPI and supports the above data that loss of different subsets of inhibitory neurons after LFPI may infact be due to neurodegenaration and not just a loss of epitope expression after trauma. Detection of FJC cells in the examined brain areas in this study also supports the fact that even surviving interneurons may still be undergoing neurodegeneration even at 8 weeks after LFPI.

In conclusion we report here progressive neurodegeneration in cortex and hippocampus detected with FJC staining and differential vulnerability of inhibitory neurons to LFPI in the different brain areas examined 8 weeks after injury. Our findings also ascertain the fact that susceptibility of interneurons to trauma is injury type and time dependent. These data taken together with our previous studies on diffuse TBI will aid in evaluation of new treatments for TBI and help target specific neuronal subtypes as a function of injury time and type. 


\section{Funding}

The work represented here was funded by the National Health and Medical Research Council of Australia Project Grant No. APP1029311.

\section{Conflict of Interest Statement}

The authors declare that the research was conducted in the absence of any commercial or financial relationships that could be construed as a potential conflict of interest.

\section{References}

Alwis, D. S., Johnstone, V., Yan, E., \& Rajan, R. (2013). Diffuse traumatic brain injury and the sensory brain. Clin Exp Pharmacol Physiol, 40(7), 473-483. doi:10.1111/14401681.12100

Alwis, D. S., Yan, E. B., Johnstone, V., Carron, S., Hellewell, S., Morganti-Kossmann, M. C., \& Rajan, R. (2016). Environmental Enrichment Attenuates Traumatic Brain Injury: Induced Neuronal Hyperexcitability in Supragranular Layers of Sensory Cortex. J Neurotrauma, 33(11), 1084-1101. doi:10.1089/neu.2014.3774 
Alwis, D. S., Yan, E. B., Morganti-Kossmann, M. C., \& Rajan, R. (2012). Sensory cortex underpinnings of traumatic brain injury deficits. PLoS One, 7(12), e52169. doi:10.1371/journal.pone.0052169

Andriessen, T. M., Jacobs, B., \& Vos, P. E. (2010). Clinical characteristics and pathophysiological mechanisms of focal and diffuse traumatic brain injury. J Cell Mol Med, 14(10), 2381-2392. doi:10.1111/j.1582-4934.2010.01164.x

Arciniegas, D. B., Held, K., \& Wagner, P. (2002). Cognitive Impairment Following Traumatic Brain Injury. Curr Treat Options Neurol, 4(1), 43-57.

Bao, F., Shultz, S. R., Hepburn, J. D., Omana, V., Weaver, L. C., Cain, D. P., \& Brown, A. (2012). A CD11d monoclonal antibody treatment reduces tissue injury and improves neurological outcome after fluid percussion brain injury in rats. $J$ Neurotrauma, 29(14), 2375-2392. doi:10.1089/neu.2012.2408

Bar-Ilan, L., Gidon, A., \& Segev, I. (2012). The role of dendritic inhibition in shaping the plasticity of excitatory synapses. Front Neural Circuits, 6, 118. doi:10.3389/fncir.2012.00118

Barinka, F., \& Druga, R. (2010). Calretinin expression in the mammalian neocortex: a review. Physiol Res, 59(5), 665-677.

Bengzon, J., Kokaia, Z., Elmer, E., Nanobashvili, A., Kokaia, M., \& Lindvall, O. (1997). Apoptosis and proliferation of dentate gyrus neurons after single and intermittent limbic seizures. Proc Natl Acad Sci U S A, 94(19), 10432-10437.

Bonislawski, D. P., Schwarzbach, E. P., \& Cohen, A. S. (2007). Brain injury impairs dentate gyrus inhibitory efficacy. Neurobiol Dis, 25(1), 163-169. doi:10.1016/j.nbd.2006.09.002

Bramlett, H. M., \& Dietrich, W. D. (2004). Pathophysiology of cerebral ischemia and brain trauma: similarities and differences. J Cereb Blood Flow Metab, 24(2), 133-150. doi:10.1097/01.WCB.0000111614.19196.04

Buitrago, M. M., Schulz, J. B., Dichgans, J., \& Luft, A. R. (2004). Short and long-term motor skill learning in an accelerated rotarod training paradigm. Neurobiology of Learning and Memory, 81(3), 211-216. doi:http://dx.doi.org/10.1016/j.nlm.2004.01.001

Cantu, D., Walker, K., Andresen, L., Taylor-Weiner, A., Hampton, D., Tesco, G., \& Dulla, C. G. (2015). Traumatic Brain Injury Increases Cortical Glutamate Network Activity by Compromising GABAergic Control. Cereb Cortex, 25(8), 2306-2320. doi:10.1093/cercor/bhu041

Carron, S. F., Yan, E. B., Allitt, B. J., \& Rajan, R. (2018). Immediate and Medium-term Changes in Cortical and Hippocampal Inhibitory Neuronal Populations after Diffuse TBI. Neuroscience, 388, 152-170. doi:10.1016/j.neuroscience.2018.07.020

Carron, S. F., Yan, E. B., Alwis, D. S., \& Rajan, R. (2016). Differential susceptibility of cortical and sub-cortical inhibitory neurons and astrocytes in the long term following diffuse traumatic brain injury. J Comp Neurol, 3530-3560. doi:10.1002/cne.24014

Condé, F., Lund, J. S., Jacobowitz, D. M., Baimbridge, K. G., \& Lewis, D. A. (1994). Local circuit neurons immunoreactive for calretinin, calbindin D-28k or parvalbumin in monkey prefronatal cortex: Distribution and morphology. J Comp Neurol, 341(1), 95116. doi:10.1002/cne.903410109 
Conti, A. C., Raghupathi, R., Trojanowski, J. Q., \& McIntosh, T. K. (1998). Experimental brain injury induces regionally distinct apoptosis during the acute and delayed posttraumatic period. J Neurosci, 18(15), 5663-5672.

D'Ambrosio, R., Maris, D. O., Grady, M. S., Winn, H. R., \& Janigro, D. (1998). Selective loss of hippocampal long-term potentiation, but not depression, following fluid percussion injury. Brain Res, 786(1-2), 64-79.

DeFelipe, J. (1997). Types of neurons, synaptic connections and chemical characteristics of cells immunoreactive for calbindin-D28K, parvalbumin and calretinin in the neocortex. J Chem Neuroanat, 14(1), 1-19.

Demeulemeester, H., Vandesande, F., Orban, G. A., Heizmann, C. W., \& Pochet, R. (1989). Calbindin D-28K and parvalbumin immunoreactivity is confined to two separate neuronal subpopulations in the cat visual cortex, whereas partial coexistence is shown in the dorsal lateral geniculate nucleus. Neurosci Lett, 99(1-2), 6-11.

Drexel, M., Kirchmair, E., Wieselthaler-Hölzl, A., Preidt, A. P., \& Sperk, G. (2012). Somatostatin and Neuropeptide Y Neurons Undergo Different Plasticity in Parahippocampal Regions in Kainic Acid-Induced Epilepsy. J Neuropathol Exp Neurol, 71(4), 312-329. doi:10.1097/NEN.0b013e31824d9882

El Bahh, B., Auvergne, R., Lere, C., Brana, C., Le Gal La Salle, G., \& Rougier, A. (2001). Decreased epileptic susceptibility correlates with neuropeptide Y overexpression in a model of tolerance to excitotoxicity. Brain Res, 894(2), 209-217.

Faden, A. I., Demediuk, P., Panter, S. S., \& Vink, R. (1989). The role of excitatory amino acids and NMDA receptors in traumatic brain injury. Science, 244(4906), 798-800.

Finnanger, T. G., Skandsen, T., Andersson, S., Lydersen, S., Vik, A., \& Indredavik, M. (2013). Differentiated patterns of cognitive impairment 12 months after severe and moderate traumatic brain injury. Brain Injury, 27(13-14), 1606-1616. doi:doi:10.3109/02699052.2013.831127

Fitzgerald, L. W., \& Dokla, C. P. (1989). Morris water task impairment and hypoactivity following cysteamine-induced reductions of somatostatin-like immunoreactivity. Brain Res, 505(2), 246-250.

Freund, T. F., \& Buzsaki, G. (1996). Interneurons of the hippocampus. Hippocampus, 6(4), 347-470. doi:10.1002/(SICI)1098-1063(1996)6:4\&lt;347::AID-HIPO1\&gt;3.0.CO;2-I

Freund, T. F., \& Katona, I. (2007). Perisomatic inhibition. Neuron, 56(1), 33-42. doi:10.1016/j.neuron.2007.09.012

Galvin, J., Froude, E. H., \& Imms, C. (2009). Sensory processing abilities of children who have sustained traumatic brain injuries. Am J Occup Ther, 63(6), 701-709.

Goldstein, L. B., \& Davis, J. N. (1990). Beam-walking in rats: studies towards developing an animal model of functional recovery after brain injury. J Neurosci Methods, 31(2), 101-107.

Gonchar, Y., Turney, S., Price, J. L., \& Burkhalter, A. (2002). Axo-axonic synapses formed by somatostatin-expressing GABAergic neurons in rat and monkey visual cortex. $J$ Comp Neurol, 443(1), 1-14.

Gurkoff, G. G., Giza, C. C., \& Hovda, D. A. (2006). Lateral fluid percussion injury in the developing rat causes an acute, mild behavioral dysfunction in the absence of 
significant cell death. Brain Research, 1077(1), 24-36. doi:https://doi.org/10.1016/j.brainres.2006.01.011

Haaland, K. Y., Temkin, N., Randahl, G., \& Dikmen, S. (1994). Recovery of simple motor skills after head injury. J Clin Exp Neuropsychol, 16(3), 448-456. doi:10.1080/01688639408402655

Hall, K. D., \& Lifshitz, J. (2010). Diffuse traumatic brain injury initially attenuates and later expands activation of the rat somatosensory whisker circuit concomitant with neuroplastic responses. Brain Res, 1323, 161-173. doi:10.1016/j.brainres.2010.01.067

Hall, S., \& Bornstein, R. A. (1991). The relationship between intelligence and memory following minor or mild closed head injury: greater impairment in memory than intelligence. J Neurosurg, 75(3), 378-381. doi:10.3171/jns.1991.75.3.0378

Hallam, T. M., Floyd, C. L., Folkerts, M. M., Lee, L. L., Gong, Q. Z., Lyeth, B. G., . . . Berman, R. F. (2004). Comparison of behavioral deficits and acute neuronal degeneration in rat lateral fluid percussion and weight-drop brain injury models. $J$ Neurotrauma, 21(5), 521-539. doi:10.1089/089771504774129865

Hendry, S. H., Jones, E. G., \& Emson, P. C. (1984). Morphology, distribution, and synaptic relations of somatostatin- and neuropeptide Y-immunoreactive neurons in rat and monkey neocortex. $J$ Neurosci, 4(10), 2497-2517.

Hestrin, S., \& Armstrong, W. E. (1996). Morphology and physiology of cortical neurons in layer I. J Neurosci, 16(17), 5290-5300.

Hicks, R., Soares, H., Smith, D., \& McIntosh, T. (1996). Temporal and spatial characterization of neuronal injury following lateral fluid-percussion brain injury in the rat. Acta Neuropathol, 91(3), 236-246.

Howell, O. W., Scharfman, H. E., Herzog, H., Sundstrom, L. E., Beck-Sickinger, A., \& Gray, W. P. (2003). Neuropeptide $\mathrm{Y}$ is neuroproliferative for post-natal hippocampal precursor cells. J Neurochem, 86(3), 646-659.

Huusko, N., Romer, C., Ndode-Ekane, X. E., Lukasiuk, K., \& Pitkanen, A. (2015). Loss of hippocampal interneurons and epileptogenesis: a comparison of two animal models of acquired epilepsy. Brain Struct Funct, 220(1), 153-191. doi:10.1007/s00429-0130644-1

Hylin, M. J., Orsi, S. A., Zhao, J., Bockhorst, K., Perez, A., Moore, A. N., \& Dash, P. K. (2013). Behavioral and Histopathological Alterations Resulting from Mild Fluid Percussion Injury. Journal of Neurotrauma, 30(9), 702-715. doi:10.1089/neu.2012.2630

Johnstone, V. P., Shultz, S. R., Yan, E. B., O'Brien, T. J., \& Rajan, R. (2014). The acute phase of mild traumatic brain injury is characterized by a distance-dependent neuronal hypoactivity. J Neurotrauma, 31(22), 1881-1895. doi:10.1089/neu.2014.3343

Johnstone, V. P., Wright, D. K., Wong, K., O'Brien, T. J., Rajan, R., \& Shultz, S. R. (2015). Experimental Traumatic Brain Injury Results in Long-Term Recovery of Functional Responsiveness in Sensory Cortex but Persisting Structural Changes and Sensorimotor, Cognitive, and Emotional Deficits. $J$ Neurotrauma. doi:10.1089/neu.2014.3785 
Johnstone, V. P., Yan, E. B., Alwis, D. S., \& Rajan, R. (2013). Cortical hypoexcitation defines neuronal responses in the immediate aftermath of traumatic brain injury. PLoS One, 8(5), e63454. doi:10.1371/journal.pone.0063454

Kawaguchi, Y., \& Kubota, Y. (1997). GABAergic cell subtypes and their synaptic connections in rat frontal cortex. Cereb Cortex, 7(6), 476-486.

Kubota, Y., \& Kawaguchi, Y. (1994). Three classes of GABAergic interneurons in neocortex and neostriatum. Jpn J Physiol, 44 Suppl 2, S145-148.

Kuhtz-Buschbeck, J. P., Hoppe, B., Golge, M., Dreesmann, M., Damm-Stunitz, U., \& Ritz, A. (2003). Sensorimotor recovery in children after traumatic brain injury: analyses of gait, gross motor, and fine motor skills. Dev Med Child Neurol, 45(12), 821-828.

Levin, H. S., Grossman, R. G., Rose, J. E., \& Teasdale, G. (1979). Long-term neuropsychological outcome of closed head injury. J Neurosurg, 50(4), 412-422. doi:10.3171/jns.1979.50.4.0412

Lew, H. L., Lee, E. H., Pan, S. S., \& Date, E. S. (2004). Electrophysiologic abnormalities of auditory and visual information processing in patients with traumatic brain injury. Am J Phys Med Rehabil, 83(6), 428-433.

Ma, Y., Hu, H., Berrebi, A. S., Mathers, P. H., \& Agmon, A. (2006). Distinct subtypes of somatostatin-containing neocortical interneurons revealed in transgenic mice. $J$ Neurosci, 26(19), 5069-5082. doi:10.1523/jneurosci.0661-06.2006

Markram, H., Toledo-Rodriguez, M., Wang, Y., Gupta, A., Silberberg, G., \& Wu, C. (2004). Interneurons of the neocortical inhibitory system. Nat Rev Neurosci, 5(10), 793-807. doi:10.1038/nrn1519

Marksteiner, J., Sperk, G., \& Maas, D. (1989). Differential increases in brain levels of neuropeptide $\mathrm{Y}$ and vasoactive intestinal polypeptide after kainic acid-induced seizures in the rat. Naunyn Schmiedebergs Arch Pharmacol, 339(1-2), 173-177.

McNamara, K. C., Lisembee, A. M., \& Lifshitz, J. (2010). The whisker nuisance task identifies a late-onset, persistent sensory sensitivity in diffuse brain-injured rats. $J$ Neurotrauma, 27(4), 695-706. doi:10.1089/neu.2009.1237

Noe, F., Pool, A. H., Nissinen, J., Gobbi, M., Bland, R., Rizzi, M., . . . Vezzani, A. (2008). Neuropeptide Y gene therapy decreases chronic spontaneous seizures in a rat model of temporal lobe epilepsy. Brain, 131(Pt 6), 1506-1515. doi:10.1093/brain/awn079

Norris, C. M., \& Scheff, S. W. (2009). Recovery of afferent function and synaptic strength in hippocampal CA1 following traumatic brain injury. J Neurotrauma, 26(12), 22692278. doi:10.1089/neu.2009.1029

Ouh, I. O., Kim, Y. M., Gim, S. A., \& Koh, P. O. (2013). Focal cerebral ischemic injury decreases calbindin expression in brain tissue and HT22 cells. Lab Anim Res, 29(3), 156-161. doi:10.5625/lar.2013.29.3.156

Parent, J. M., Yu, T. W., Leibowitz, R. T., Geschwind, D. H., Sloviter, R. S., \& Lowenstein, D. H. (1997). Dentate granule cell neurogenesis is increased by seizures and contributes to aberrant network reorganization in the adult rat hippocampus. $J$ Neurosci, 17(10), 3727-3738.

Pavlov, I., Huusko, N., Drexel, M., Kirchmair, E., Sperk, G., Pitkanen, A., \& Walker, M. C. (2011). Progressive loss of phasic, but not tonic, GABAA receptor-mediated 
inhibition in dentate granule cells in a model of post-traumatic epilepsy in rats. Neuroscience, 194, 208-219. doi:10.1016/j.neuroscience.2011.07.074

Raymond, M. J., Bennett, T. L., Malia, K. B., \& Bewick, K. C. (1996). Rehabilitation of visual processing deficits following brain injury. NeuroRehabilitation, 6(3), 229-239. doi:10.3233/nre-1996-6309

Rogers, J. H. (1992). Immunohistochemical markers in rat cortex: co-localization of calretinin and calbindin-D28k with neuropeptides and GABA. Brain Res, 587(1), 147-157.

Rudy, B., Fishell, G., Lee, S., \& Hjerling-Leffler, J. (2011). Three groups of interneurons account for nearly $100 \%$ of neocortical GABAergic neurons. Dev Neurobiol, 71(1), 45-61. doi:10.1002/dneu.20853

Sato, M., Chang, E., Igarashi, T., \& Noble, L. J. (2001). Neuronal injury and loss after traumatic brain injury: time course and regional variability. Brain Res, 917(1), 45-54.

Scheyltjens, I., \& Arckens, L. (2016). The Current Status of Somatostatin-Interneurons in Inhibitory Control of Brain Function and Plasticity. Neural Plasticity, 2016, 8723623. doi:10.1155/2016/8723623

Schmued, L. C., Albertson, C., \& Slikker, W., Jr. (1997). Fluoro-Jade: a novel fluorochrome for the sensitive and reliable histochemical localization of neuronal degeneration. Brain Res, 751(1), 37-46.

Shultz, S. R., Bao, F., Omana, V., Chiu, C., Brown, A., \& Cain, D. P. (2012a). Repeated mild lateral fluid percussion brain injury in the rat causes cumulative long-term behavioral impairments, neuroinflammation, and cortical loss in an animal model of repeated concussion. J Neurotrauma, 29(2), 281-294. doi:10.1089/neu.2011.2123

Shultz, S. R., MacFabe, D. F., Foley, K. A., Taylor, R., \& Cain, D. P. (2011). A single mild fluid percussion injury induces short-term behavioral and neuropathological changes in the Long-Evans rat: support for an animal model of concussion. Behav Brain Res, 224(2), 326-335. doi:10.1016/j.bbr.2011.06.012

Shultz, S. R., MacFabe, D. F., Foley, K. A., Taylor, R., \& Cain, D. P. (2012b). Subconcussive brain injury in the Long-Evans rat induces acute neuroinflammation in the absence of behavioral impairments. Behav Brain Res, 229(1), 145-152. doi:10.1016/j.bbr.2011.12.015

Sick, T. J., Perez-Pinzon, M. A., \& Feng, Z. Z. (1998). Impaired expression of long-term potentiation in hippocampal slices 4 and $48 \mathrm{~h}$ following mild fluid-percussion brain injury in vivo. Brain Res, 785(2), 287-292.

Smith, D. H., Chen, X. H., Pierce, J. E., Wolf, J. A., Trojanowski, J. Q., Graham, D. I., \& McIntosh, T. K. (1997). Progressive atrophy and neuron death for one year following brain trauma in the rat. $J$ Neurotrauma, 14(10), 715-727. doi:10.1089/neu.1997.14.715

Sohal, V. S., Zhang, F., Yizhar, O., \& Deisseroth, K. (2009). Parvalbumin neurons and gamma rhythms enhance cortical circuit performance. Nature, 459(7247), 698-702. doi:10.1038/nature07991

Tan, X. L., Wright, D. K., Liu, S., Hovens, C., O'Brien, T. J., \& Shultz, S. R. (2016). Sodium selenate, a protein phosphatase $2 \mathrm{~A}$ activator, mitigates hyperphosphorylated tau and 
improves repeated mild traumatic brain injury outcomes. Neuropharmacology, 108, 382-393. doi:10.1016/j.neuropharm.2016.05.001

Toth, Z., Hollrigel, G. S., Gorcs, T., \& Soltesz, I. (1997). Instantaneous perturbation of dentate interneuronal networks by a pressure wave-transient delivered to the neocortex. J Neurosci, 17(21), 8106-8117.

Vezzani, A., \& Sperk, G. (2004). Overexpression of NPY and Y2 receptors in epileptic brain tissue: an endogenous neuroprotective mechanism in temporal lobe epilepsy? Neuropeptides, 38(4), 245-252. doi:10.1016/j.npep.2004.05.004

Witgen, B. M., Lifshitz, J., Smith, M. L., Schwarzbach, E., Liang, S. L., Grady, M. S., \& Cohen, A. S. (2005). Regional hippocampal alteration associated with cognitive deficit following experimental brain injury: a systems, network and cellular evaluation. Neuroscience, 133(1), 1-15. doi:10.1016/j.neuroscience.2005.01.052

Wright, D. K., Liu, S., van der Poel, C., McDonald, S. J., Brady, R. D., Taylor, L., . . Shultz, S. R. (2017). Traumatic Brain Injury Results in Cellular, Structural and Functional Changes Resembling Motor Neuron Disease. Cereb Cortex, 27(9), 4503-4515. doi:10.1093/cercor/bhw254

Xu, H., Jeong, H. Y., Tremblay, R., \& Rudy, B. (2013). Neocortical somatostatin-expressing GABAergic interneurons disinhibit the thalamorecipient layer 4. Neuron, 77(1), 155167. doi:10.1016/j.neuron.2012.11.004

Yan, E. B., Johnstone, V. P., Alwis, D. S., Morganti-Kossmann, M. C., \& Rajan, R. (2013). Characterising effects of impact velocity on brain and behaviour in a model of diffuse traumatic axonal injury. Neuroscience, 248, 17-29. doi:10.1016/j.neuroscience.2013.05.045

Zhang, B., Chen, X., Lin, Y., Tan, T., Yang, Z., Dayao, C., .. . Zhang, J. (2011). Impairment of synaptic plasticity in hippocampus is exacerbated by methylprednisolone in a rat model of traumatic brain injury. Brain Res, 1382, 165-172. doi:10.1016/j.brainres.2011.01.065

Zhang, W., Yamawaki, R., Wen, X., Uhl, J., Diaz, J., Prince, D. A., \& Buckmaster, P. S. (2009). Surviving hilar somatostatin interneurons enlarge, sprout axons, and form new synapses with granule cells in a mouse model of temporal lobe epilepsy. The Journal of neuroscience : the official journal of the Society for Neuroscience, 29(45), 1424714256. doi:10.1523/JNEUROSCI.3842-09.2009

Figure legends

Figure 1.Effects of Lateral Fluid Percussion Injury (LFPI) on behaviour and spatial cognition. (b-d) changes in behaviour from prior to treatment and up to 8 weeks post injury. (a,e,f) Behavioural changes post treatment. Dotted lines separate pre (-3 to -1) and post-surgery (day 1 to week 8) periods. (a)Whisker Nuisance task scores. Total scores of the whisker nuisance task components for sham and LFPI groups. (b)Rotarod. Grip strength and motor coordination as assessed using the rotarod. The "\% rotarod score" was calculated for each animal by expressing performance on a particular test day as a percentage of the maximum pre-trauma score for that same animal. Data shown are the average of all animals in sham and LFPI groups at that particular time point. (c\&d) Beam Walk. LFPI animals exhibited an increased number of slips and falls compared to shams (c) and scored worse than shams in the beam walk task even at 8 weeks (d). (e\&f) Elevated Plus Maze. 
Time spent in the open arm of the maze is reciprocally related to anxiety (e) and number of entries into the closed arm ( $f$ ). No significant differences were detected between the treatment groups for EPM.

Spatial cognition following LFPI using the water maze task, ( $g, h, i)$ Acquisition tasks. No significant differences were detected in search time (g), direct and circle swims (h) as well as swim speed (i) between treatment groups during the acquisition phase. (j,k,l) Reversal tasks. LFPI rats took significantly longer to locate the hidden platform in the water maze compared to shams for the first reversal trial (j) and had significantly lesser direct and circle swims than shams (k) during the reversal phase. (l) Swim speed during the reversal period were not significant between LFPI and sham animals

Figure 2. Effects of LFPI on cortical thickness. (a) Interhemispheric thickness of the somatosensory cortex (left set of bar graphs) and the motor cortex (right set of bar graphs) in LFPI and Sham animals. Each bar graph represents mean thickness $(\mu m \pm S D)$ in LFPI $(n=6)$ and Sham $(n=6)$ animals, with each animal providing 3 coronal sections from the appropriate cortex. No significant change was detected in thickness of cortical laminae in the somatosensory (b) and motor cortex (c) between treatment groups at 8 weeks after LFPI.

Figure 3. Effects of LFPI on immunoreactivity on PV, CR and SOM in somatosensory at 8 weeks post injury. Perpendicular sections through the (A-E) somatosensory cortex at 8 weeks, comparing immunoreactivity for (a)PV, (b)CB, (c)CR, (d)NPY and (e)SOM in LFPI and sham animals. In the top (a-c) and bottom (d-e) panels are somatosensory perpendicular sections from the ipsilateral and contralateral sides of LFPI animals in comparison with a sham for interneuronal immunoreactivity. Scale bar equals 700 $\mu m$ and applies to all photomicrographs.

Figure 4. Effects of LFPI on neuronal densities for immunoreactivity for calcium binding proteins and neuropeptides in somatosensory cortex. Each bar graphs represents ipsilateral (I) and contralateral (C) neuronal density (neurons $/ \mathrm{mm}^{2}$ ) (6-8 sections per animal) of LFPI animals $(n=10)$ as percentages of corresponding sham control values $(n=10)$ (dashed line $=100 \%$ ) for calcium binding proteins $(a-c)$ and neuropeptides (d\&e) for the respective cortical layer. Statistical significances: ${ }^{*} p<0.05,{ }^{* *} p<0.01$ as compared to sham controls, $\# p<0.05, \# \# p<0.01$, \#\#p<0.001 as compared to the contralateral side.

Figure 5. Interneuronal morphology in the somatosensory cortex a: PV stained multipolar neurons with long processes in the supragranular layers, red arrows indicate immunoreactive puncta outlining target cells. $b$ : Bipolar CB cells in infragranular layers with vertical orientation. c: CR positive cells in layer 1 of the somatosensory cortex. d: Bipolar vertically oriented NPY neurons in supragranular layers. e: SOM stained neurons in supragranular layers of the somatosensory cortex. Scale bar equals $100 \mu \mathrm{m}$ and applies to all photomicrographs.

Figure 6. Effects of LFPI on immunoreactivity for calcium-binding proteins and neuropeptides in motor cortex at 8 weeks. Perpendicular sections through the motor cortex, showing immunoreactivity for (a) Parvalbumin (PV), (b) Calbindin (CB), (c) Calretinin (CR), (d) Neuropeptide Y (NPY) and (e) Somatostatin (SOM) in LFPI and sham animals. No change in neuron numbers were observed for any of the stains at 8 weeks in the motor cortex. Scale bar equals $400 \mu \mathrm{m}$ and applies to all photomicrographs.

Figure 7. Effects of LFPI on neuronal densities for immunoreactivity for calcium binding proteins and neuropeptides in the motor cortex. Each bar graphs represents ipsilateral (I) and contralateral (C) neuronal density (neurons $/ \mathrm{mm}^{2}$ ) (6-8 sections per animal) of LFPI animals $(n=10)$ as percentages of corresponding sham 
control values $(n=10)$ (dashed line $=100 \%)$ for calcium binding proteins $(a-c)$ and neuropeptides (d\&e) for the respective cortical layer.

Figure 8. Interneuronal morphology in the motor cortex $a$ : $P V$ multipolar cells in the supragranular layers of the motor cortex. $b$ : Multipolar CB cells in infragranular layers with vertical orientation. $c$ : CR bipolar cells in the supragranular motor cortex. $d$ : spindle shaped NPY neurons in supragranular layers. e: rounded and spindle shaped SOM stained neurons in supragranular layers. Scale bar equals 100 $\mu$ m and applies to all photomicrographs.

Figure 9. Effects of LFPI on hippocampal interneurons 8 weeks post injury. Photomontage showing PV immunoreactivity in DG of a LFPI (a) and sham animal (b) at 8 weeks. Note strongly stained PV positive cells in sham (b) and patchy loss of cells and PV-IR fibres in LFPI animal (a) (indicated by black arrows). $c \& d$ show CB immunoreactivity in CA1 of a LFPI (a) and sham animal (b). Note strongly stained CB positive cells in sham (d) and complete loss of CB cells in LFPI animal (c) (indicated by black arrows). E\&F show NPY immunoreactivity in CA1 of a LFPI (e) and sham animal ( $f$ ) at 8 weeks. Note strongly stained NPY positive cells in the LFPI animals (e) (indicated by black arrows). SOM neurons were increased in the LFPI animals $(g)$ in CA2/3 when compared with shams (h). Scale bar equals $400 \mu \mathrm{m}$ in all photomicrographs.

Figure 10. Effects of LFPI on neuronal numbers for immunoreactivity for calcium binding proteins and neuropeptides in the dorsal hippocampus. Each bar graphs represents ipsilateral (I) and contralateral (C) average number of neurons per section (mean cells/section) (6-8 sections per animal) of LFPI animals $(n=10)$ as percentages of corresponding sham control values $(n=10)$ (dashed line $=100 \%$ ) for calcium binding proteins (a-c) and neuropeptides (d\&e) for the respective hippocampal sub-regions CA1, CA2/3 and DG. Statistical

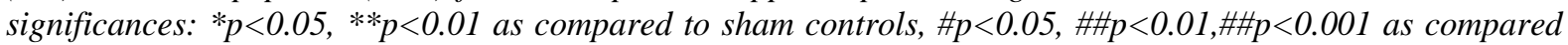
to the contralateral side

Figure 11. Interneuronal morphology in the dorsal hippocampus a: $P V$ multipolar cells and PV-IR puncta outlining target cells in CA1 as indicated by black arrows. $b$ : Bipolar CB cells in CA2/3 with vertical orientation. c: CR-IR puncta in the DG and CR fibres as indicated by black arrows. d\&e: Dense NPY neurons (d) and SOM stained neurons (e) in the hilar region of the DG as indicated by black arrows. Scale bar equals $100 \mu \mathrm{m}$ and applies to all photomicrographs.

Figure 12. Fluoro-Jade C positive cells observed bilaterally in the rat brain 8 weeks after LFPI

Fluoro jade $C$ stain allowed for histological detection of degenerating neurons in different brain areas following LFPI. Detection of FJC positive cells confirmed the extent of neurodegeneration in the cortex and hippocampus. Sections extending from $3.7 \mathrm{~mm}$ to $1.7 \mathrm{~mm}$ rostral to bregma were used for analysis in primary motor cortex and sections extending from $-2.30 \mathrm{~mm}$ to -4.16 caudal to bregma were used for analysis of somatosensory cortex and dorsal hippocampus. Stained sections were assessed for FJC positive cells, brain regions of positive staining were rated as low (yellow), moderate (orange) or high intensity (red) as depicted. Large number of FJC positive cells representing degenerating cells depicted in red in were observed in the ipsilateral somatosensory cortex of LFPI animals. Mild FJC immunoreactivity was observed in the CA1, CA2/3 and DG of LFPI animals depicted in yellow. Fewer FJC positive cells and moderate staining were also detected in the contralateral somatosensory cortex, corpus callosum (CC) (depicted in orange) and low intensity staining in DG (depicted in yellow) at 8 weeks after LFPI.

Figure 13. Fluoro-Jade C staining neurodegeneration in the somatosensory cortex and dorsal hippocampus Representative Photomicrographs of FJC staining 8 weeks post in jury in LFPI animals. No FJC positive cells were detected in sham animals in somatosensory cortex (a) and dorsal hippocampus (b). Note the absence of FJC staining and presence of only DAPI staining of healthy neurons in sham animals ( $a \& b)$. Note Fluoro Jade 
$C$ staining in the ipsilateral cortex and along the pial surface of LFPI animals (c). Large degenerating FJC positively stained neurons were detected in the somatosensory cortex (d), CA1 (e), CA2/3 ( $f$ ) ipsilateral $(g)$ and contralateral (h) DG of LFPI animals indicated by thick white arrows. Individual Scale bars apply to each photomicrograph. Scale bar equals $2 \mathrm{~mm}(a \& c), 900 \mu \mathrm{m}(b)$ and $100 \mu \mathrm{m}(\mathrm{d}-\mathrm{h})$ 
Table 4: Semiquantitative analysis of brain regions for fluoro-jade $C$ neuronal degeneration

$\underline{\text { Region }}$

$\underline{\text { LFPI Animals }}$

Motor cortex

Somatosensory Cortex

$+++$

Hippocampal CA1

Hippocampal CA2/3

Dentate Gyrus (DG)

$+$

$+$

$+$

A semi quantitative analysis of Fluoro Jade C staining in LFPI animals within select regions of interest (ROIs), including cortex and hippocampus to score positive FJC immunoreactivity, ranging from none $(-)$, to mild $(+)$, moderate $(++)$ and strong $(+++)$ staining at 8 weeks after LFPI. 
Table.1 Post injury measures for LFPI and Sham animals

\begin{tabular}{|c|c|c|c|c|}
\hline LFPI Animal \# & weight $(g)$ & apnea (sec) & $\begin{array}{l}\text { hind limb reflex } \\
\text { (sec) }\end{array}$ & self-righting (sec) \\
\hline 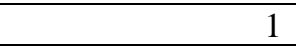 & 360 & 20 & 216 & 596 \\
\hline 2 & 345 & 26 & 185 & 604 \\
\hline 3 & 350 & 18 & 190 & 621 \\
\hline 4 & 335 & 25 & 209 & 694 \\
\hline 5 & 325 & 35 & 264 & 701 \\
\hline 6 & 365 & 25 & 211 & 587 \\
\hline 7 & 375 & 21 & 161 & 467 \\
\hline 8 & 350 & 17 & 180 & 750 \\
\hline 9 & 390 & 22 & 193 & 774 \\
\hline 10 & 350 & 20 & 275 & 719 \\
\hline Sham Animal \# & weight $(g)$ & apnea (sec) & $\begin{array}{l}\text { hind limb reflex } \\
\text { (sec) }\end{array}$ & self-righting (sec) \\
\hline (2) & 370 & 0 & 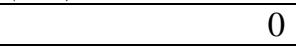 & 275 \\
\hline 2 & 350 & 0 & 0 & 301 \\
\hline 3 & 340 & 0 & 0 & 195 \\
\hline 4 & 370 & 0 & 0 & 300 \\
\hline 5 & 375 & 0 & 0 & 184 \\
\hline 6 & 335 & 0 & 0 & 149 \\
\hline 7 & 350 & 0 & 0 & 204 \\
\hline 8 & 345 & 0 & 0 & 256 \\
\hline 9 & 335 & 0 & 0 & 148 \\
\hline
\end{tabular}


Table.2 Laminar thickness in somatosensory and motor cortical layers

\begin{tabular}{|c|c|c|c|c|c|c|c|c|c|c|c|c|}
\hline \multicolumn{7}{|c|}{ Somatosensory Cortex } & \multicolumn{6}{|c|}{ Motor Cortex } \\
\hline & L1 & $\mathrm{L} 2 / 3$ & L4 & L5 & L6 & Total & L1 & $\mathrm{L} 2 / 3$ & L4 & L5 & L6 & Total \\
\hline $\begin{array}{l}\text { Sham } \\
\text { Ipsi- } \\
\text { lateral }\end{array}$ & $\begin{array}{l}124.5 \\
\mu \mathrm{m} \pm \\
18.98\end{array}$ & $\begin{array}{l}401.2 \\
1 \mu \mathrm{m} \\
\pm \\
57.72\end{array}$ & $\begin{array}{l}134.9 \\
8 \mu \mathrm{m} \\
\pm \\
22.76\end{array}$ & $\begin{array}{l}135.2 \\
5 \mu \mathrm{m} \\
\pm \\
24.02\end{array}$ & $\begin{array}{l}381.2 \\
2 \mu \mathrm{m} \\
\pm \\
49.18\end{array}$ & $\begin{array}{l}1177 . \\
18 \mu \mathrm{m} \\
\pm \\
144.8 \\
9\end{array}$ & $\begin{array}{l}151.8 \\
3 \mu \mathrm{m} \\
\pm \\
15.65\end{array}$ & $\begin{array}{l}408.8 \\
2 \mu \mathrm{m} \\
\pm \\
60.18\end{array}$ & $\begin{array}{l}148.5 \\
0 \mu \mathrm{m} \\
\pm \\
7.25\end{array}$ & $\begin{array}{l}146.6 \\
1 \mu \mathrm{m} \\
\pm \\
19.46\end{array}$ & $\begin{array}{l}577.6 \\
0 \mu \mathrm{m} \\
\pm \\
99.75\end{array}$ & $\begin{array}{l}1430.38 \\
\mu \mathrm{m} \pm \\
175.96\end{array}$ \\
\hline $\begin{array}{l}\text { Sham } \\
\text { Contra- } \\
\text { lateral }\end{array}$ & $\begin{array}{l}123.3 \\
2 \mu \mathrm{m} \\
\pm \\
10.7 \\
\end{array}$ & $\begin{array}{l}469.1 \\
9 \mu \mathrm{m} \\
\pm \\
35.15 \\
\end{array}$ & $\begin{array}{l}151.9 \\
6 \mu \mathrm{m} \\
\pm \\
22.11 \\
\end{array}$ & $\begin{array}{l}137.8 \\
3 \mu \mathrm{m} \\
\pm \\
16.63 \\
\end{array}$ & $\begin{array}{l}412.6 \\
4 \mu \mathrm{m} \\
\pm \\
38.25 \\
\end{array}$ & $\begin{array}{l}1292 . \\
96 \mu \mathrm{m} \\
\pm \\
76.40 \\
\end{array}$ & $\begin{array}{l}149.1 \\
1 \mu \mathrm{m} \\
\pm \\
14.38 \\
\end{array}$ & $\begin{array}{l}463.3 \\
1 \mu \mathrm{m} \\
\pm \\
32.89 \\
\end{array}$ & $\begin{array}{l}162.5 \\
8 \mu \mathrm{m} \\
\pm \\
17.01 \\
\end{array}$ & $\begin{array}{l}154.9 \\
8 \mu \mathrm{m} \\
\pm \\
20.92 \\
\end{array}$ & $\begin{array}{l}580.6 \\
9 \mu \mathrm{m} \\
\pm \\
82.96 \\
\end{array}$ & $\begin{array}{l}1510.68 \\
\mu \mathrm{m} \\
\pm 125.95\end{array}$ \\
\hline $\begin{array}{l}\text { LFPI } \\
\text { Ipsi- } \\
\text { lateral }\end{array}$ & $\begin{array}{l}101.0 \\
6 \mu \mathrm{m} \\
\pm \\
8.69\end{array}$ & $\begin{array}{l}420.8 \\
2 \mu \mathrm{m} \\
\pm \\
43.96\end{array}$ & $\begin{array}{l}115.2 \\
0 \mu \mathrm{m} \\
\pm \\
10.95\end{array}$ & $\begin{array}{l}113.4 \\
4 \mu \mathrm{m} \\
\pm \\
13.62\end{array}$ & $\begin{array}{l}362.1 \\
6 \mu \mathrm{m} \\
\pm \\
72.92\end{array}$ & $\begin{array}{l}1112 . \\
69 \mu \mathrm{m} \\
\pm \\
122.0 \\
5\end{array}$ & $\begin{array}{l}134.4 \\
7 \mu \mathrm{m} \\
\pm \\
13.87\end{array}$ & $\begin{array}{l}399.6 \\
3 \mu \mathrm{m} \\
\pm \\
41.35\end{array}$ & $\begin{array}{l}133.6 \\
0 \mu \mathrm{m} \\
\pm \\
9.64\end{array}$ & $\begin{array}{l}134.9 \\
5 \mu \mathrm{m} \\
\pm \\
12.68\end{array}$ & $\begin{array}{l}505.9 \\
1 \mu \mathrm{m} \\
\pm \\
88.18\end{array}$ & $\begin{array}{l}1308.58 \\
\mu \mathrm{m} \pm \\
142.03\end{array}$ \\
\hline $\begin{array}{l}\text { LFPI } \\
\text { Contra- } \\
\text { lateral }\end{array}$ & $\begin{array}{l}116.7 \\
7 \mu \mathrm{m} \\
\pm \\
14.0 \\
\end{array}$ & $\begin{array}{c}468.7 \\
3 \mu \mathrm{m} \\
\pm \\
58.88 \\
\end{array}$ & $\begin{array}{c}128.4 \\
9 \mu \mathrm{m} \\
\pm \\
9.34 \\
\end{array}$ & $\begin{array}{c}133.2 \\
8 \mu \mathrm{m} \\
\pm \\
5.67 \\
\end{array}$ & $\begin{array}{l}412.8 \\
1 \mu \mathrm{m} \\
\pm \\
38.16 \\
\end{array}$ & $\begin{array}{l}1260 . \\
10 \mu \mathrm{m} \\
\pm \\
84.04\end{array}$ & $\begin{array}{c}132.3 \\
4 \mu \mathrm{m} \\
\pm \\
10.83\end{array}$ & $\begin{array}{c}383.5 \\
2 \mu \mathrm{m} \\
\pm \\
59.47\end{array}$ & $\begin{array}{c}137.5 \\
7 \mu \mathrm{m} \\
\pm \\
20.70 \\
\end{array}$ & $\begin{array}{c}142.3 \\
3 \mu \mathrm{m} \\
\pm \\
22.10 \\
\end{array}$ & $\begin{array}{c}576.8 \\
0 \mu \mathrm{m} \\
\pm \\
52.49 \\
\end{array}$ & $\begin{array}{c}1372.59 \\
\mu \mathrm{m} \pm \\
128.41\end{array}$ \\
\hline
\end{tabular}

Interhemispheric thickness of the somatosensory cortex and the motor cortex in LFPI and Sham animals. No significant differences were detected in total or laminar thickness in somatosensory and motor cortices at 8 weeks after LFPI. Data represented as mean $(\mu \mathrm{m}) \pm$ S.D for cortical laminae and total cortical thickness. 


\begin{tabular}{|c|c|c|c|c|c|c|c|c|c|}
\hline \multicolumn{10}{|c|}{ e) Sqavatisstimbin } \\
\hline \multicolumn{4}{|c|}{ 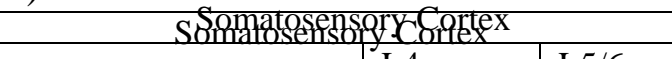 } & \multicolumn{3}{|c|}{ Moforter artertex } & \multicolumn{3}{|c|}{ H Hi } \\
\hline$L 2 / 3$ & $\mathrm{~L} 2 / 3$ & $\mathrm{~L}^{4}$ & $\mathrm{~L} 5 / 6^{16}$ & $2 / 2 / 3^{2 / 3}$ & \begin{tabular}{l|l|} 
L4 & Ł4 \\
\end{tabular} & $\mathrm{L} 5 / 6 / 6$ & GAA1 & CA2/3 & $\mathrm{DG}^{\mathrm{DG}}$ \\
\hline $\begin{array}{l}\text { Sham } \\
\text { Sham }\end{array}$ & $\begin{array}{l}38 \pm \\
14.38\end{array}$ & 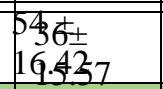 & $\begin{array}{l}4719 \pm 5.6 \\
8.73\end{array}$ & $\begin{array}{r}049.77 \pm \\
6.694 .94\end{array}$ & $\begin{array}{r}53 \pm 9.16 \pm \\
7.24 \\
\end{array}$ & $\begin{array}{l}48.75 \pm \\
8.384 .79\end{array}$ & $\begin{array}{c}3219.83 \\
6.02\end{array}$ & $\begin{array}{l}116 \pm+19 \\
2.36\end{array}$ & $\begin{array}{l}15 \pm \pm \\
2.24 .61 \\
\end{array}$ \\
\hline 邽Sillatefefal & $\begin{array}{l}23 \pm \\
7.97^{*}\end{array}$ & $\begin{array}{l}17 \pm \\
9.79^{* *, \# \#}\end{array}$ & $\begin{array}{l}12 \pm \\
9.79\end{array}$ & $\begin{array}{l}\beta \\
\begin{array}{l}\text { t9 } \\
19\end{array}\end{array}$ & $\begin{array}{l}.53 \pm 20 \pm \\
12.9312 .9\end{array}$ & $\begin{array}{r}44.76 \pm \\
19.064 .89 \\
\end{array}$ & $\begin{array}{l}29 \pm \\
7.83^{* *}, \ldots \#\end{array}$ & \begin{tabular}{l|l} 
& $13 \pm$ \\
$3.67^{*}$
\end{tabular} & \begin{tabular}{l|l} 
& $21 \pm$ \\
& $5.50^{\#}$
\end{tabular} \\
\hline $\begin{array}{l}\text { Ebhtfalatefer } \\
\text { al }\end{array}$ & $\begin{array}{l}29 \pm \\
8.66^{*}\end{array}$ & $\begin{array}{r}39 \pm \\
25.10 \mathrm{~B} \\
4.39 \\
\end{array}$ & $\begin{array}{l}28 \pm \\
8.91^{* *}\end{array}$ & \begin{tabular}{|l|}
$17 \pm$ \\
$48 \pm$ \\
7.67 \\
\end{tabular} & \begin{tabular}{r|r}
89 & $19 \pm$ \\
15 & 9.06 \\
14 & 89 \\
\end{tabular} & $\begin{array}{l}17 \pm \\
48.32 \\
8.10 \\
\end{array}$ & \begin{tabular}{l|}
$14 \pm$ \\
$2.8 \neq$ \\
10.39 \\
\end{tabular} & $\begin{array}{l}7 \pm 3.18 \\
14 \pm \\
3.55 \\
\end{array}$ & \begin{tabular}{|l}
$14 \pm$ \\
$14 . \pm 1$ \\
5.27 \\
\end{tabular} \\
\hline \multicolumn{10}{|c|}{ b) Calbindin } \\
\hline \multicolumn{4}{|c|}{ Somatosensory Cortex } & \multicolumn{3}{|c|}{ Motor Cortex } & \multicolumn{3}{|c|}{ Hippocampus } \\
\hline & $\mathrm{L} 2 / 3$ & L4 & $\mathrm{L} 5 / 6$ & $\mathrm{~L} 2 / 3$ & L4 & $\mathrm{L} 5 / 6$ & CA1 & CA2/3 & DG \\
\hline Sham & $\begin{array}{l}21 \pm \\
5.01\end{array}$ & $23 \pm 7.80$ & $\begin{array}{l}23 \pm \\
5.91\end{array}$ & $\begin{array}{l}18 \pm \\
9.30\end{array}$ & $\begin{array}{l}15 \pm \\
6.02\end{array}$ & $\begin{array}{l}17 \pm \\
5.49\end{array}$ & $13 \pm 4.34$ & $6 \pm 2.11$ & $\begin{array}{c}5 \pm \\
1.43\end{array}$ \\
\hline Ipsilateral & $\begin{array}{l}18 \pm \\
8.63\end{array}$ & $\begin{array}{c}18 \pm \\
16.68\end{array}$ & $\begin{array}{c}16 \pm \\
11.62^{\#}\end{array}$ & $\begin{array}{l}17 \pm \\
4.96\end{array}$ & $\begin{array}{c}13 \pm \\
11.45\end{array}$ & $\begin{array}{l}18 \pm \\
5.39\end{array}$ & $\begin{array}{l}12 \pm \\
2.20^{\#}\end{array}$ & $\begin{array}{c}7 \pm \\
1.23^{\#}\end{array}$ & $\begin{array}{c}6 \pm \\
1.53\end{array}$ \\
\hline $\begin{array}{c}\text { Contralater } \\
\text { al } \\
\end{array}$ & \begin{tabular}{|l|}
$23 \pm$ \\
5.39 \\
\end{tabular} & $24 \pm 4.80$ & $\begin{array}{l}25 \pm \\
6.16 \\
\end{array}$ & $\begin{array}{l}18 \pm \\
6.40 \\
\end{array}$ & $\begin{array}{l}16 \pm \\
4.29 \\
\end{array}$ & $\begin{array}{l}18 \pm \\
3.40 \\
\end{array}$ & $9 \pm 3.39^{*}$ & $5 \pm 1.89$ & $\begin{array}{c}5 \pm \\
1.84 \\
\end{array}$ \\
\hline \multicolumn{10}{|c|}{ c) Calretinin } \\
\hline \multicolumn{4}{|c|}{ Somatosensory Cortex } & \multicolumn{3}{|c|}{ Motor Cortex } & \multicolumn{3}{|c|}{ Hippocampus } \\
\hline & $\mathrm{L} 2 / 3$ & L4 & $\mathrm{L} 5 / 6$ & $\mathrm{~L} 2 / 3$ & L4 & L5/6 & CA1 & CA2/3 & DG \\
\hline Sham & $24 \pm 3.71$ & $\begin{array}{l}24 \pm \\
8.40\end{array}$ & $\begin{array}{l}16 \pm \\
3.24\end{array}$ & $\begin{array}{l}33 \pm \\
4.47\end{array}$ & $\begin{array}{l}30 \pm \\
7.49\end{array}$ & $\begin{array}{l}24 \pm \\
4.65\end{array}$ & $20 \pm 5.06$ & $\begin{array}{l}10 \pm \\
2.41\end{array}$ & $\begin{array}{l}18 \pm \\
3.62\end{array}$ \\
\hline Ipsilateral & $\begin{array}{c}17 \pm \\
6.34^{*}, \#\end{array}$ & $\begin{array}{l}19 \pm \\
9.86\end{array}$ & $\begin{array}{l}14 \pm \\
3.85\end{array}$ & $\begin{array}{l}33 \pm \\
6.53\end{array}$ & $\begin{array}{l}33 \pm \\
5.98\end{array}$ & $\begin{array}{l}25 \pm \\
4.36\end{array}$ & $20 \pm 3.57$ & $\begin{array}{c}11 \pm \\
1.48^{\#}\end{array}$ & $\begin{array}{c}19 \pm \\
1.88^{\# \#}\end{array}$ \\
\hline $\begin{array}{l}\text { Contralater } \\
\text { al }\end{array}$ & $24 \pm 5.61$ & $\begin{array}{l}25 \pm \\
8.44 \\
\end{array}$ & $\begin{array}{l}17 \pm \\
4.07 \\
\end{array}$ & $\begin{array}{l}34 \pm \\
2.75 \\
\end{array}$ & $\begin{array}{l}30 \pm \\
7.22\end{array}$ & $\begin{array}{l}24 \pm \\
4.64 \\
\end{array}$ & $18 \pm 3.92$ & $9 \pm 1.67$ & $\begin{array}{l}16 \pm \\
2.19 \\
\end{array}$ \\
\hline \multicolumn{10}{|c|}{ d) Neuropeptide Y } \\
\hline \multicolumn{4}{|c|}{ Somatosensory Cortex } & \multicolumn{3}{|c|}{ Motor Cortex } & \multicolumn{3}{|c|}{ Hippocampus } \\
\hline & $\mathrm{L} 2 / 3$ & L4 & $\mathrm{L} 5 / 6$ & $\mathrm{~L} 2 / 3$ & L4 & $\mathrm{L} 5 / 6$ & CA1 & CA2/3 & DG \\
\hline Sham & $24 \pm 3.42$ & $\begin{array}{l}16 \pm \\
3.57\end{array}$ & $\begin{array}{l}22 \pm \\
4.42\end{array}$ & $\begin{array}{l}16 \pm \\
6.69\end{array}$ & $\begin{array}{l}10 \pm \\
3.78\end{array}$ & $\begin{array}{l}17 \pm \\
6.76\end{array}$ & $20 \pm 5.18$ & $\begin{array}{l}9 \pm \\
3.32\end{array}$ & $\begin{array}{l}16 \pm \\
4.89\end{array}$ \\
\hline Ipsilateral & $\begin{array}{l}22 \pm \\
15.07\end{array}$ & $\begin{array}{l}19 \pm \\
14.73 \\
\end{array}$ & $\begin{array}{l}19 \pm \\
10.26 \\
\end{array}$ & $\begin{array}{l}12 \pm \\
9.10\end{array}$ & $\begin{array}{l}16 \pm \\
14.23 \\
\end{array}$ & $\begin{array}{l}11 \pm \\
6.57\end{array}$ & $26 \pm 6.67^{*}, \#$ & $\begin{array}{l}12 \pm \\
4.14^{\#}\end{array}$ & $\begin{array}{l}19 \pm \\
5.09\end{array}$ \\
\hline $\begin{array}{l}\text { Contralater } \\
\text { al }\end{array}$ & $27 \pm 5.65$ & $\begin{array}{l}16 \pm \\
5.57 \\
\end{array}$ & $\begin{array}{l}24 \pm \\
4.75 \\
\end{array}$ & $\begin{array}{l}18 \pm \\
6.19 \\
\end{array}$ & $\begin{array}{l}12 \pm \\
7.93 \\
\end{array}$ & $\begin{array}{l}13 \pm \\
4.84 \\
\end{array}$ & $18 \pm 6.91$ & $\begin{array}{l}7 \pm \\
3.37 \\
\end{array}$ & $\begin{array}{l}14 \pm \\
6.32 \\
\end{array}$ \\
\hline
\end{tabular}

\section{Table.3: Interneuronal numbers in LFPI and sham animals in 3 brain regions}

In table 3 highlighted boxes indicate significant data. Data shown as mean \pm standard deviation. Statistical significance: ${ }^{*} p<0.05,{ }^{* *} p<0.01,{ }^{* * *} p<0.001$ as compared to sham controls (Mann-Whitney U-test); $\# p<0.05$, 
$\# \# p<0.01$, \#\#\#p<0.001 as compared to the contralateral side (Mann-Whitney U-test) \#\#\#p<0.001 as compared to the contralateral side (Mann-Whitney U-test)

This article is protected by copyright. All rights reserved. 

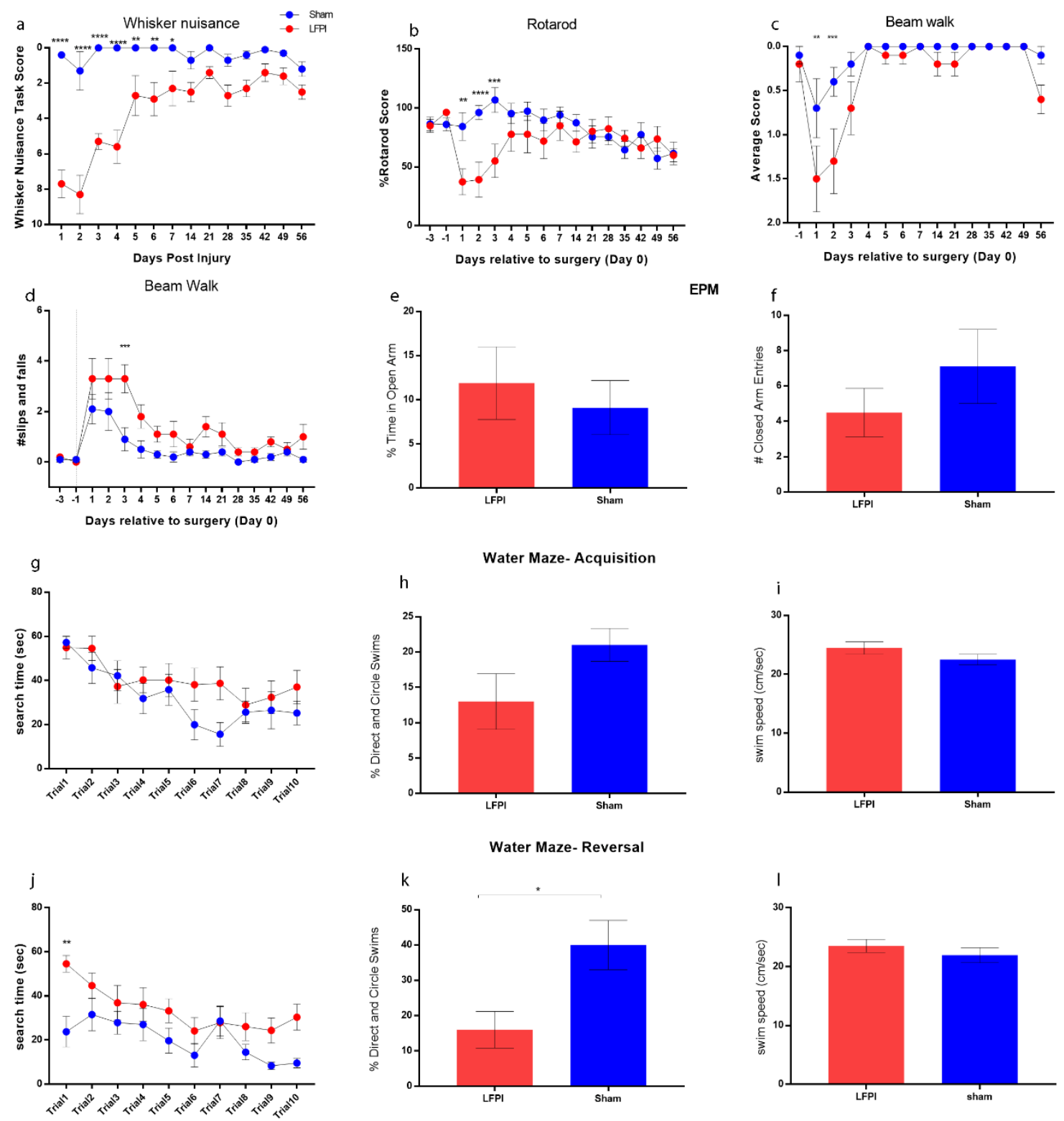

This article is protected by copyright. All rights reserved. 

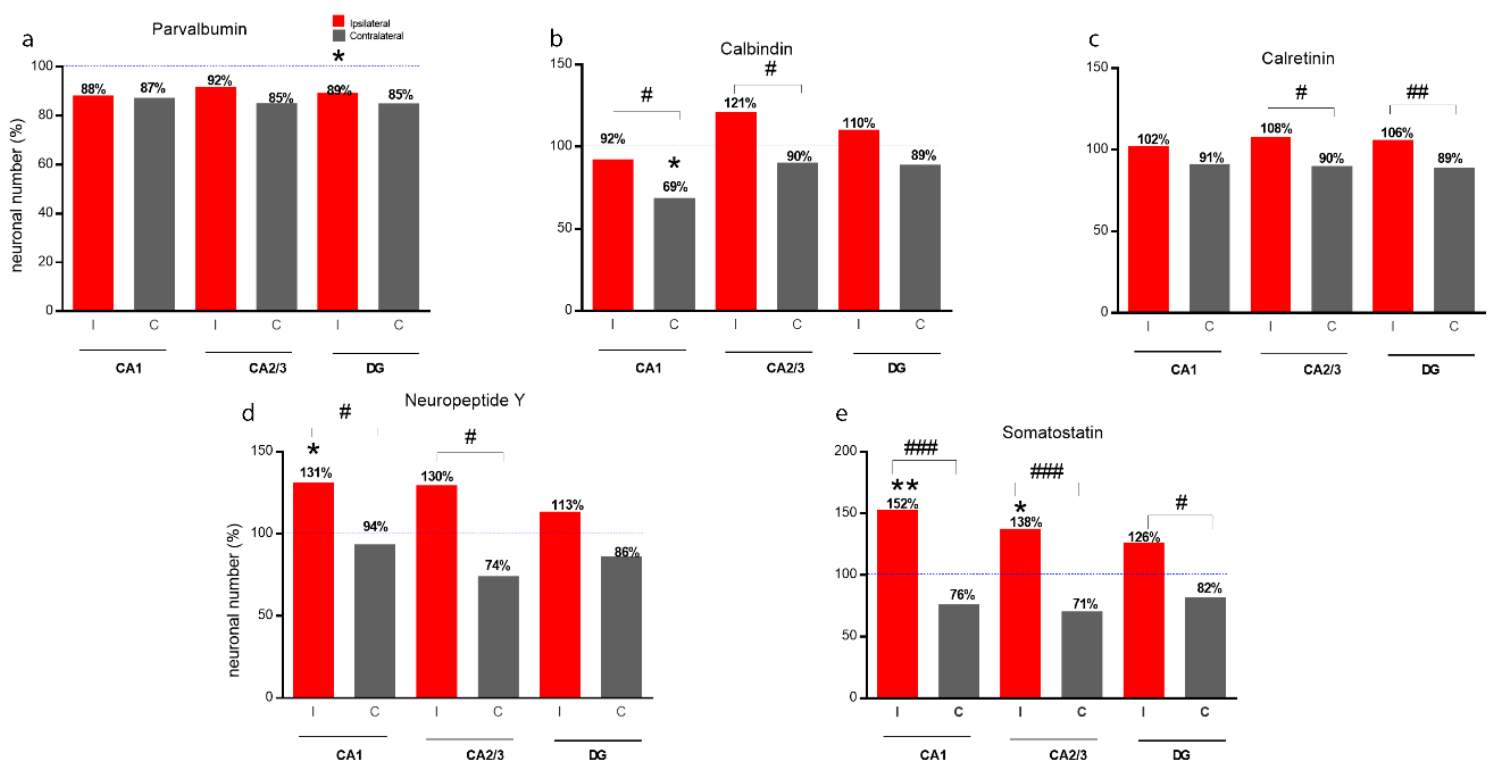

This article is protected by copyright. All rights reserved. 


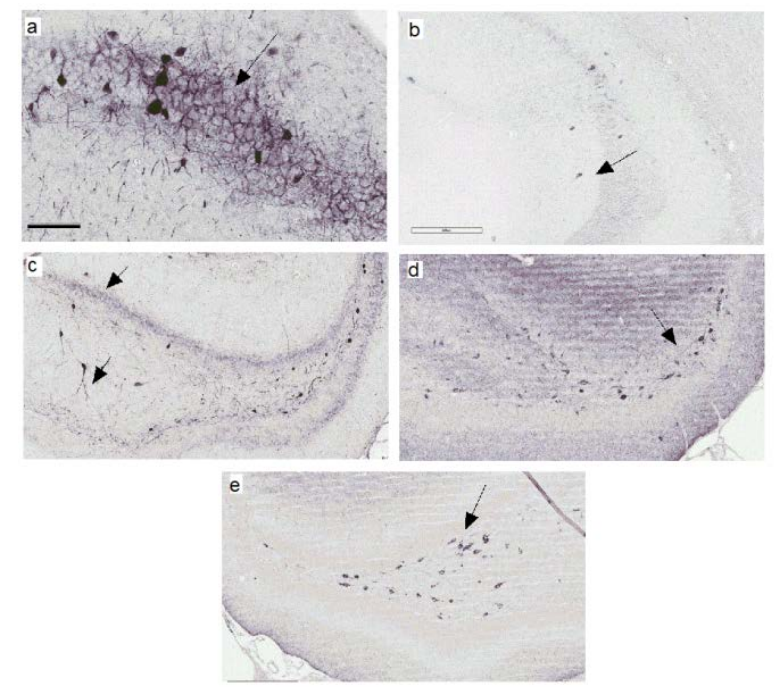

This article is protected by copyright. All rights reserved. 


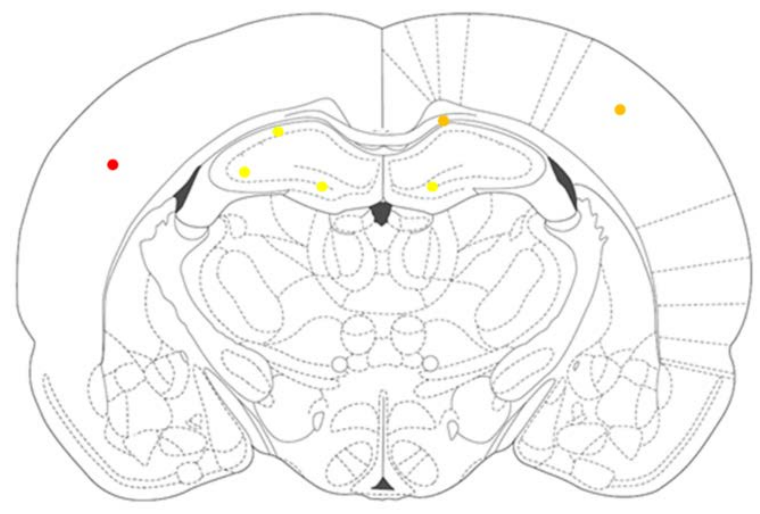

This article is protected by copyright. All rights reserved. 

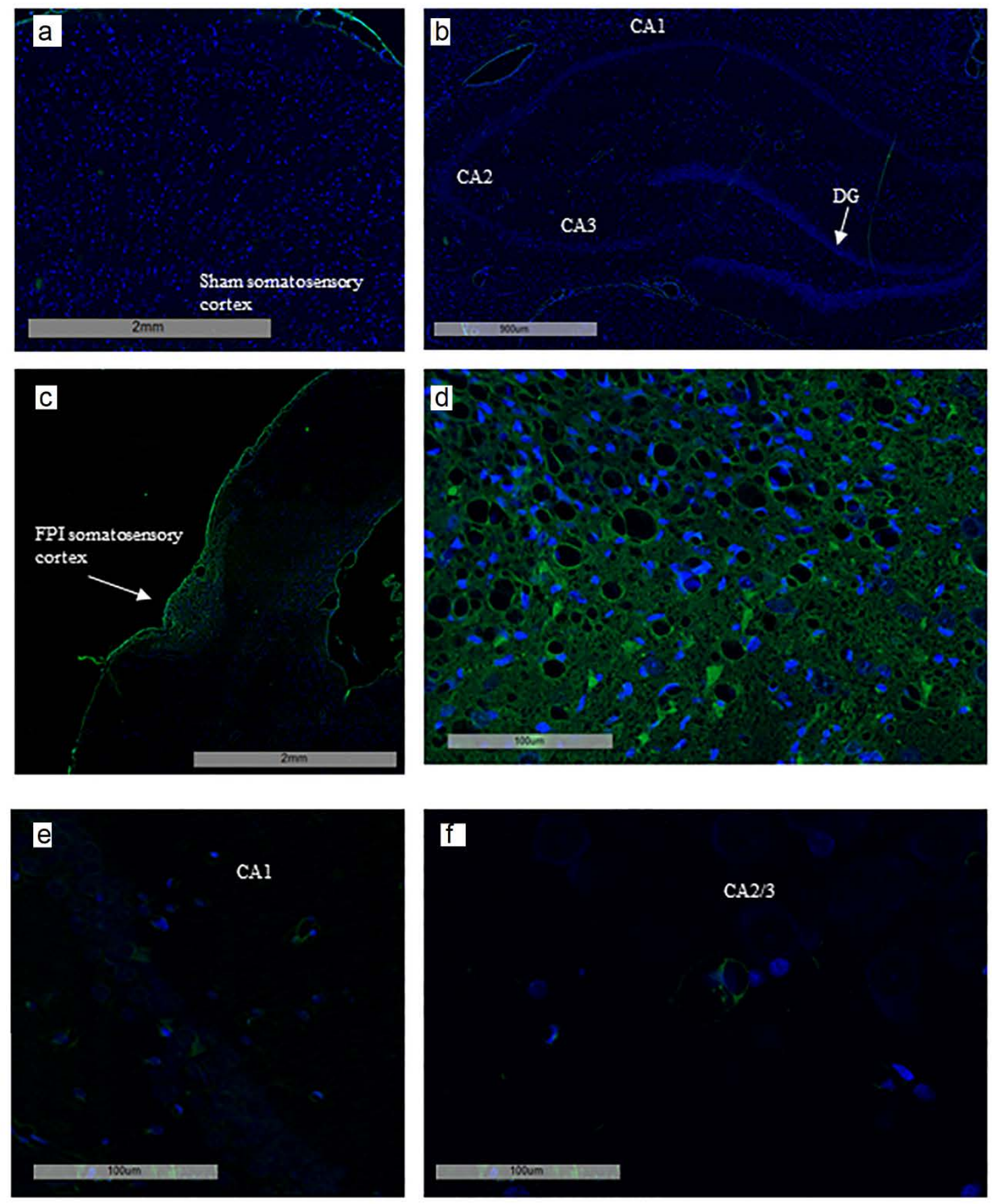

f
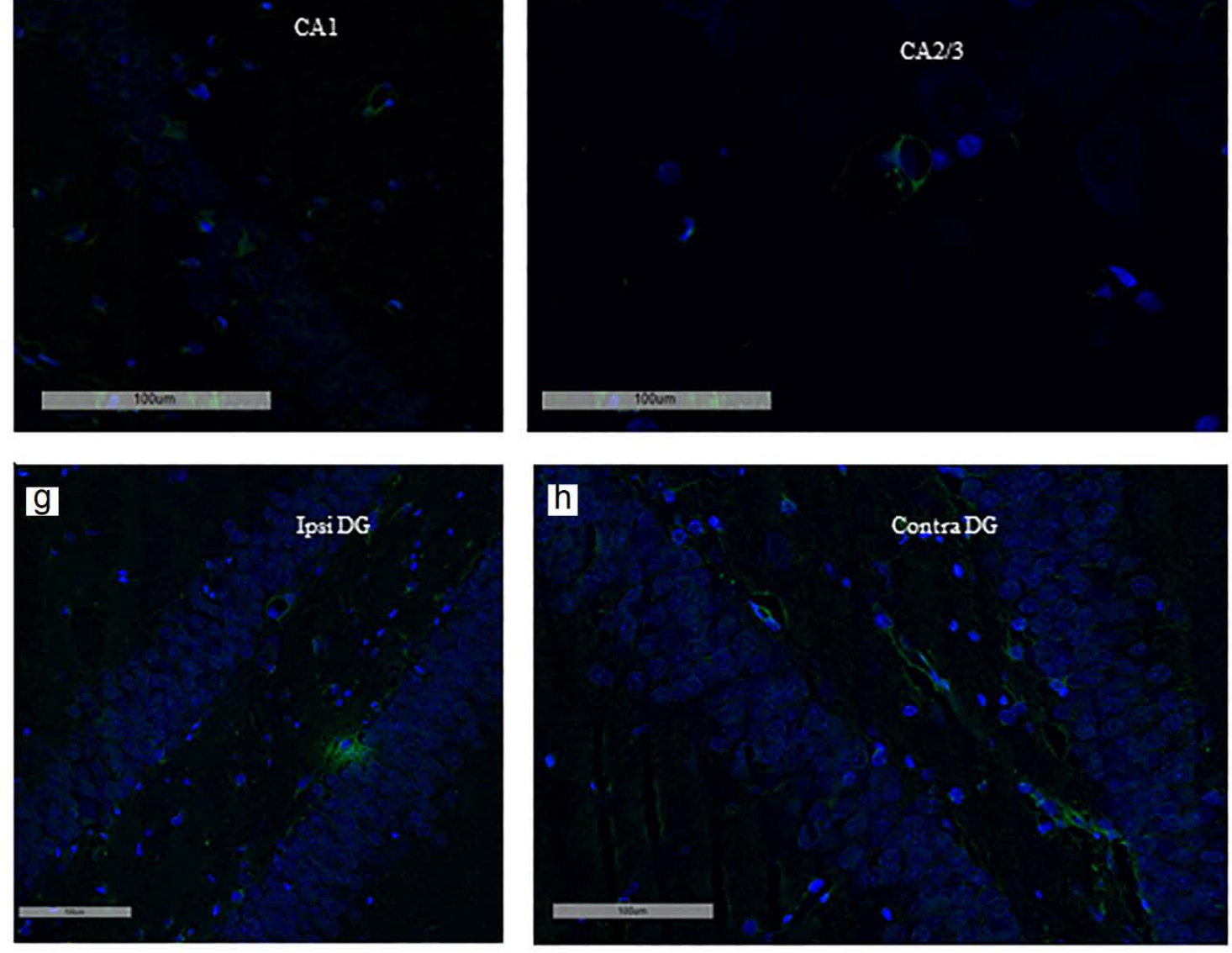

This article is protected by copyright. All rights reserved. 


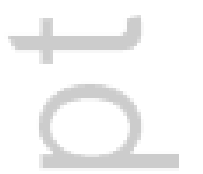

4 

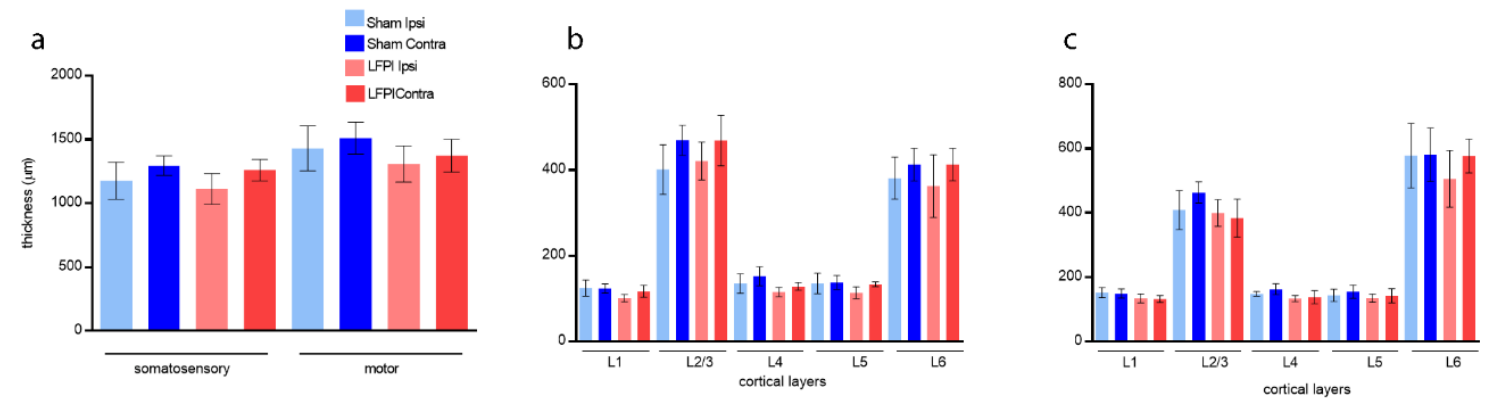

This article is protected by copyright. All rights reserved. 

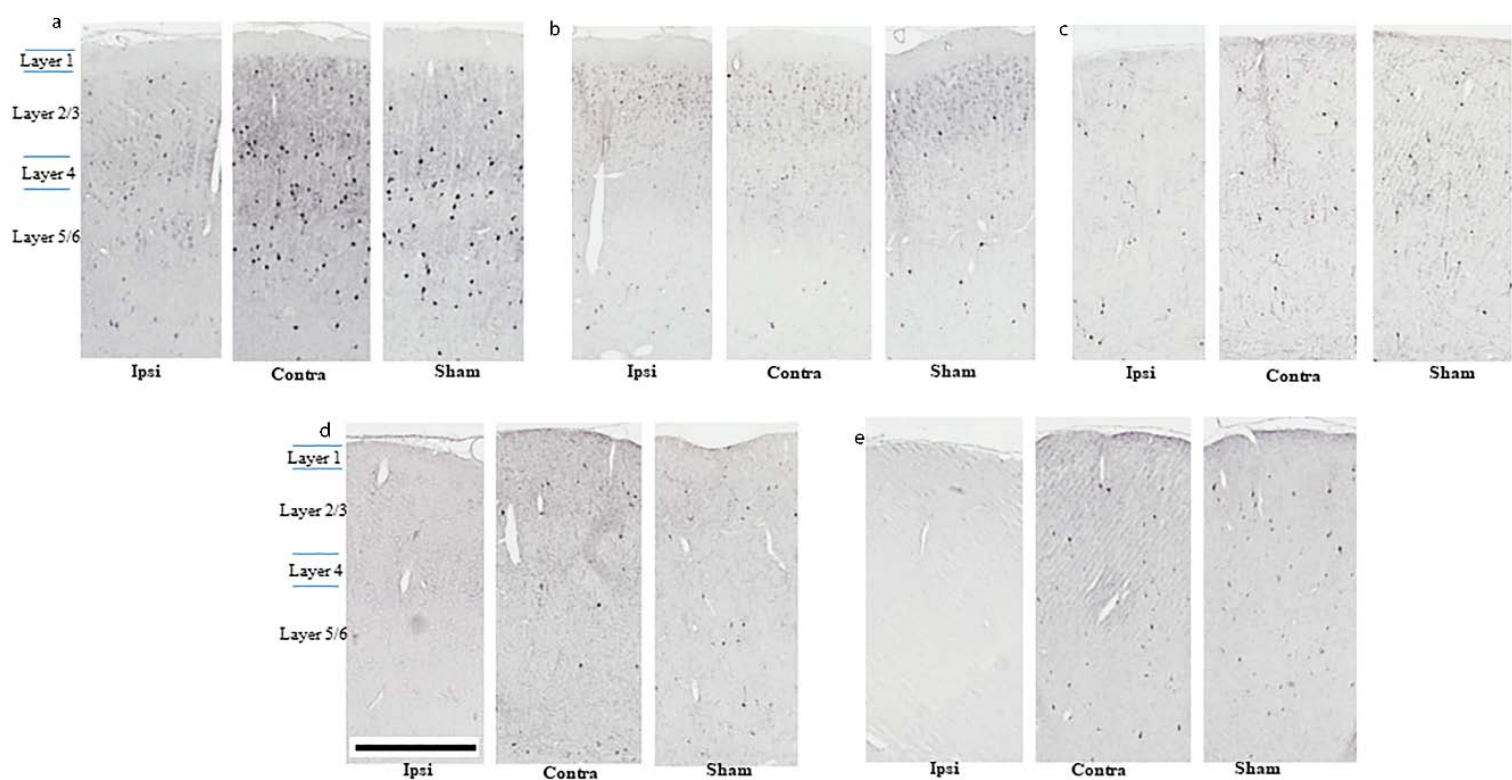

This article is protected by copyright. All rights reserved. 

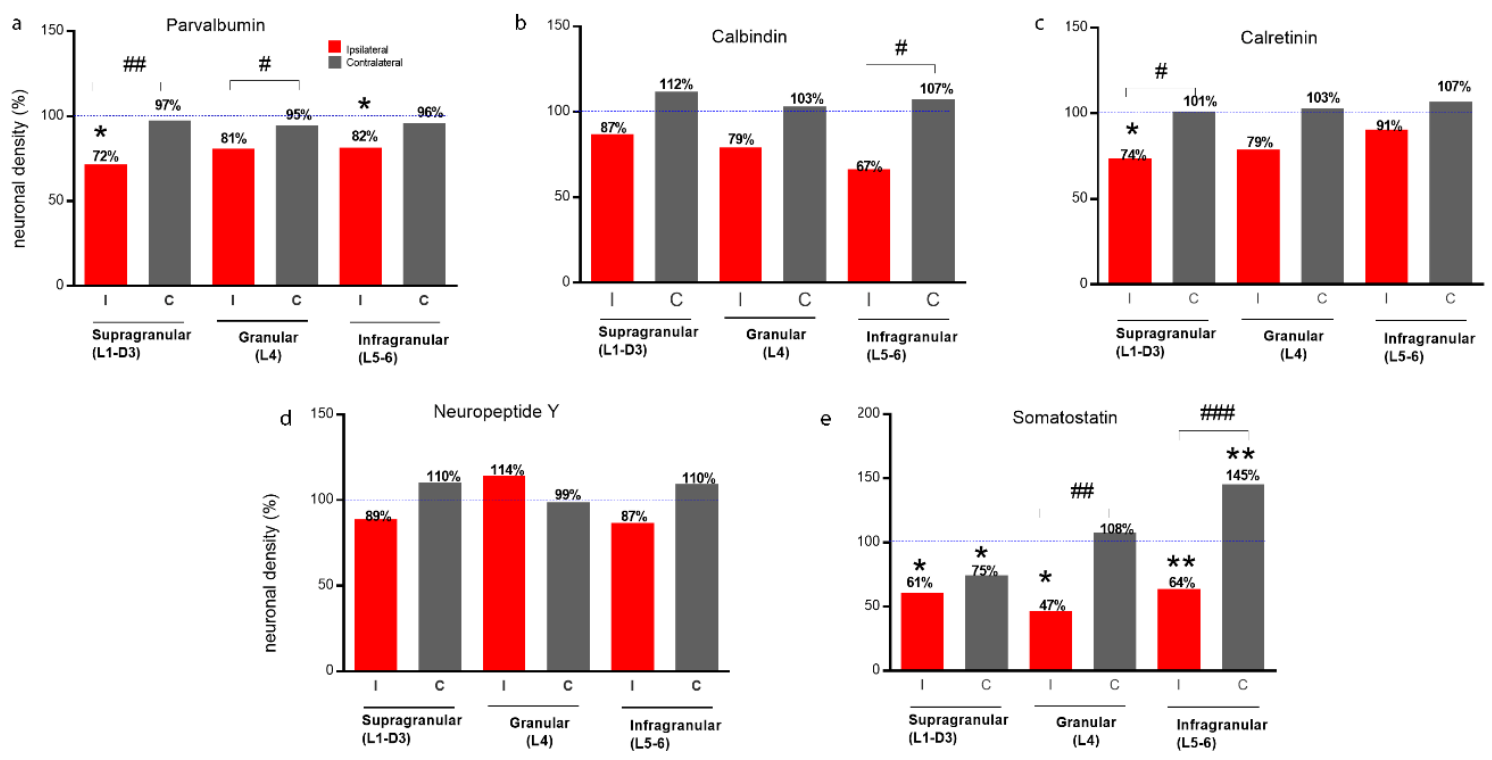

This article is protected by copyright. All rights reserved. 


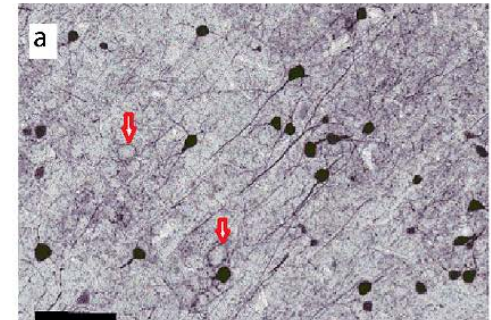

d

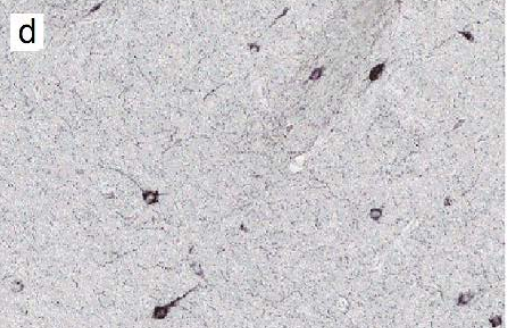

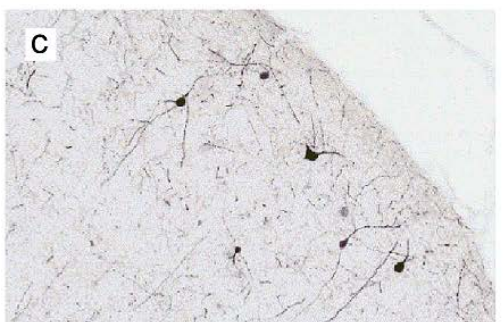

e.
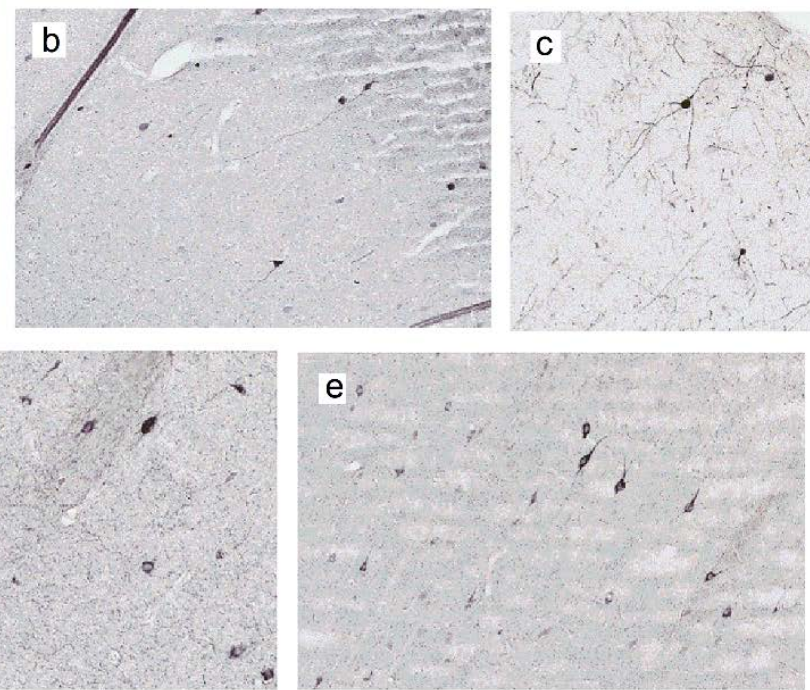

$\infty$

난 

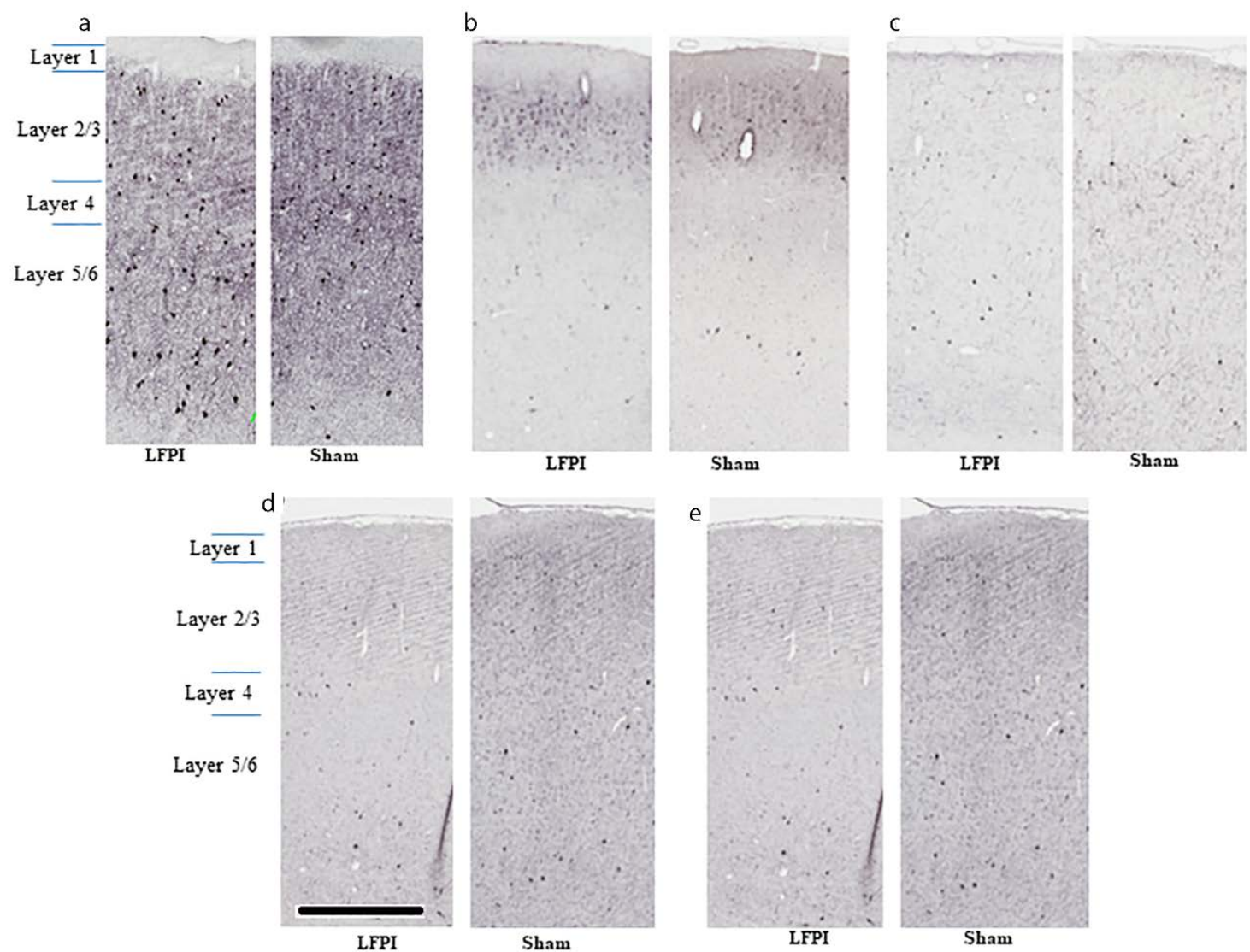

Sham 

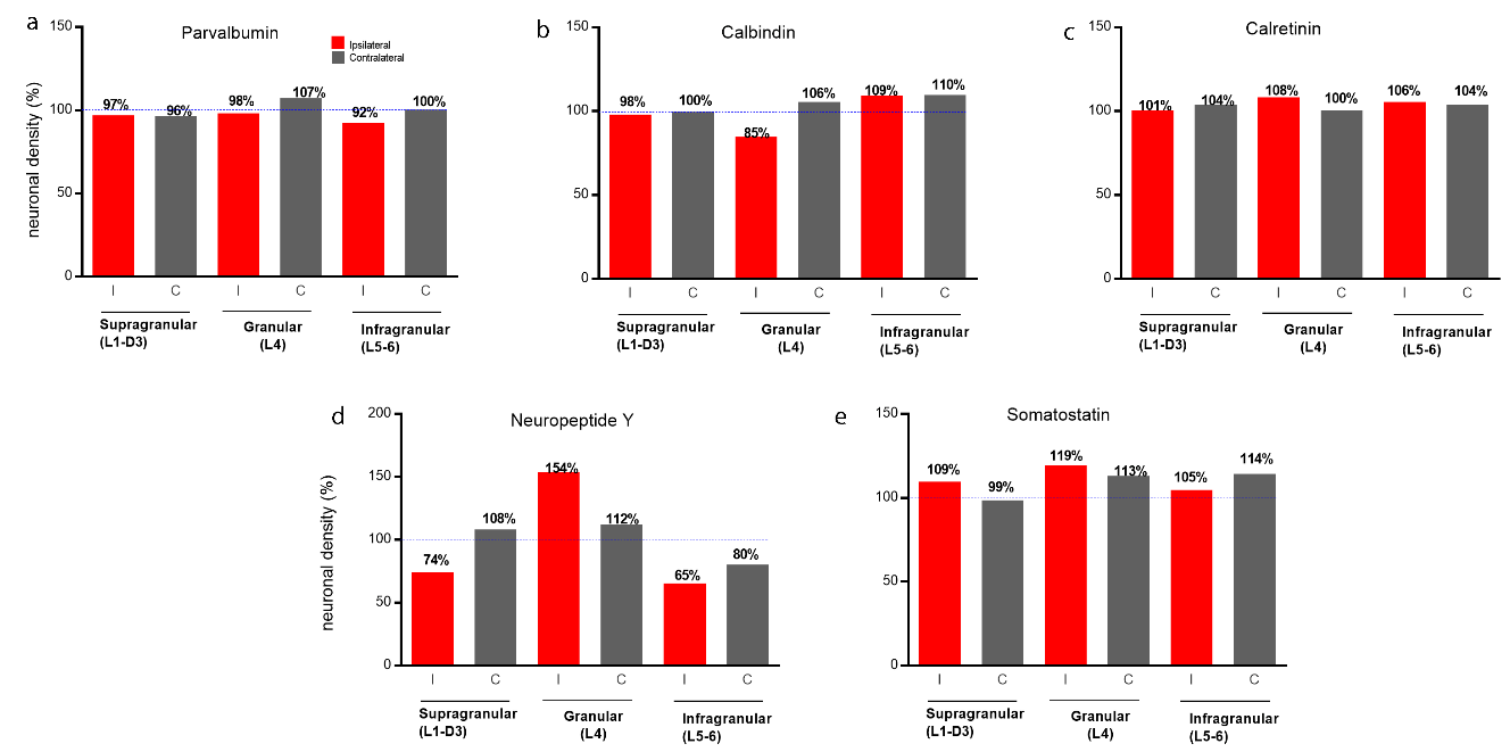

This article is protected by copyright. All rights reserved. 


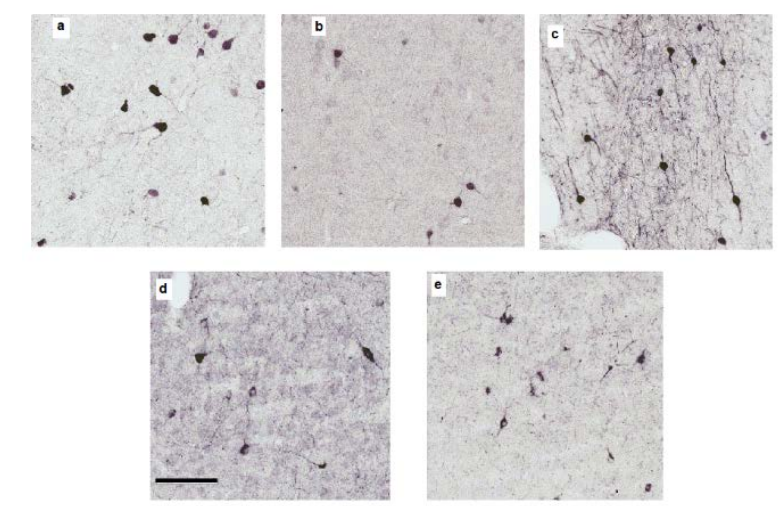

This article is protected by copyright. All rights reserved. 

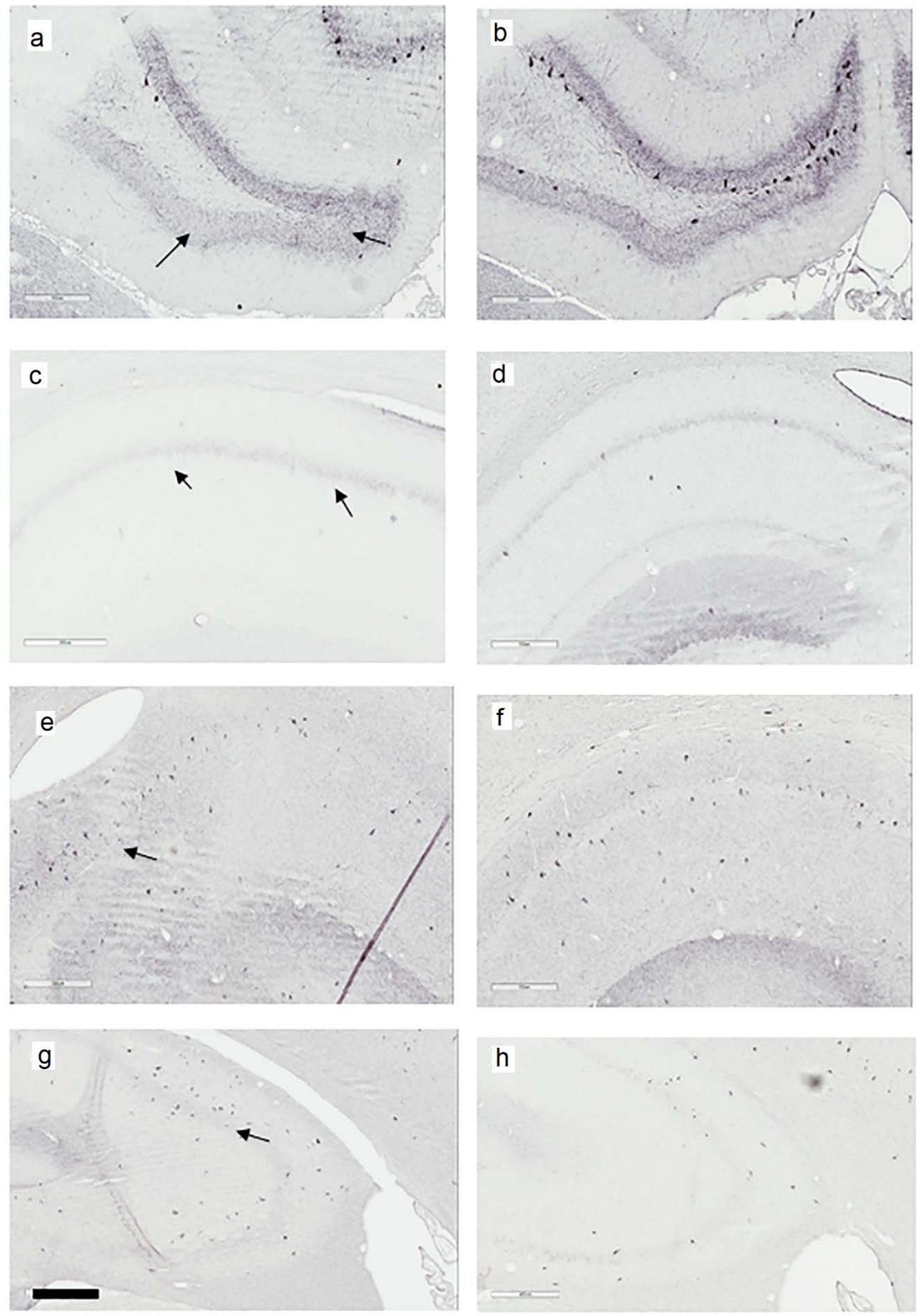

This article is protected by copyright. All rights reserved. 


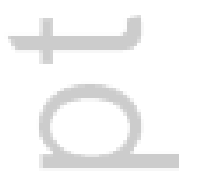

4 


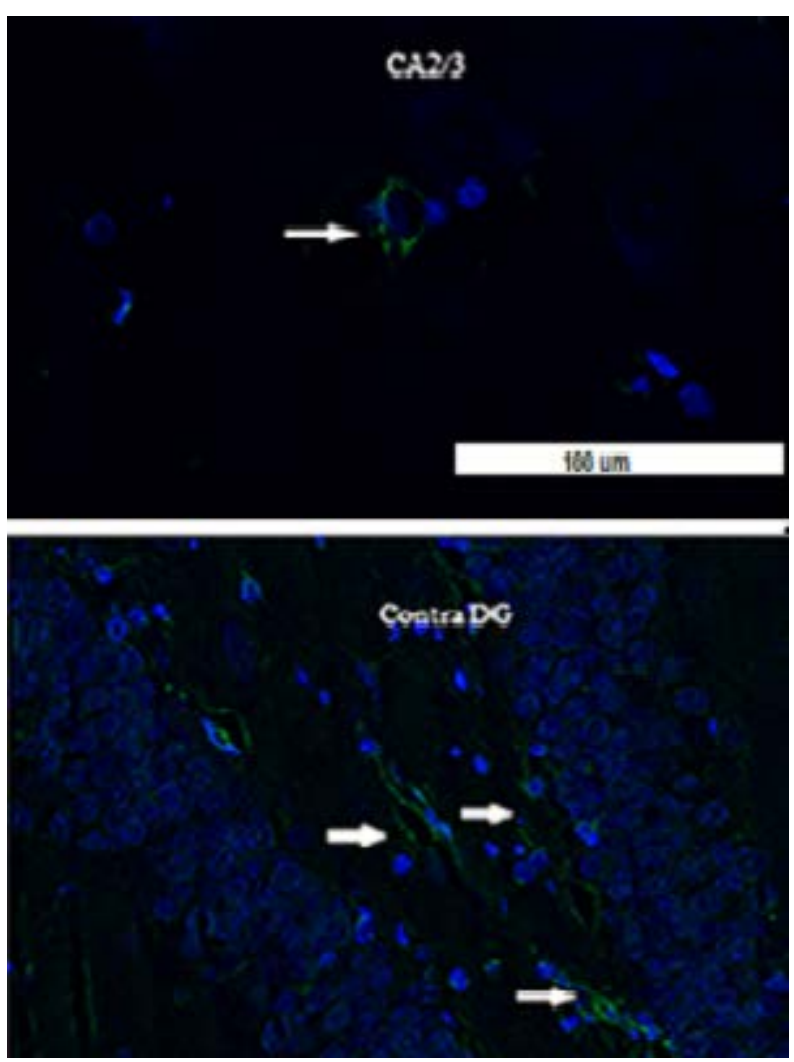

This article is protected by copyright. All rights reserved. 
Table.1 Post injury measures for LFPI and Sham animals

\begin{tabular}{|c|c|c|c|c|}
\hline LFPI Animal \# & weight $(g)$ & apnea (sec) & $\begin{array}{l}\text { hind limb reflex } \\
\text { (sec) }\end{array}$ & self-righting (sec) \\
\hline 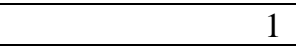 & 360 & 20 & 216 & 596 \\
\hline 2 & 345 & 26 & 185 & 604 \\
\hline 3 & 350 & 18 & 190 & 621 \\
\hline 4 & 335 & 25 & 209 & 694 \\
\hline 5 & 325 & 35 & 264 & 701 \\
\hline 6 & 365 & 25 & 211 & 587 \\
\hline 7 & 375 & 21 & 161 & 467 \\
\hline 8 & 350 & 17 & 180 & 750 \\
\hline 9 & 390 & 22 & 193 & 774 \\
\hline 10 & 350 & 20 & 275 & 719 \\
\hline Sham Animal \# & weight $(g)$ & apnea (sec) & $\begin{array}{l}\text { hind limb reflex } \\
\text { (sec) }\end{array}$ & self-righting (sec) \\
\hline (2) & 370 & 0 & 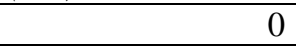 & 275 \\
\hline 2 & 350 & 0 & 0 & 301 \\
\hline 3 & 340 & 0 & 0 & 195 \\
\hline 4 & 370 & 0 & 0 & 300 \\
\hline 5 & 375 & 0 & 0 & 184 \\
\hline 6 & 335 & 0 & 0 & 149 \\
\hline 7 & 350 & 0 & 0 & 204 \\
\hline 8 & 345 & 0 & 0 & 256 \\
\hline 9 & 335 & 0 & 0 & 148 \\
\hline
\end{tabular}


Table.2 Laminar thickness in somatosensory and motor cortical layers

\begin{tabular}{|c|c|c|c|c|c|c|c|c|c|c|c|c|}
\hline \multicolumn{7}{|c|}{ Somatosensory Cortex } & \multicolumn{6}{|c|}{ Motor Cortex } \\
\hline & L1 & $\mathrm{L} 2 / 3$ & L4 & L5 & L6 & Total & L1 & $\mathrm{L} 2 / 3$ & L4 & L5 & L6 & Total \\
\hline $\begin{array}{l}\text { Sham } \\
\text { Ipsi- } \\
\text { lateral }\end{array}$ & $\begin{array}{l}124.5 \\
\mu \mathrm{m} \pm \\
18.98\end{array}$ & $\begin{array}{l}401.2 \\
1 \mu \mathrm{m} \\
\pm \\
57.72\end{array}$ & $\begin{array}{l}134.9 \\
8 \mu \mathrm{m} \\
\pm \\
22.76\end{array}$ & $\begin{array}{l}135.2 \\
5 \mu \mathrm{m} \\
\pm \\
24.02\end{array}$ & $\begin{array}{l}381.2 \\
2 \mu \mathrm{m} \\
\pm \\
49.18\end{array}$ & $\begin{array}{l}1177 . \\
18 \mu \mathrm{m} \\
\pm \\
144.8 \\
9\end{array}$ & $\begin{array}{l}151.8 \\
3 \mu \mathrm{m} \\
\pm \\
15.65\end{array}$ & $\begin{array}{l}408.8 \\
2 \mu \mathrm{m} \\
\pm \\
60.18\end{array}$ & $\begin{array}{l}148.5 \\
0 \mu \mathrm{m} \\
\pm \\
7.25\end{array}$ & $\begin{array}{l}146.6 \\
1 \mu \mathrm{m} \\
\pm \\
19.46\end{array}$ & $\begin{array}{l}577.6 \\
0 \mu \mathrm{m} \\
\pm \\
99.75\end{array}$ & $\begin{array}{l}1430.38 \\
\mu \mathrm{m} \pm \\
175.96\end{array}$ \\
\hline $\begin{array}{l}\text { Sham } \\
\text { Contra- } \\
\text { lateral }\end{array}$ & $\begin{array}{l}123.3 \\
2 \mu \mathrm{m} \\
\pm \\
10.7 \\
\end{array}$ & $\begin{array}{l}469.1 \\
9 \mu \mathrm{m} \\
\pm \\
35.15 \\
\end{array}$ & $\begin{array}{l}151.9 \\
6 \mu \mathrm{m} \\
\pm \\
22.11 \\
\end{array}$ & $\begin{array}{l}137.8 \\
3 \mu \mathrm{m} \\
\pm \\
16.63 \\
\end{array}$ & $\begin{array}{l}412.6 \\
4 \mu \mathrm{m} \\
\pm \\
38.25 \\
\end{array}$ & $\begin{array}{l}1292 . \\
96 \mu \mathrm{m} \\
\pm \\
76.40 \\
\end{array}$ & $\begin{array}{l}149.1 \\
1 \mu \mathrm{m} \\
\pm \\
14.38 \\
\end{array}$ & $\begin{array}{l}463.3 \\
1 \mu \mathrm{m} \\
\pm \\
32.89 \\
\end{array}$ & $\begin{array}{l}162.5 \\
8 \mu \mathrm{m} \\
\pm \\
17.01 \\
\end{array}$ & $\begin{array}{l}154.9 \\
8 \mu \mathrm{m} \\
\pm \\
20.92 \\
\end{array}$ & $\begin{array}{l}580.6 \\
9 \mu \mathrm{m} \\
\pm \\
82.96 \\
\end{array}$ & $\begin{array}{l}1510.68 \\
\mu \mathrm{m} \\
\pm 125.95\end{array}$ \\
\hline $\begin{array}{l}\text { LFPI } \\
\text { Ipsi- } \\
\text { lateral }\end{array}$ & $\begin{array}{l}101.0 \\
6 \mu \mathrm{m} \\
\pm \\
8.69\end{array}$ & $\begin{array}{l}420.8 \\
2 \mu \mathrm{m} \\
\pm \\
43.96\end{array}$ & $\begin{array}{l}115.2 \\
0 \mu \mathrm{m} \\
\pm \\
10.95\end{array}$ & $\begin{array}{l}113.4 \\
4 \mu \mathrm{m} \\
\pm \\
13.62\end{array}$ & $\begin{array}{l}362.1 \\
6 \mu \mathrm{m} \\
\pm \\
72.92\end{array}$ & $\begin{array}{l}1112 . \\
69 \mu \mathrm{m} \\
\pm \\
122.0 \\
5\end{array}$ & $\begin{array}{l}134.4 \\
7 \mu \mathrm{m} \\
\pm \\
13.87\end{array}$ & $\begin{array}{l}399.6 \\
3 \mu \mathrm{m} \\
\pm \\
41.35\end{array}$ & $\begin{array}{l}133.6 \\
0 \mu \mathrm{m} \\
\pm \\
9.64\end{array}$ & $\begin{array}{l}134.9 \\
5 \mu \mathrm{m} \\
\pm \\
12.68\end{array}$ & $\begin{array}{l}505.9 \\
1 \mu \mathrm{m} \\
\pm \\
88.18\end{array}$ & $\begin{array}{l}1308.58 \\
\mu \mathrm{m} \pm \\
142.03\end{array}$ \\
\hline $\begin{array}{l}\text { LFPI } \\
\text { Contra- } \\
\text { lateral }\end{array}$ & $\begin{array}{l}116.7 \\
7 \mu \mathrm{m} \\
\pm \\
14.0 \\
\end{array}$ & $\begin{array}{c}468.7 \\
3 \mu \mathrm{m} \\
\pm \\
58.88 \\
\end{array}$ & $\begin{array}{c}128.4 \\
9 \mu \mathrm{m} \\
\pm \\
9.34 \\
\end{array}$ & $\begin{array}{c}133.2 \\
8 \mu \mathrm{m} \\
\pm \\
5.67 \\
\end{array}$ & $\begin{array}{l}412.8 \\
1 \mu \mathrm{m} \\
\pm \\
38.16 \\
\end{array}$ & $\begin{array}{l}1260 . \\
10 \mu \mathrm{m} \\
\pm \\
84.04\end{array}$ & $\begin{array}{c}132.3 \\
4 \mu \mathrm{m} \\
\pm \\
10.83\end{array}$ & $\begin{array}{c}383.5 \\
2 \mu \mathrm{m} \\
\pm \\
59.47\end{array}$ & $\begin{array}{c}137.5 \\
7 \mu \mathrm{m} \\
\pm \\
20.70 \\
\end{array}$ & $\begin{array}{c}142.3 \\
3 \mu \mathrm{m} \\
\pm \\
22.10 \\
\end{array}$ & $\begin{array}{c}576.8 \\
0 \mu \mathrm{m} \\
\pm \\
52.49 \\
\end{array}$ & $\begin{array}{c}1372.59 \\
\mu \mathrm{m} \pm \\
128.41\end{array}$ \\
\hline
\end{tabular}

Interhemispheric thickness of the somatosensory cortex and the motor cortex in LFPI and Sham animals. No significant differences were detected in total or laminar thickness in somatosensory and motor cortices at 8 weeks after LFPI. Data represented as mean $(\mu \mathrm{m}) \pm$ S.D for cortical laminae and total cortical thickness. 
Table.3: Interneuronal numbers in LFPI and sham animals in 3 brain regions

\begin{tabular}{|c|c|c|c|c|c|c|c|c|c|c|c|}
\hline \multicolumn{12}{|c|}{ a) Parvalbumin } \\
\hline \multicolumn{4}{|c|}{ Somatosensory Cortex } & \multicolumn{5}{|c|}{ Motor Cortex } & \multicolumn{3}{|c|}{ Hippocampus } \\
\hline \multicolumn{2}{|c|}{$\mathrm{L} 2 / 3$} & L4 & L5/6 & $\mathrm{L} 2 / 3$ & \multicolumn{2}{|c|}{ L4 } & L5 & & CA1 & CA2/3 & DG \\
\hline Sham & $\begin{array}{l}54 \pm \\
14.39 \\
\end{array}$ & $\begin{array}{l}54 \pm \\
16.42\end{array}$ & $\begin{array}{l}47 \pm \\
8.73\end{array}$ & $\begin{array}{l}49 \pm \\
6.69\end{array}$ & \multicolumn{2}{|c|}{$53 \pm 9.23$} & $\begin{array}{l}48 \\
8.3\end{array}$ & & $32 \pm 5.83$ & $\begin{array}{l}16 \pm \\
2.36\end{array}$ & $\begin{array}{l}16 \pm \\
2.21\end{array}$ \\
\hline Ipsilateral & $\begin{array}{l}39 \pm \\
8.30^{*}, \#\end{array}$ & $\begin{array}{l}44 \pm \\
9.58^{\#}\end{array}$ & $\begin{array}{l}38 \pm \\
7.84^{*}\end{array}$ & $\begin{array}{l}48 \pm \\
6.19\end{array}$ & \multicolumn{2}{|c|}{$\begin{array}{l}52 \pm \\
12.93\end{array}$} & $\begin{array}{l}44 \\
9.0\end{array}$ & & $28 \pm 4.99$ & $\begin{array}{l}15 \pm \\
2.18\end{array}$ & $\begin{array}{l}15 \pm \\
3.28^{*}\end{array}$ \\
\hline $\begin{array}{l}\text { Contralater } \\
\text { al }\end{array}$ & $\begin{array}{l}53 \pm \\
8.81\end{array}$ & $\begin{array}{l}51 \pm \\
4.39\end{array}$ & $45 \pm 6.02$ & $\begin{array}{l}48 \pm \\
7.67\end{array}$ & \multicolumn{2}{|c|}{$\begin{array}{c}15 \pm \\
14.89 \\
\end{array}$} & & $\begin{array}{l}48 \pm \\
3.10\end{array}$ & $\begin{array}{c}28 \pm \\
10.39\end{array}$ & $\begin{array}{l}14 \pm \\
3.55\end{array}$ & $\begin{array}{l}14 \pm \\
5.27\end{array}$ \\
\hline \multicolumn{12}{|c|}{ b) Calbindin } \\
\hline \multicolumn{4}{|c|}{ Somatosensory Cortex } & \multicolumn{5}{|c|}{ Motor Cortex } & \multicolumn{3}{|c|}{ Hippocampus } \\
\hline \multicolumn{2}{|r|}{$\mathrm{L} 2 / 3$} & $\mathrm{~L} 4$ & $\mathrm{~L} 5 / 6$ & $\mathrm{~L} 2 / 3$ & \multicolumn{2}{|c|}{ L4 } & & $\mathrm{L} 5 / 6$ & CA1 & CA2/3 & DG \\
\hline Sham & $\begin{array}{l}21 \pm \\
5.01 \\
\end{array}$ & $23 \pm 7.80$ & $\begin{array}{l}23 \pm \\
5.91 \\
\end{array}$ & $\begin{array}{l}18 \pm \\
9.30 \\
\end{array}$ & \multicolumn{2}{|c|}{$\begin{array}{l}15 \pm \\
6.02\end{array}$} & & $\begin{array}{l}17 \pm \\
5.49 \\
\end{array}$ & $13 \pm 4.34$ & $6 \pm 2.11$ & $\begin{array}{c}5 \pm \\
1.43 \\
\end{array}$ \\
\hline Ipsilateral & $\begin{array}{l}18 \pm \\
8.63\end{array}$ & $\begin{array}{c}18 \pm \\
16.68\end{array}$ & $\begin{array}{c}16 \pm \\
11.62^{\#}\end{array}$ & $\begin{array}{l}17 \pm \\
4.96\end{array}$ & \multicolumn{2}{|c|}{$\begin{array}{c}13 \pm \\
11.45\end{array}$} & & $\begin{array}{l}18 \pm \\
5.39\end{array}$ & $\begin{array}{l}12 \pm \\
2.20^{\#}\end{array}$ & $\begin{array}{c}7 \pm \\
1.23^{\#}\end{array}$ & $\begin{array}{c}6 \pm \\
1.53\end{array}$ \\
\hline $\begin{array}{c}\text { Contralater } \\
\text { al }\end{array}$ & $\begin{array}{l}23 \pm \\
5.39\end{array}$ & $24 \pm 4.80$ & $\begin{array}{l}25 \pm \\
6.16\end{array}$ & $\begin{array}{l}18 \pm \\
6.40\end{array}$ & \multicolumn{2}{|c|}{$\begin{array}{l}16 \pm \\
4.29\end{array}$} & & $\begin{array}{l}18 \pm \\
3.40\end{array}$ & $9 \pm 3.39^{*}$ & $5 \pm 1.89$ & $\begin{array}{l}5 \pm \\
1.84\end{array}$ \\
\hline \multicolumn{12}{|c|}{ c) Calretinin } \\
\hline \multicolumn{4}{|c|}{ Somatosensory Cortex } & \multicolumn{5}{|c|}{ Motor Cortex } & \multicolumn{3}{|c|}{ Hippocampus } \\
\hline \multicolumn{2}{|c|}{$\mathrm{L} 2 / 3$} & L4 & L5/6 & $\mathrm{L} 2 / 3$ & \multicolumn{2}{|c|}{ L4 } & \multicolumn{2}{|c|}{$\mathrm{L} 5 / 6$} & \multirow{2}{*}{\begin{tabular}{c|} 
CA1 \\
$20 \pm 5.06$
\end{tabular}} & CA2/3 & DG \\
\hline Sham & $24 \pm 3.71$ & $\begin{array}{l}24 \pm \\
8.40\end{array}$ & $\begin{array}{l}16 \pm \\
3.24\end{array}$ & $\begin{array}{l}33 \pm \\
4.47\end{array}$ & \multicolumn{2}{|c|}{$\begin{array}{l}30 \pm \\
7.49\end{array}$} & \multicolumn{2}{|c|}{$\begin{array}{l}24 \pm \\
4.65\end{array}$} & & $\begin{array}{l}10 \pm \\
2.41\end{array}$ & $\begin{array}{l}18 \pm \\
3.62\end{array}$ \\
\hline Ipsilateral & $\begin{array}{c}17 \pm \\
6.34^{*, \#}\end{array}$ & $\begin{array}{l}19 \pm \\
9.86\end{array}$ & $\begin{array}{l}14 \pm \\
3.85\end{array}$ & $\begin{array}{l}33 \pm \\
6.53\end{array}$ & & $\begin{array}{l}3 \pm \\
98\end{array}$ & & $5 \pm$ & $20 \pm 3.57$ & $\begin{array}{l}11 \pm \\
1.48^{\#}\end{array}$ & $\begin{array}{c}19 \pm \\
1.88^{\# \#}\end{array}$ \\
\hline $\begin{array}{l}\text { Contralater } \\
\text { al }\end{array}$ & $24 \pm 5.61$ & $\begin{array}{l}25 \pm \\
8.44 \\
\end{array}$ & $\begin{array}{l}17 \pm \\
4.07 \\
\end{array}$ & $\begin{array}{l}34 \pm \\
2.75 \\
\end{array}$ & $\begin{array}{l}30 \\
7.2\end{array}$ & & $\begin{array}{l}24 \\
4.6 \\
\end{array}$ & & $18 \pm 3.92$ & $9 \pm 1.67$ & $\begin{array}{l}16 \pm \\
2.19 \\
\end{array}$ \\
\hline d) Neurop & ptide Y & & & & & & & & & & \\
\hline & omatosenso & ry Cortex & & & Iotor & Corte & & & Hip & pocampus & \\
\hline & $\mathrm{L} 2 / 3$ & L4 & L5/6 & $\mathrm{L} 2 / 3$ & L4 & & L5/ & & CA1 & CA2/3 & DG \\
\hline Sham & $24 \pm 3.42$ & $\begin{array}{l}16 \pm \\
3.57\end{array}$ & $\begin{array}{l}22 \pm \\
4.42\end{array}$ & $\begin{array}{l}16 \pm \\
6.69\end{array}$ & $\begin{array}{l}10= \\
3.78\end{array}$ & & $\begin{array}{l}17 \\
6.7\end{array}$ & & $20 \pm 5.18$ & $\begin{array}{l}9 \pm \\
3.32\end{array}$ & $\begin{array}{l}16 \pm \\
4.89\end{array}$ \\
\hline Ipsilateral & $\begin{array}{l}22 \pm \\
15.07\end{array}$ & $\begin{array}{l}19 \pm \\
14.73\end{array}$ & $\begin{array}{l}19 \pm \\
10.26\end{array}$ & $\begin{array}{l}12 \pm \\
9.10\end{array}$ & $\begin{array}{l}16 \\
14 .\end{array}$ & & $\begin{array}{l}11 \\
6.5\end{array}$ & & $26 \pm 6.67^{*}, \#$ & $\begin{array}{l}12 \pm \\
4.14^{\#}\end{array}$ & $\begin{array}{l}19 \pm \\
5.09\end{array}$ \\
\hline $\begin{array}{l}\text { Contralater } \\
\text { al }\end{array}$ & $27 \pm 5.65$ & $\begin{array}{l}16 \pm \\
5.57 \\
\end{array}$ & $\begin{array}{l}24 \pm \\
4.75 \\
\end{array}$ & $\begin{array}{l}18 \pm \\
6.19\end{array}$ & $\begin{array}{l}12 \\
7.9\end{array}$ & & $\begin{array}{l}13 \\
4.8\end{array}$ & & $18 \pm 6.91$ & $\begin{array}{l}7 \pm \\
3.37\end{array}$ & $\begin{array}{l}14 \pm \\
6.32\end{array}$ \\
\hline e) Somato & tatin & & & & & & & & & & \\
\hline & Somatosen & sory Cortex & & & & tor $\mathrm{Cs}$ & ortex & & & ippocampl & \\
\hline $\mathrm{L} 2 / 3$ & & L4 & $\mathrm{L} 5 / 6$ & $\mathrm{~L} 2 / 3$ & & L4 & & $\mathrm{L} 5 / 6$ & CA1 & CA2/3 & DG \\
\hline Sham & $\begin{array}{l}38 \pm \\
11.38\end{array}$ & $\begin{array}{l}36 \pm \\
15.57\end{array}$ & $19 \pm 5.6$ & $\begin{array}{l}17 \pm \\
14.94\end{array}$ & & $\begin{array}{l}16 \pm \\
7.24\end{array}$ & & $\begin{array}{l}15 \pm \\
4.79\end{array}$ & $\begin{array}{l}19 \pm \\
6.02\end{array}$ & $9 \pm 3.71$ & $\begin{array}{l}17 \pm \\
4.61\end{array}$ \\
\hline Ipsilateral & $\begin{array}{l}23 \pm \\
7.97^{*}\end{array}$ & $\begin{array}{l}17 \pm \\
9.79^{* *, \# \#}\end{array}$ & $\begin{array}{l}12 \pm \\
9.79^{* *, \ldots \#+}\end{array}$ & $19 \pm$ & 7.55 & $\begin{array}{l}20 \pm \\
12.9\end{array}$ & & $\begin{array}{l}16 \pm \\
4.89\end{array}$ & $\begin{array}{l}29 \pm \\
7.83^{*, \ldots \# \#}\end{array}$ & $\begin{array}{l}13 \pm \\
3.67^{*}, \ldots+\ldots\end{array}$ & $\begin{array}{l}21 \pm \\
5.50^{\#}\end{array}$ \\
\hline $\begin{array}{l}\text { Contralater } \\
\text { al }\end{array}$ & $\begin{array}{l}29 \pm \\
8.66^{*}\end{array}$ & $\begin{array}{l}39 \pm \\
25.03\end{array}$ & $\begin{array}{l}28 \pm \\
8.91^{* *}\end{array}$ & $17 \pm$ & 5.89 & $\begin{array}{l}19 \pm \\
9.06\end{array}$ & & $\begin{array}{l}17 \pm \\
6.32\end{array}$ & $\begin{array}{l}14 \pm \\
6.67\end{array}$ & $7 \pm 3.18$ & $\begin{array}{l}14 \pm \\
6.31\end{array}$ \\
\hline
\end{tabular}


In table 3 highlighted boxes indicate significant data. Data shown as mean \pm standard deviation. Statistical significance: ${ }^{*} p<0.05,{ }^{* *} p<0.01,{ }^{* * *} p<0.001$ as compared to sham controls (Mann-Whitney U-test); \#p $<0.05$, $\# \# p<0.01$, \#\#\#p<0.001 as compared to the contralateral side (Mann-Whitney U-test) \#\#\#p<0.001 as compared to the contralateral side (Mann-Whitney U-test) 
Table 4: Semiquantitative analysis of brain regions for fluoro-jade $C$ neuronal degeneration

$\underline{\text { Region }}$

$\underline{\text { LFPI Animals }}$

Motor cortex

Somatosensory Cortex

$+++$

Hippocampal CA1

Hippocampal CA2/3

Dentate Gyrus (DG)

$+$

$+$

$+$

A semi quantitative analysis of Fluoro Jade C staining in LFPI animals within select regions of interest (ROIs), including cortex and hippocampus to score positive FJC immunoreactivity, ranging from none $(-)$, to mild $(+)$, moderate $(++)$ and strong $(+++)$ staining at 8 weeks after LFPI. 

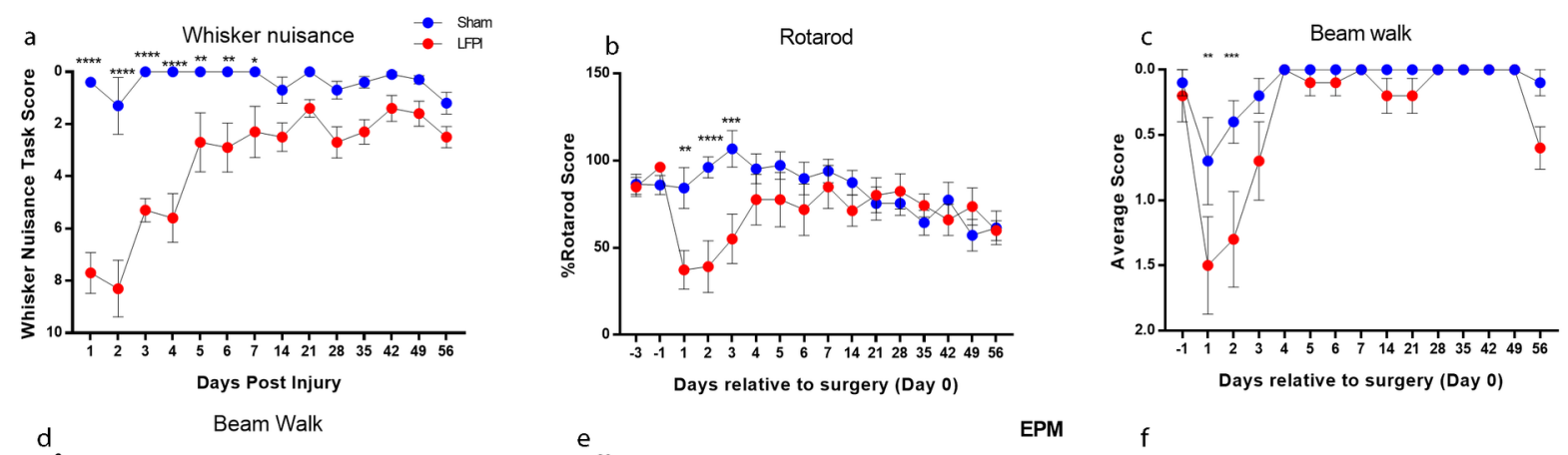

Days relative to surgery (Day 0 )
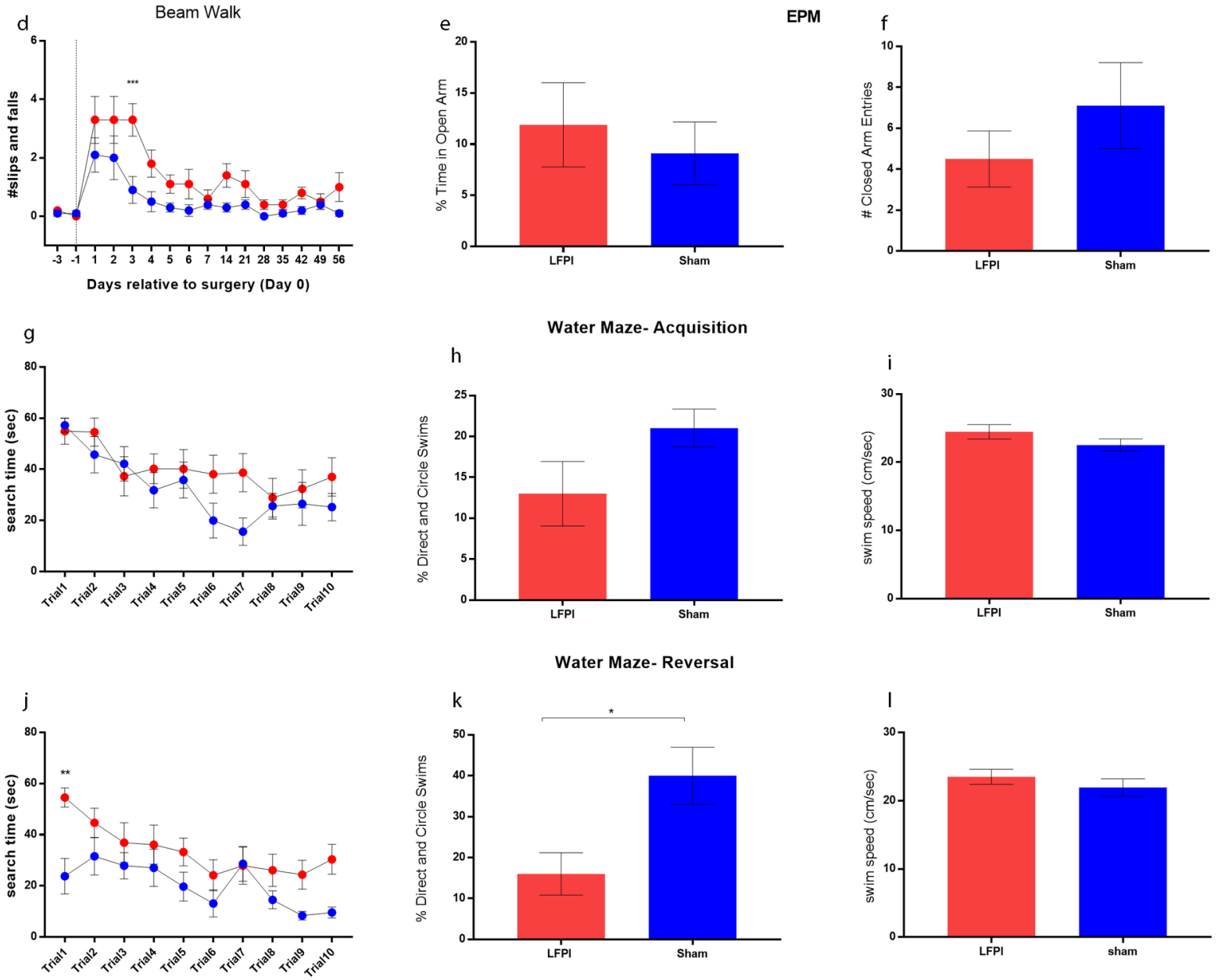

CNE_24746_Fig 1.tif 

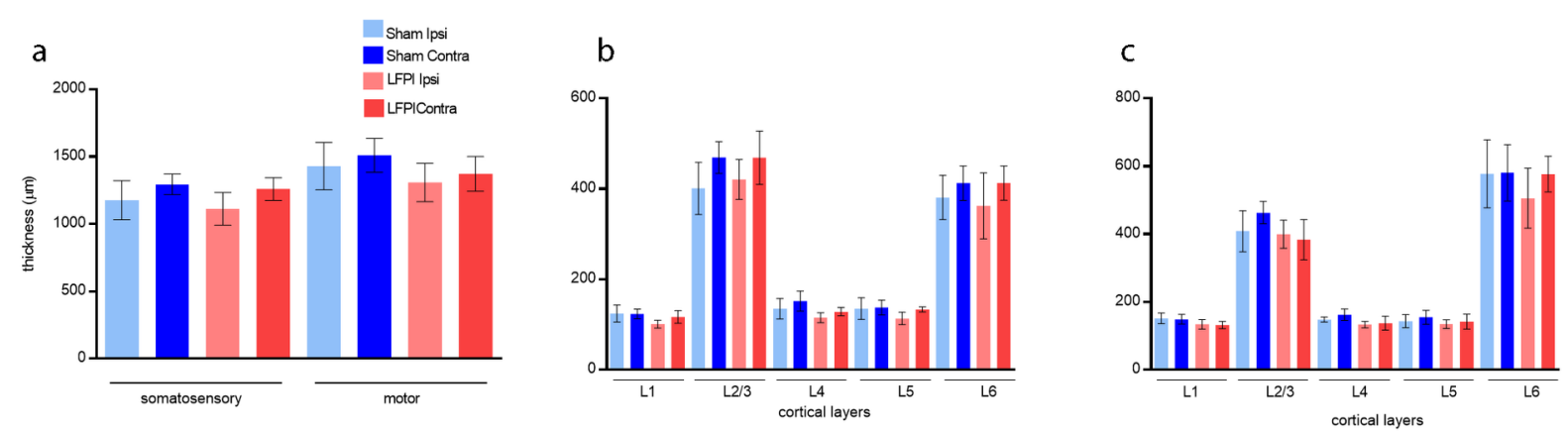

CNE_24746_Fig 2.tif

This article is protected by copyright. All rights reserved. 

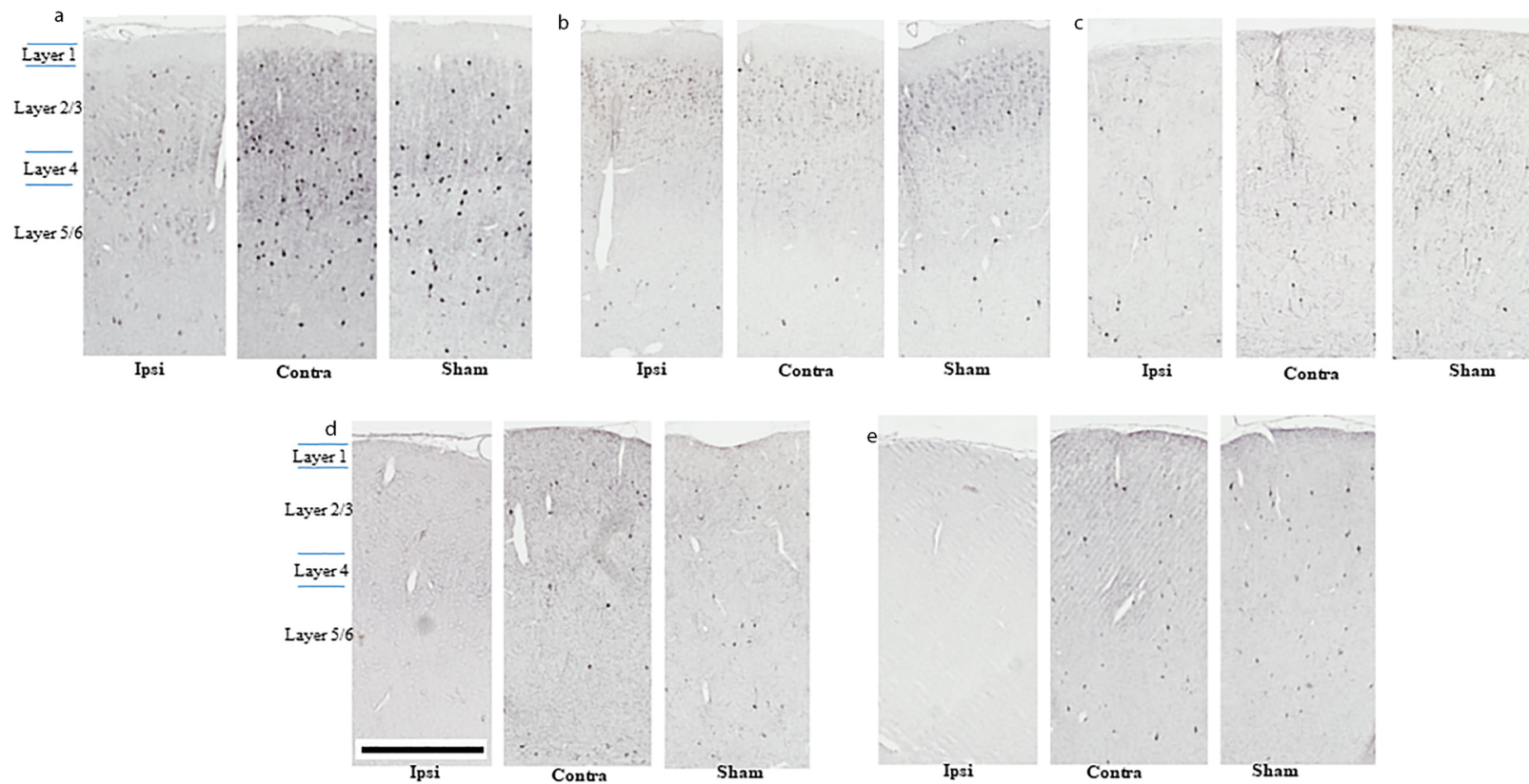

CNE_24746_Fig 3.tif 

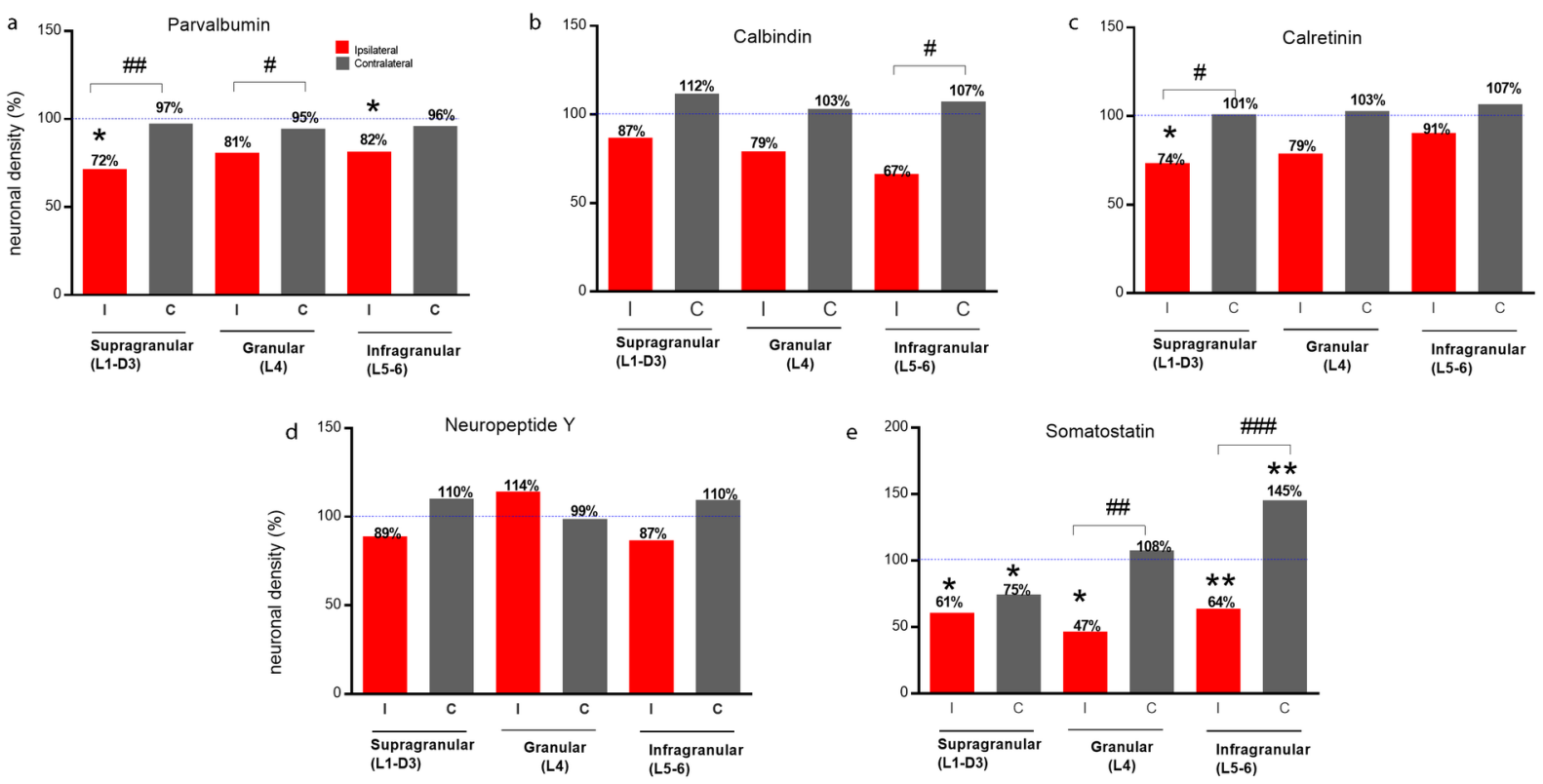

CNE_24746_Fig 4.tif

This article is protected by copyright. All rights reserved. 

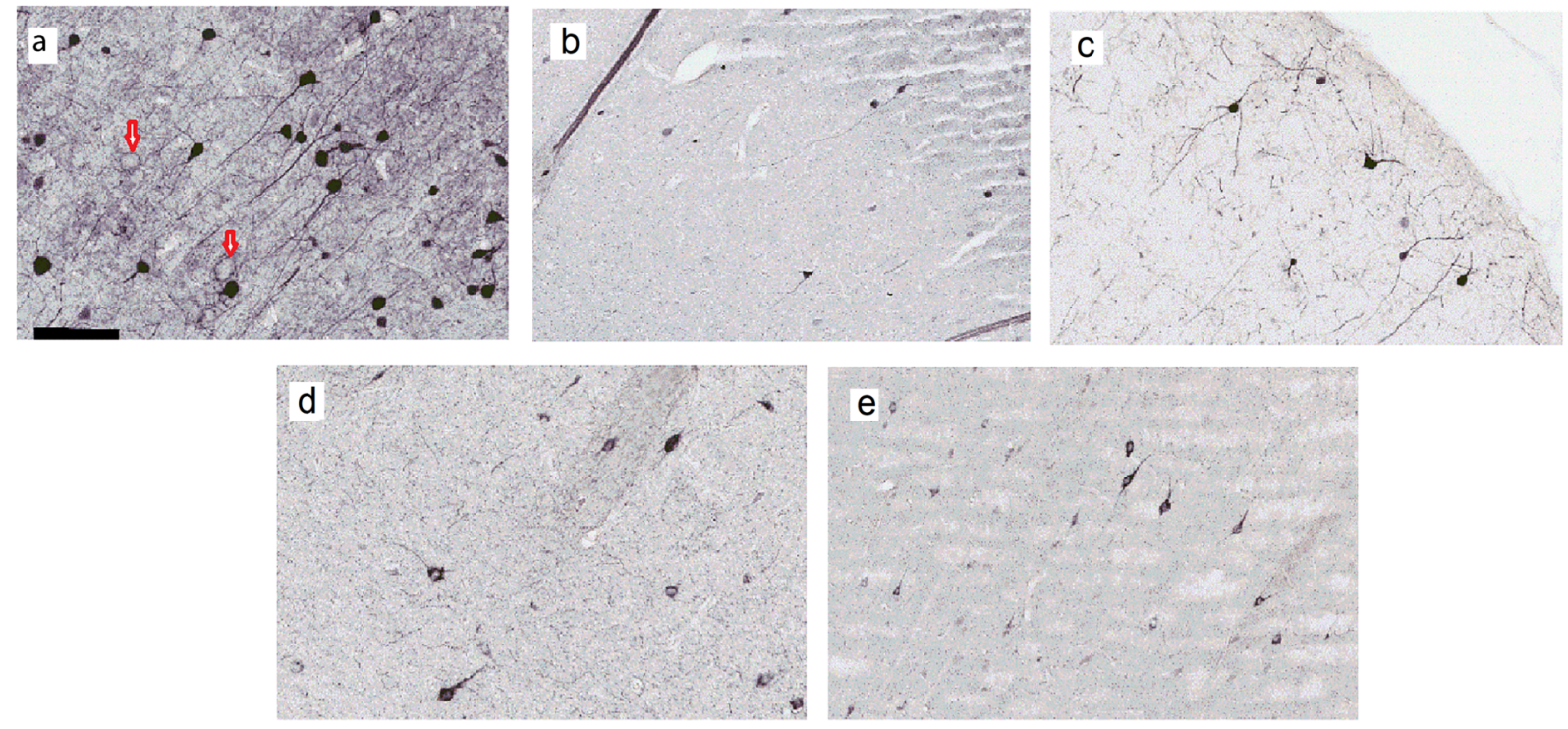

CNE_24746_Fig 5.tif

This article is protected by copyright. All rights reserved. 

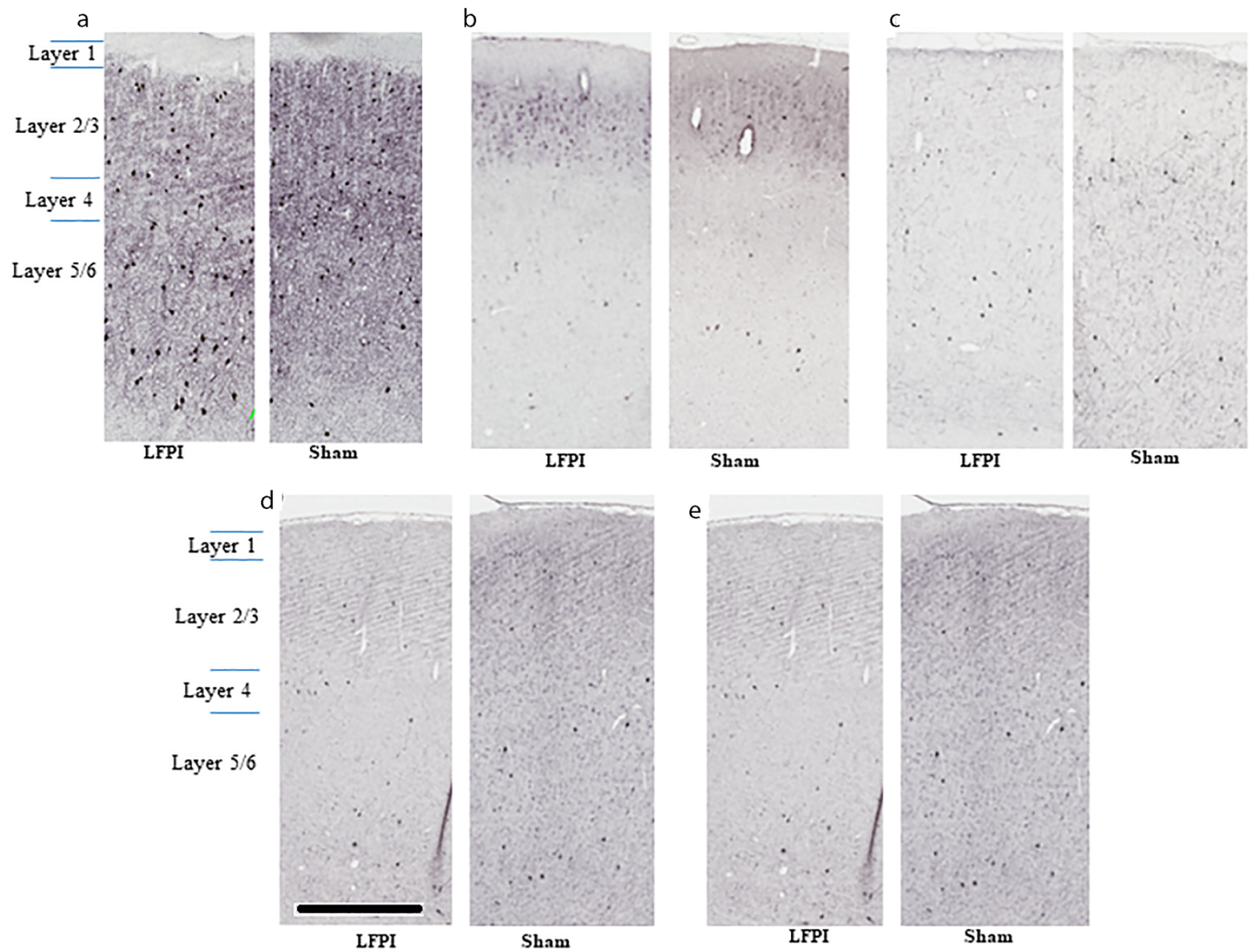

CNE_24746_Fig 6.tif 

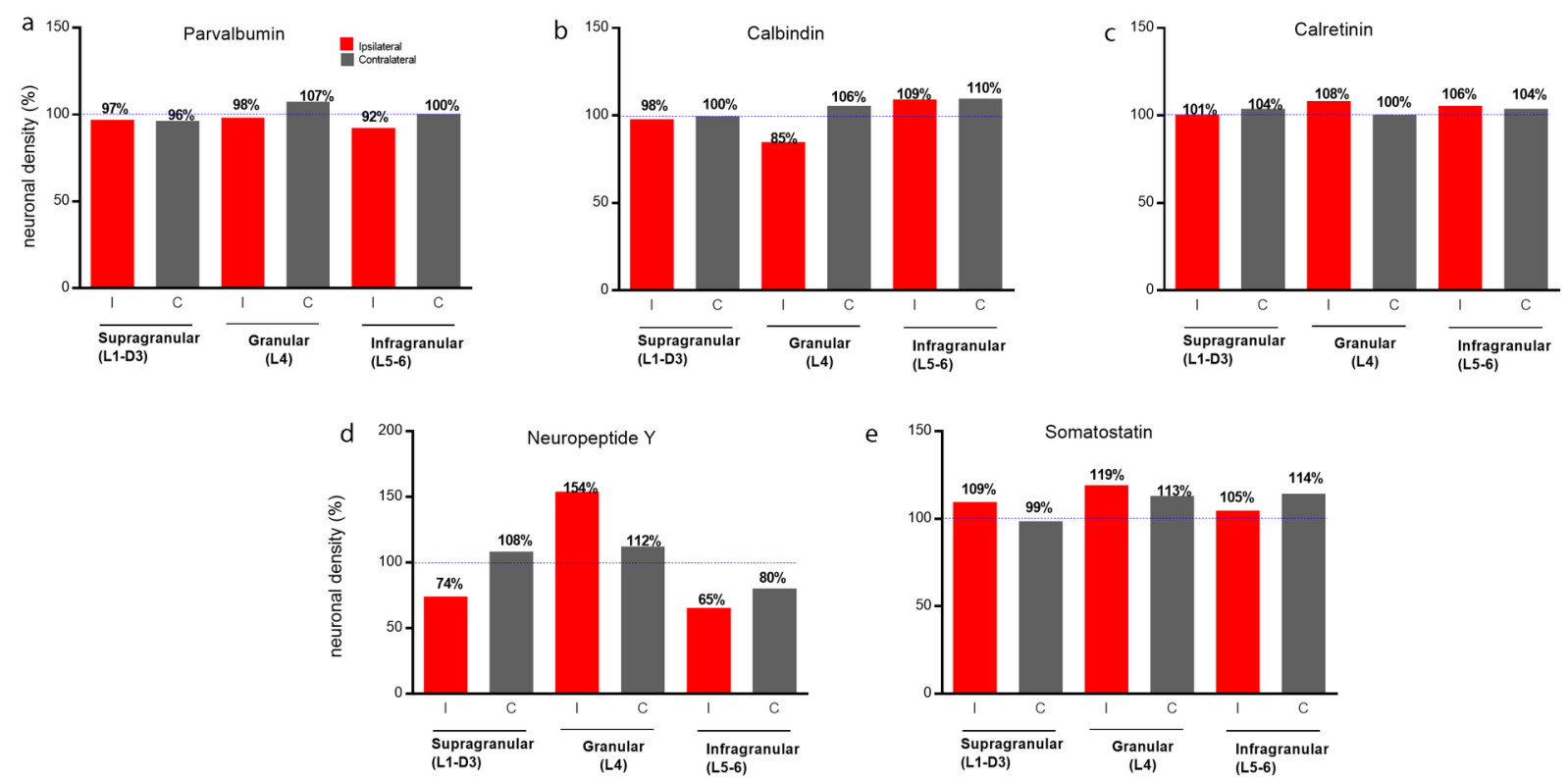

CNE_24746_Fig 7.tif 


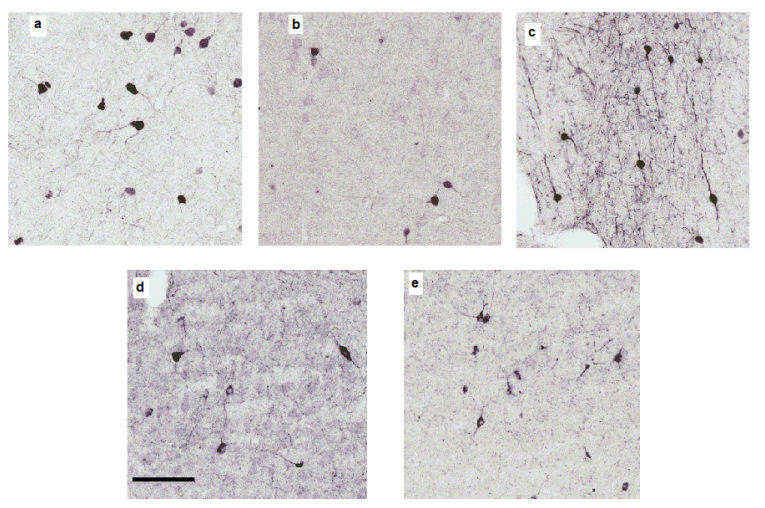

CNE_24746_Fig 8.tif

This article is protected by copyright. All rights reserved. 

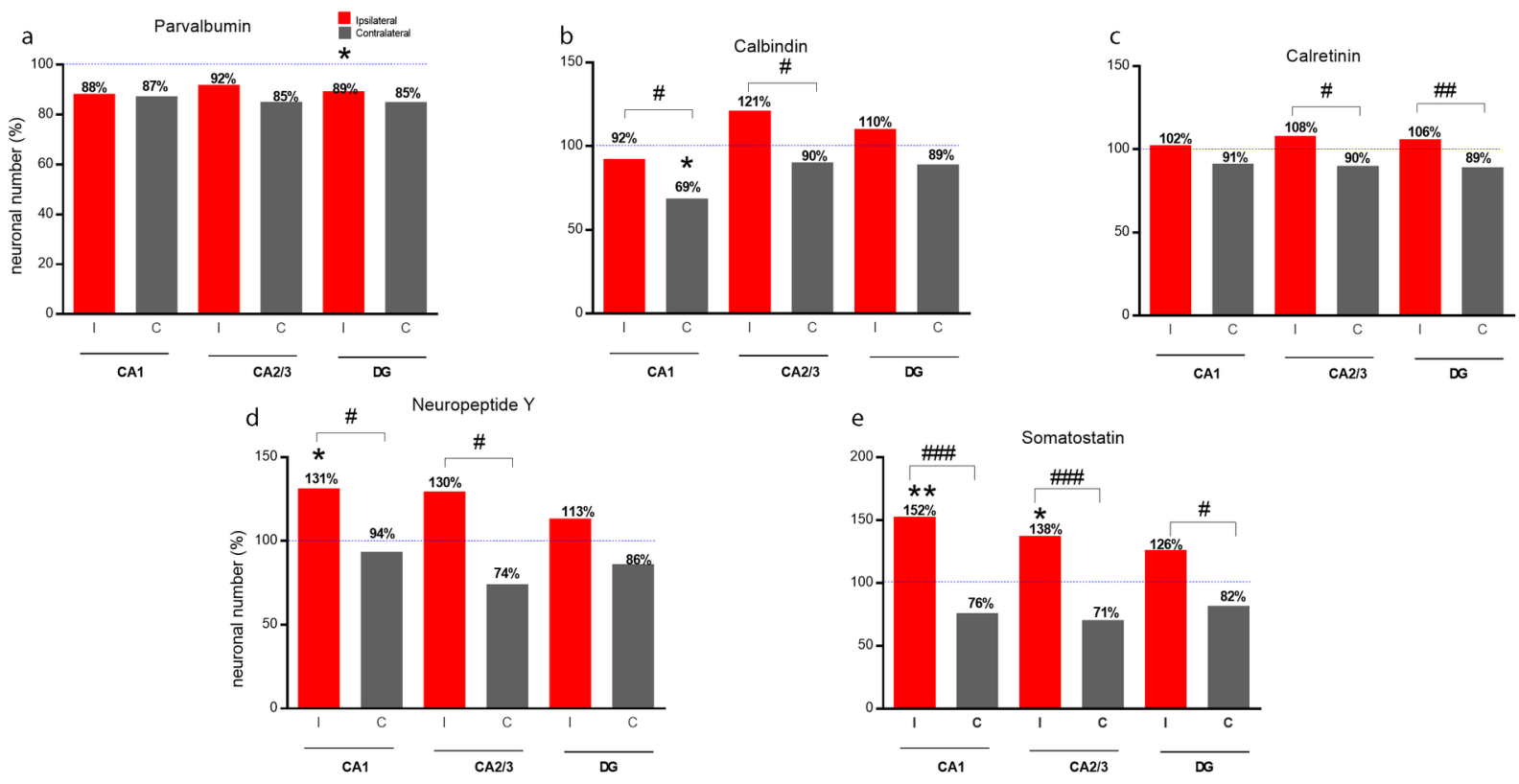

CNE_24746_Fig 10.tif 


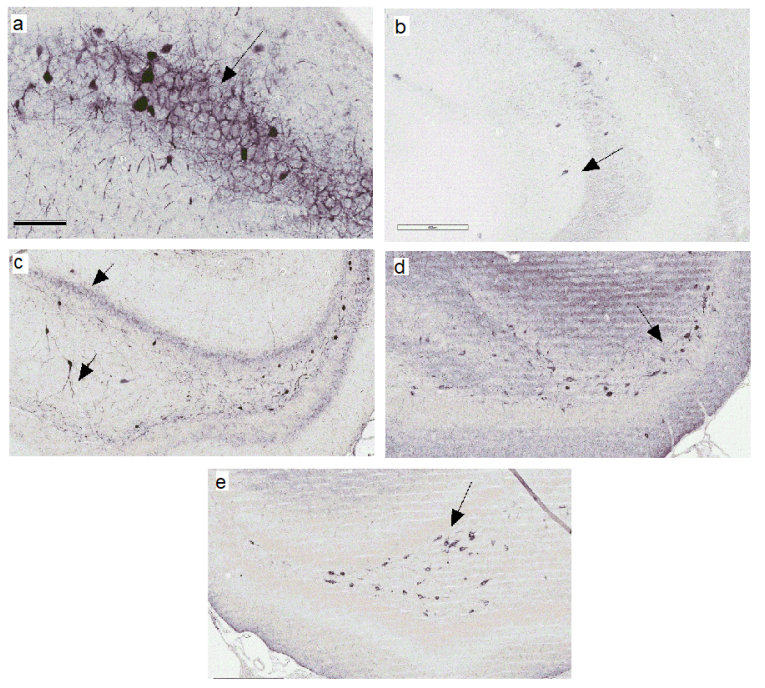

CNE_24746_Fig 11.tif

This article is protected by copyright. All rights reserved. 


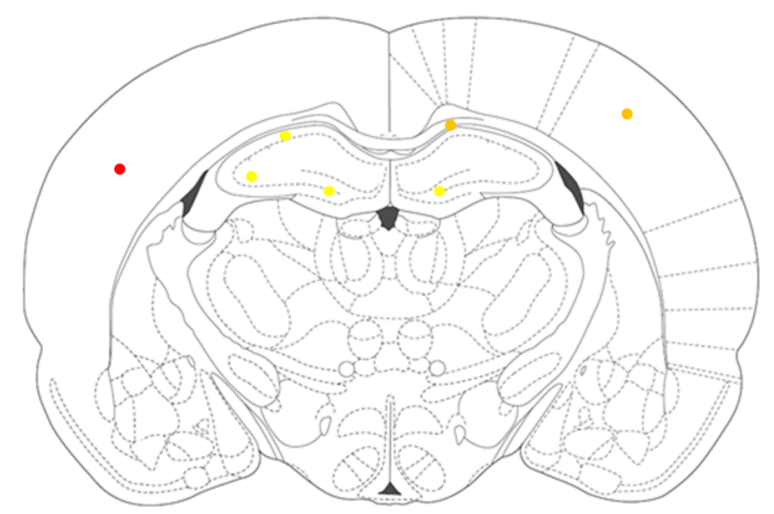

CNE_24746_Fig 12.tif

This article is protected by copyright. All rights reserved. 
Using immunohistochemistry and Fluoro-Jade C authors show differential vulnerability of inhibitory neurons and progressive neurodegeneration in cortex and hippocampus following lateral fluid percussion injury (LFPI)

Graphical abstract figure shows Fluoro-Jade C stained degenerating neurons in the CA2/3 and Dentate gyrus of LFPI animals. 

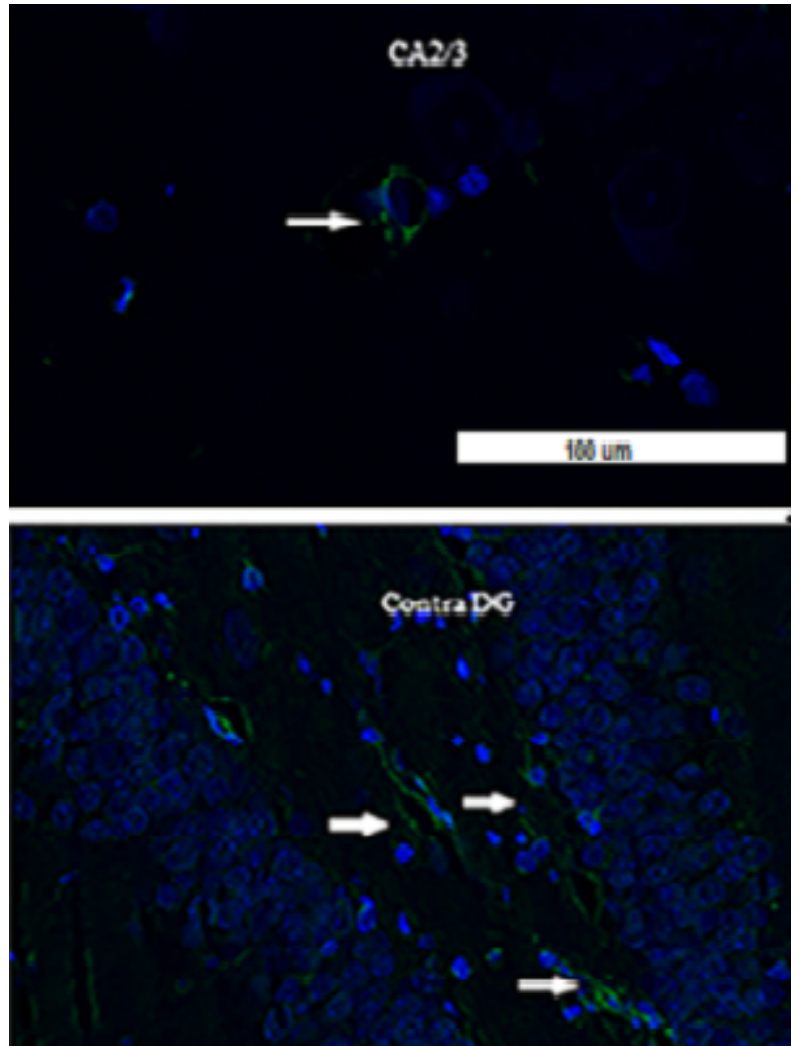

CNE_24746_updated_Graphical_abstract.tif

This article is protected by copyright. All rights reserved. 